\title{
Metal Speciation in Model Solutions and Environmental Aqueous Samples by Depletive Stripping Chronopotentiometry
}

\author{
by \\ MIN YANG \\ M.Sc. (Wuhan University, Wuhan, China)
}

A thesis submitted to the Faculty of Graduate Studies and Research in partial fulfillment of the requirements for the degree of

Master of Science

Department of Chemistry

Carleton University

Ottawa, Ontario

June, 2006

C copyright 2006

Min Yang 


$\begin{array}{ll}\begin{array}{l}\text { Library and } \\ \text { Archives Canada }\end{array} & \begin{array}{l}\text { Bibliothèque et } \\ \text { Archives Canada }\end{array} \\ \begin{array}{l}\text { Published Heritage } \\ \text { Branch }\end{array} & \begin{array}{l}\text { Direction du } \\ \text { Patrimoine de l'édition }\end{array} \\ \begin{array}{l}\text { 395 Wellington Street } \\ \text { Ottawa ON K1A ON4 }\end{array} & \begin{array}{l}\text { 395, rue Wellington } \\ \text { Ottawa ON K1A ON4 } \\ \text { Canada }\end{array}\end{array}$

Your file Votre référence ISBN: 978-0-494-18378-6 Our file Notre référence ISBN: 978-0-494-18378-6

NOTICE:

The author has granted a nonexclusive license allowing Library and Archives Canada to reproduce, publish, archive, preserve, conserve, communicate to the public by telecommunication or on the Internet, loan, distribute and sell theses worldwide, for commercial or noncommercial purposes, in microform, paper, electronic and/or any other formats.

The author retains copyright ownership and moral rights in this thesis. Neither the thesis nor substantial extracts from it may be printed or otherwise reproduced without the author's permission.
AVIS:

L'auteur a accordé une licence non exclusive permettant à la Bibliothèque et Archives Canada de reproduire, publier, archiver, sauvegarder, conserver, transmettre au public par télécommunication ou par l'Internet, prêter, distribuer et vendre des thèses partout dans le monde, à des fins commerciales ou autres, sur support microforme, papier, électronique et/ou autres formats.

L'auteur conserve la propriété du droit d'auteur et des droits moraux qui protège cette thèse. $\mathrm{Ni}$ la thèse ni des extraits substantiels de celle-ci ne doivent être imprimés ou autrement reproduits sans son autorisation.
In compliance with the Canadian

Privacy Act some supporting forms may have been removed from this thesis.

While these forms may be included in the document page count, their removal does not represent any loss of content from the thesis.
Conformément à la loi canadienne sur la protection de la vie privée, quelques formulaires secondaires ont été enlevés de cette thèse.

Bien que ces formulaires aient inclus dans la pagination, il n'y aura aucun contenu manquant.

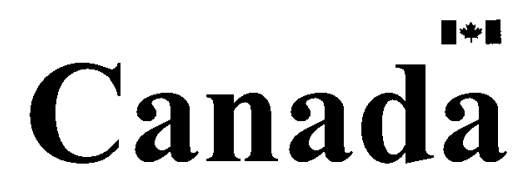




\begin{abstract}
Depletive stripping chronopotentiometry (SCP), a new, recently developed electroanalytical technique, has been investigated and evaluated in terms of metal speciation in aqueous samples containing dissolved organic compound (DOC). The effect of stripping current on metal determination has been studied, as well as that of deposition time and stirring speed on diffusion layer thickness. At low stripping current and high stirring speed, depletive condition can be attained and linear diffusion may be approached at a Static Mercury Drop Electrode (SMDE). Scanned Stripping Chronopotentiometry (SSCP) has been applied to simple homogeneous complexes, e.g. cadmium and lead with pyridine- 2, 6-dicarboxylic acid, nitrilo-triacetic acid and the stability constants have been validated by comparison with those obtained from Pseudopolarography (Scanned Stripping Voltammetry, SSV) under the same experimental conditions. The results determined by both techniques are in good agreement with the literature values. SSCP has been further exploited in metal complexation in the presence of heterogeneous fulvic acid (FA), a kind of humic substances which is one of the largest fractions of dissolved organic matter (DOM) in aquatic systems. The stability constants, heterogeneities and diffusion coefficients of complexes of $\mathrm{Cd}(\mathrm{II}), \mathrm{Pb}$ (II) and $\mathrm{Zn}$ (II) with FA have been determined by SSCP and Pseudopolarography for comparison. Besides, I pioneered efforts to apply SCP to real samples, in which the effect of dilution of Copper Cliff Mine effluent water samples (Sudbury, Ontario) with tap water on the average conditional stability constants of DOC of zinc and cadmium was investigated by complexometric titration followed by SCP. Compared with similar work reported in the literatures, the results of SCP are reasonable. Depletive stripping chronopotentiometry (SCP) may offer
\end{abstract}


more reliable information on metal speciation compared with stripping voltammetry (SV) because of its elimination or reduction of secondary effects. 


\section{ACKNOWLEDGEMENTS}

I wish to thank my supervisor, Distinguished Research Professor C.L. Chakrabarti for his guidance, support and encouragement.

I also wish to thank all the past and present members of the research laboratory, especially Dr. Ismail Al-Fasfous, Jiujiang Zhao, Rong Wang, Tahir Yapici, Parhthra Chakrabarti, Jianfu Deng and Yamini Gopalapillai for their help and cooperation.

I am grateful to my parents, my husband, my sister and my son for their unconditional love and support. 


\section{TABLE OF CONTENTS}

Acceptance Sheet

Abstract

iii

Acknowledgements

$\mathbf{v}$

List of Tables

$\begin{array}{ll}\text { List of Figures } & \text { xiii }\end{array}$

ChAPTER 1. INTRODUCTION 1

1.1 Speciation Definition $\quad 2$

1.2 Speciation Parameters $\quad 4$

1.3 Speciation Techniques $\quad 5$

1.3.1 Electroanalytical Speciation Techniques $\quad 8$

1.3.2 Weakness of Current Electrochemical Speciation

Techniques

1.4 Hypothesis $\quad 14$

$\begin{array}{ll}1.5 \text { Thesis Organization } & 14\end{array}$ 
2.1 Humic Substances

2.2 Chronopotentiometry

2.2.1 Stripping Chronopotentiometry

2.2.2 Scanned Stripping Chronopotentiometry (SSCP) and Scanned Stripping Voltammetry (Pseudopolarography or SSV) in Metal Speciation

ChAPTER 3. Depletive Stripping Chronopotentiometry and Comparison of Scanned Stripping Chronopotentiometry (SSCP) with Pseudopolarography (SSV) for Homogeneous Complexes Using Static Mercury Drop Electrode

3.1 Introduction 
3.3.4 Electrochemical Parameters

3.4 Results and Discussion

3.4.1 Stripping Chronopotentiometry Peak

3.4.2 Optimization of the Stripping Current

3.4.3 Diffusion Layer Thickness

3.4.4 Comparison of SSCP with Pseudopolarography

3.4.4.1 Variation of Deposition Time

3.4.4.2 Labile Complexes: Cd(II)-PDCA and $\mathrm{Pb}$ (II)-PDCA

3.4.4.3 Quasi-labile Complexes: Cd(II)-NTA and $\mathrm{Pb}$ (II)-NTA 


\section{CHAPTER 4. Depletive Scanned Stripping \\ Chronopotentiometry: Study of \\ Heterogeneous Complexant, Suwannee \\ River Fulvic Acid, on Metal Speciation \\ Described by Differential Equilibrium \\ Functions Using Static Mercury Drop \\ Electrode}

58

$\begin{array}{lll}4.1 & \text { Introduction } & 59\end{array}$

$\begin{array}{lll}4.2 & \text { Theory } & 60\end{array}$

4.2.1 Scanned Stripping Chronopotentiometry for $\quad 60$

Heterogeneous Complexes

4.2.2 Differential Equilibrium Function

4.2.3 Diffusion Coefficient

64

$\begin{array}{lll}4.3 & \text { Experimental } & 65\end{array}$

4.3.1 Materials and Reagents $\quad 65$

4.3.2 Suwannee River Fulvic Acid Model Solutions 66

$\begin{array}{ll}\text { 4.3.3 Apparatus } & 66\end{array}$

4.3.4 Electrochemical Parameters 66

$\begin{array}{ll}\text { 4.3.5 Data Analysis } & 67\end{array}$

ix 


\section{Chapter 5. COMPLEXOMETRIC TITRATION OF COPPER CLIFF MINE EFFLUENT WATERS BY DEPLETIVE STRIPPING CHRONOPOTENTIOMETRY TO STUDY THE EFFECT OF DILUTION ON STABILITY CONSTANTS OF DOC COMPLEXES WITH ZINC AND CADMIUM} 76 
5.4.1Characteristics and Compositions of the Samples

5.4.2 Titration Curve 


\section{LIST OF TABLES}

Table 1 Combinations of separation methods and trace analysis techniques used for species identification

Table 2 Toxicity and electrochemical lability of some metal species in natural waters

Table 3 Comparisons of determined stability constants of homogenous metal complexes by depletive scanned stripping chronopotentiometry and pseudo-polargraphy

Table 4 Complexation parameters of $2 \times 10^{-7} \mathrm{~mol} \mathrm{~L}^{-1} \mathrm{M}(\mathrm{II})$ in the presence of Suwannee River Fulvic Acid (SRFA) determined by depletive SSCP

Table 5 Complexation parameters of $2 \times 10^{-7} \mathrm{~mol} \mathrm{~L}^{-1} \mathrm{M}(\mathrm{II})$ in the presence of Suwannee River Fulvic Acid (SRFA) determined by pseudopolarography

Table 6 Characteristics and compositions of Copper Cliff Mine undiluted effluent waters (100\%) and diluted effluent waters $(45 \%)$

Table 7 Conditional stability constants of metal-DOC complexes in the $45 \%$ and $100 \%$ Copper Cliff Mine effluent waters determined by complexometric titration using SCP 


\section{LIST OF FIGURES}

Figure 1 Family tree of main electroanalytical methods 9

Figure 2 Exemplification of different possible $-\mathrm{OH}$ and $-\mathrm{COOH} \quad 18$ groups in a hypothetical humic acid polymer

Figure 3 Current excitation (A) and potential response (B) for Chronopotentiometry

Figure 4 Stripping chronopotentiometry (SCP) curves for Cd(II) at a SMDE as function of deposition potential

Figure 5 Effects of logarithm of stripping current, $\log i_{s}$, on transition time and peak position of $2 \times 10^{-7} \mathrm{M} \mathrm{Pb}$ (II) determined by stripping chronopotentiometry (SCP)

Figure 6 Variation of diffusion layer thickness, $\delta$, of $2 \times 10^{-7} \mathrm{M}$ $\mathrm{Pb}$ (II) with the stirring speed determined by SCP at different deposition times

Figure 7 Experimentally determined SSCP curves of $5 \times 10^{-7} \mathrm{M}$ $\mathrm{Pb}$ (II) at two different deposition times

Figure 8 Experimentally determined depletive SSCP curves for $\mathrm{Cd}(\mathrm{II})$ in the presence of different concentrations of PDCA at SMDE

Figure 9 Experimentally determined pseudopolarograms for $\mathrm{Cd}(\mathrm{II})$ in the presence of different concentrations of PDCA at SMDE

xiii 
Figure 10 Experimentally determined depletive SSCP curves for $\mathrm{Cd}(\mathrm{II})$ in the presence of different concentrations of NTA at SMDE

Figure 11 Experimentally determined pseudopolarograms of Cd(II) in the presence of different concentrations of NTA at SMDE

Figure 12 Log analysis of SSCP curves for Cd(II) in the presence of different concentrations of PDCA shown in Figure 8

Figure 13 Log analysis of pseudopolarograms for $\mathrm{Cd}$ (II) in the presence of different concentrations of PDCA shown in Figure 9

Figure 14 Log analysis of SSCP curves for Cd(II) in the presence of different concentrations of NTA shown in Figure 10

Figure 15 Log analysis of pseudopolarograms for $\mathrm{Cd}(\mathrm{II})$ in the presence of different concentrations of NTA shown in Figure 11

Figure 16 Simulated polarographic curves for the reduction of $M$ under non-complexing conditions, in the presence of a simple ligand and in the presence of a heterogeneous complexant

Figure 17 Experimentally determined depletive SSCP curves for $\mathrm{Pb}(\mathrm{II})$ in the presence of different concentrations of SRFA at SMDE

Figure 18 Experimentally determined pseudopolarograms for $\mathrm{Pb}$ (II) 75 in the presence of different concentrations of SRFA at SMDE 
- Chapter 1-

Introduction

Reproduced with permission of the copyright owner. Further reproduction prohibited without permission. 


\subsection{Speciation Definition}

Analytical chemistry began as a science in the early $19^{\text {th }}$ century. It was only in the early 1960s that questions were raised concerning the chemical form of the trace elements and that need for an analytical methodology developed subsequently.

'Speciation', a word borrowed from the biological sciences, has become a concept in analytical chemistry, expressing the idea that the specific chemical forms of an element should be considered individually. The underlying reason for this is that the characteristics of just one species of an element may have such a radical impact on living systems (even at extremely low levels) that the total element concentration becomes of little value in determining the impact of the trace element [1].

The International Union for Pure and Applied Chemistry (IUPAC) has defined elemental speciation in chemistry as follows [2]:

i. Chemical species. Chemical element: specific form of an element defined as to isotopic composition, electronic or oxidation state, and/or complex or molecular structure.

ii. Speciation analysis. Analytical chemistry: analytical activities of identifying and/or measuring the quantities of one or more individual chemical species in a sample.

iii. Speciation of an element; speciation. Distribution of an element amongst defined chemical species in a system. 
iv. Fractionation. Process of classification of analytes or a group of analytes from a certain sample according to physical (e.g., size, solubility) or chemical (e.g., bonding, reactivity) properties.

As explained in the IUPAC paper [2], it is often not possible to determine the concentrations of the different chemical species that sum up to the total concentration of an element in a given matrix. Often, chemical species present in a given sample are not stable enough to be determined as such. During the procedure, the partitioning of the element among its species may be changed. For example, this can be caused by a change in $\mathrm{pH}$ necessitated by the analytical procedure, or by intrinsic properties of measurement methods that affect the equilibrium between species. Also in many cases the large number of individual species (e.g., in metal-humic acid complexes or metal complexes in biological fluids) will make it impossible to determine the exact speciation. The practice is then to identify various classes of the elemental species.

Besides the suspected elemental species of anthropogenic origin, there is the barely fathomable domain of the species that developed along with life on earth. Whereas the total trace element concentration may be static, the species may be highly dynamic. They will change continuously with respect to changes in the surrounding environment, depending on chemical parameters such as $\mathrm{pH}$ value or concentration of potential ligands for complex formation, the physiological state of a cell, and state of health of a living entity. Therefore, thermodynamic but also kinetic stability of elemental species in the environment has to be taken into account. 


\subsection{Speciation Parameters}

Due to the impossibility of obtaining the concentrations of different chemical species in a system, we have to appeal to speciation parameters, which are linked with each other to characterize the distribution of metal species. Speciation parameters, independent of analytical techniques used, are quantitative measures of speciation characteristics of chemical species. Some important speciation parameters, which are typically used in electroanalytical method, are described below:

1) Free Metal Ion Concentration ([$\left.\left.M^{n+}\right]\right)$ : The most important parameter for "FreeIon-Activity-Model" (FIAM) which has been frequently applied in the interpretation of the biouptake of metals from complex media $[119,202,203]$. The free ion activity is often a good predicator of the bioavailability of the metal, and hence, its nutrient or toxic effect.

2) Diffusion Coefficient $(D)$ : The mobility of a particular chemical species plays a significant role in the biological impact in natural environment. The species cannot elicit their toxic response until they come into contact with the biological membrane and eventually penetrate it [26]. Diffusion coefficient is a direct measure of how quickly the chemical species can reach the biological membrane.

3) Stability Constant (K): The thermodynamic stability of a metal complex (which is a measure of the availability of free metal ions at equilibrium) is doubtless important in characterizing metal species in the aquatic and the terrestrial environment [10-12]. Determination of stability constant requires the establishment of equilibrium or pseudo-equilibrium before the measurement can 
be made. Although measurement of this parameter is straightforward for homogeneous systems (such as inorganic complexes), it may be difficult to measure this parameter for heterogeneous systems, e.g. those containing naturally-occurring organic complexants like humic substances, which are chemically and physically heterogeneous complexants because of different types of functional groups. The heterogeneity determines the metal ion binding, hence the stability constants of metal complexes of naturally-occurring organic complexants. Instead of discrete value of stability constant, a large range of stability constants is often observed and the interpretation becomes uncertain. An average stability constant is often estimated for a group of metal complexes having close values of stability constants.

4) Dissociation rate coefficient $\left(k_{d}\right)$ : Dissociation rate coefficient is a measure of the rate at which metal complex dissociates to free metal ion. It is a very important speciation parameter, especially in the case where free metal ion is the bioavailable species.

\subsection{Speciation Techniques}

Speciation studies require the detection of trace level quantities of elements in the samples. At the same time, the measurements should provide information about the chemical forms or structures in which the element is present. Since, however, there are few 'species-specific' measuring techniques, most speciation schemes involve two major operations, namely, separation of the species of interest from the matrix and evaluation of the element content in the separated fractions. 
The alternative approaches to separation fall into a number of general categories such as differentiation between species based on size or charge/size effects; chromatographic processes; solvent extraction; and selective chemical reactions.

For analysis of the separated fractions, the techniques used need to be highly sensitive, and preferably reasonably selective. Analytical techniques possessing these attributes are listed in conjunction with separation modes in Table 1.

Speciation measurements have been made in waters by a variety of techniques, including electro-analysis, ion exchange, dialysis, ultra-filtration, solvent extraction and computer modeling [5-7]. 
Table 1 Combinations of separation methods and trace analysis techniques used for species identification [4]

\begin{tabular}{ll}
\hline Separation mode & Analytical technique \\
\hline Liquid chromatography (column, & Plasma emission spectrometry, AAS (flame \\
HPLC, gel permeation) & and graphite furnace), fluorimetry, \\
& electrochemical sensors, neutron activation \\
& analysis \\
Gas chromatography & Specific detectors (e.g. flame photometric, \\
& electron capture, AAS) \\
Ion chromatography & Conductance, refractive index, indirect UV \\
& absorbance, electrochemical sensors \\
Ion exchange (columns) & ASV, \\
Solvent extraction & microtitrations \\
Electro-deposition & AAS, ICP, ASV, spectrophotometry \\
\hline
\end{tabular}




\subsubsection{Electroanalytical Speciation Techniques}

In comparison with many analytical techniques, electroanalytical techniques are unique in that they are based on interfacial phenomena. Electroanalytical techniques have certain features that are advantageous for speciation analysis. In contrast to Atomic Absorption Spectrometry (AAS) or Inductively Coupled Plasma-Mass Spectrometry (ICP-MS), they belong to the low energy excitation techniques, which is the reason why they are species selective rather than element selective. Another advantage of the application of electrochemical techniques to the study of metal speciation in aquatic systems is that the mathematical description of the metal fate on an electrode and a natural interface is often largely similar [3]. Besides the above, many of them exhibit excellent detection limits coupled with a wide dynamic range.

Electroanalytical techniques can be classified in various ways. An approach mainly based on the character of the measured signals and their excitation is shown in Figure 1. 


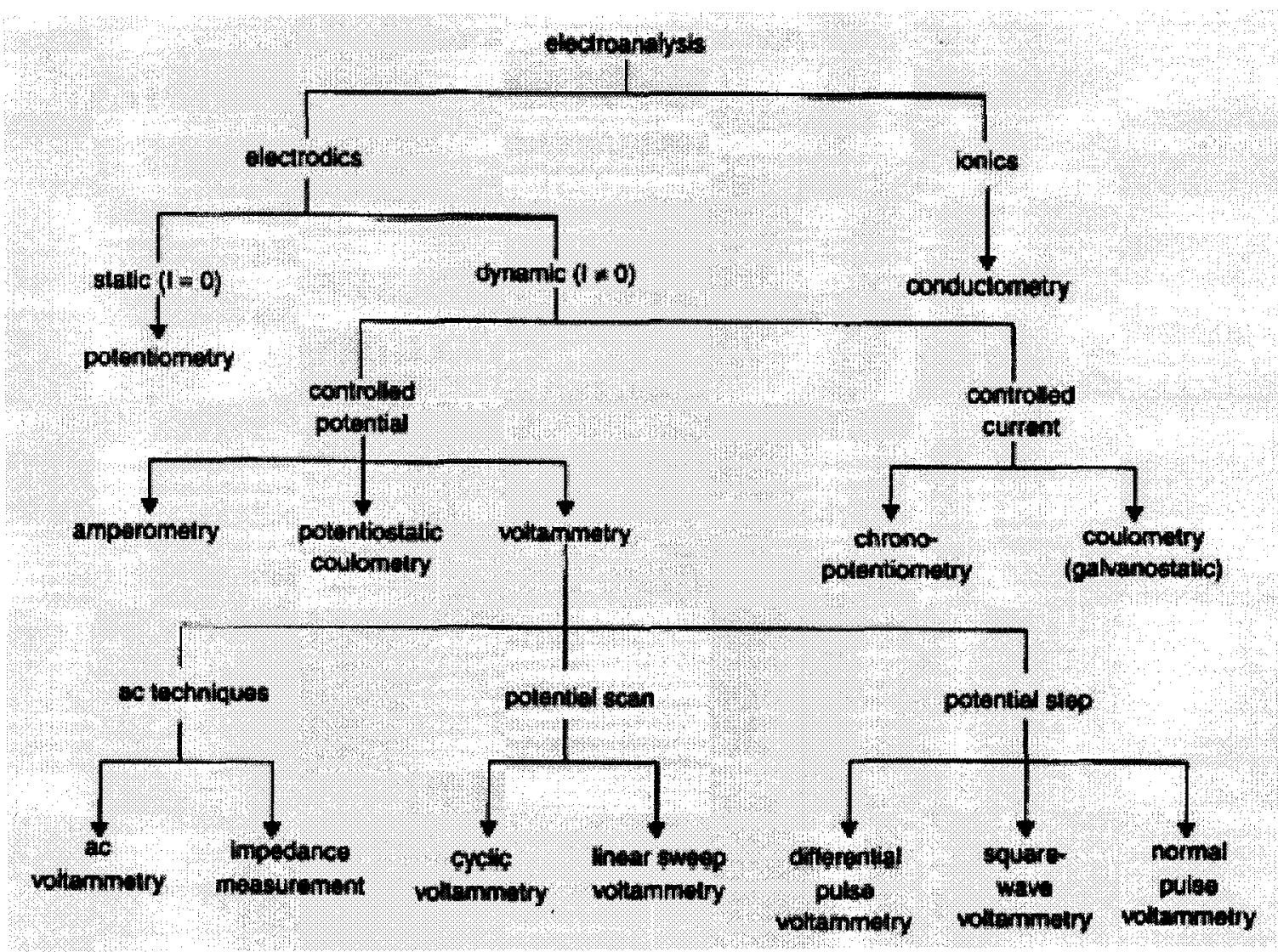

Figure 1 Family tree of main electroanalytical methods [1] 
Electroanalytical techniques have been used extensively in studies of waters. For example, ion-selective electrodes allow measurement of the activity of free hydrated ions in solution (species highly relevant in toxicity studies) and voltammetric methods (polarography and ASV) exhibit a high degree of selectivity for highly labile species. Electrochemical techniques also facilitate identification of the valency state of elements such as $\mathrm{Fe}, \mathrm{Cr}, \mathrm{Tl}, \mathrm{Sn}, \mathrm{Mn}, \mathrm{Sb}, \mathrm{As}, \mathrm{Se}, \mathrm{V}, \mathrm{U}$ and I. For several other elements only one state is electrochemically active, and redox state speciation becomes a special case of labile/inert species discrimination.

There are two main reasons for studying the speciation of elements in waters - to understand either the biological or the geochemical cycling of the elements [9]. Biological cycling includes bioaccumulation, bioconcentration, bioavailability and toxicity, and geochemical cycling involves dissolution, transportation, adsorption and precipitation of the element in the water system. Electroanalytical techniques may cover all these aspects and satisfy the requirements of providing speciation information based on labile/inert discrimination, redox state and half-wave potential measurements. Table 2 correlates the electrochemical lability of some species with their toxicity in natural waters. 
Table 2 Toxicity and electrochemical lability of some species in natural waters $[5,7,8]$

\begin{tabular}{ccc}
\hline Species & Toxicity & Electrochemical lability \\
\hline $\mathrm{As}(\mathrm{III})$ & High & High \\
$\mathrm{As}(\mathrm{V})$ & Low & Low \\
$\mathrm{Cr}(\mathrm{III})$ & Low & Low \\
$\mathrm{Cr}(\mathrm{VI})$ & High & High \\
$\mathrm{Tl}(\mathrm{I})$ & High & High \\
$\mathrm{Tl}(\mathrm{III})$ & Low & Low \\
$\mathrm{Cu}{ }^{2+}$ & High & High \\
$\mathrm{CuCl}_{2}$ & High & High \\
$\mathrm{CuCO}_{3}$ & Low & High \\
$\mathrm{Cu}^{2+}-\mathrm{fulvic}^{2}$ acid & Low & Low \\
$\mathrm{Cu}^{2+} / \mathrm{humic} \mathrm{acid-Fe}_{2} \mathrm{O}_{3}$ & Medium & Medium \\
\hline
\end{tabular}




\subsubsection{Weakness of Current Electrochemical Speciation Techniques}

Electrochemical techniques which incorporate a pre-concentration step (deposition step), e.g. stripping voltammetry (SV) and stripping chronopotentiometry (SCP), are of particular utility for studies on trace metal complexation relevant to environmental and biological systems since they can provide adequate sensitivity and speciation information. Most workers effectively determine complexation parameters under limiting-current conditions [13-15], i.e. from changes in the stripping peak potential and the limiting current determined at deposition potentials sufficiently negative of the reduction potential of the metal species in the samples. However, the complete potentialcurrent curve is inherently richer in information content because as a voltammorgram is recorded, from the foot of the wave to the limiting current region, it scans completely the relevant parts of the stability distribution and the corresponding parts of the rate constant distribution [16]. DC polarography could provide the voltammorgram, however it lacks the sensitivity required for measurements under environmentally realistic conditions. The curves constructed from stripping voltammetry (SV) peak magnitude, recorded as a function of deposition potential, may provide similar information [17-19]. That is, the stripping technique can be considered to act as an amplification of the complete steadystate polarographic wave. Such curves have been termed pseudopolarograms or scanned stripping voltammograms.

The speciation information content of SV measurement is potentially very rich: the amount of material accumulated in the electrode is a measure of the metal ion speciation in solution and is determined by the dissociation rate constants and diffusion coefficients 
for the metal complexes present as well as by the effective diffusion layer thickness during deposition. However, SV measurements are usually made under nondepletive conditions (i.e., not all of the accumulated metal is reoxidized from the electrode during the stripping step), and they thus rely on the measurement of a transient current signal that is taken to represent the concentration of metal accumulated in the electrode volume [20]. Induced metal adsorption is practically unavoidable when transient SV modes or incompletely depletive SCP (high stripping current, denoted as the $i_{s} \tau^{1 / 2}$ regime) are used to study metal complexation, which gives rise to disproportional signal enhancements [21-23]. Another important effect to consider is that during the stripping step, a relatively high local concentration of metal ions is generated at the electrode surface. This may ultimately lead to saturation of ligand at the electrode surface and thus result in broadened peaks with reduced magnitude and peak potential $E_{\mathrm{p}}$ values that are less negative than expected [13,22-25], even if the ligand is in relatively large excess over the metal in the bulk solution. The formation of adsorbed complexes during the stripping step may also influence the shape and position of the stripping peaks. Therefore, the SV and non-depletive SCP may not provide a reliable measure of the metal accumulated in the electrode during the stripping step for environmentally relevant samples, which contain a range of ligands with distributed stability constants, dissociation rate constants, and diffusion coefficients when these 'secondary effects' are present. Pseudopolarography (scanned stripping voltammetry), which suffers from the above 'secondary effect', is hence of limited value for interpretation and determination of metal speciation parameters. 


\subsection{Hypothesis}

Based on the preceding discussion, the hypothesis is formulated that the 'secondary effects' that plague the experimental determination can be avoided or minimized by applying Stripping Chronopotentiometry (SCP), which applies low stripping current to reoxidize the accumulated metal slowly and depletively from the electrode; and Scanned Stripping Chronopotentiometry (SSCP) may provide more reliable information on the metal speciation in the solution under depletive condition.

The above hypothesis was tested as follows.

1 The SSCP was applied to metals in model solution of homogeneous (simple) ligand and heterogeneous ligand (humic substances).

2 The results of SSCP were compared with those obtained by Pseudopolarography, in which widely exploited Differential Pulse Stripping Voltammetry (DP-SV) were utilized as a stripping mode.

3 The heterogeneity in metal complexation by a well-characterized Suwannee River Fulvic Acid (SRFA) was investigated by both SSCP and Pseudopolarography.

4 The complexometic titration followed by SCP was employed to study the conditional stability constants, $K$, of metal-organic complexes in Copper Cliff Mine effluent water samples, Sudbury, ON.

\subsection{Thesis Organization}

Chapter 1 presents a brief introduction of speciation techniques and current electrochemical metal speciation status, and proposes the hypothesis and objective of this 
work. Chapter 2 introduces the scientific background of humic substances and the theory of stirpping chronopotentiometry. In order to validate the technique of depletive stripping chronopotentiometry, depletive scanned stripping chronopotentiometry and pseudopolarography are used comparatively to determine the stability constants of metal complexes in homogeneous systems with logarithmic analysis of the curves in Chapter 3. Chapter 4 describes both depletive scanned stripping chronopotentiometry and pseudopolarography to investigate the heterogeneity, diffusion coefficients and stability constants of metal-fulvic acid complexes in model solutions. Complexometric titrations followed by depletive stripping chronopotentiometry are explored to study the effects of dilution on the determined stability constants of $\mathrm{Zn}$ (II)- and $\mathrm{Cd}(\mathrm{II})-\mathrm{DOC}$ complexes in Copper Cliff Mine effluent samples from Sudbury, Ontario and the results are presented in Chapter 5. 
- Chapter 2-

Scientific Background

Reproduced with permission of the copyright owner. Further reproduction prohibited without permission. 


\subsection{Humic Substances}

Humic substances (HS) are present in soils, waters, and sediments, in both soluble and insoluble forms. These macromolecular substances are derived from plants, algal and microbial materials [28]. Humic substances are considered natural polyelectrolytic organic compounds of complex structure involving a proportion of more or less condensed aromatic rings with a large number of attached $-\mathrm{OH}$ and $-\mathrm{COOH}$ groups [29,30] (typical example in Figure 2).

Humic substances, consisting of humic acid, fulvic acid and humin, are essentially a mixture of compounds of different molecular weights. More recently, due to novel applications of nuclear magnetic resonance spectroscopy, fluorescence correlation spectroscopy, atomic force microscopy, pyrolysis mass spectrometry, and numerical modeling, the representation of humic substances as predominantly consisting of small and relatively simple near spherical molecules $(1-2 \mathrm{~nm})$ able to form reversible aggregates has been accepted [29,34-37]. The sizes of individual HS place them at the limit of the domain of (macro) molecules and colloids. 


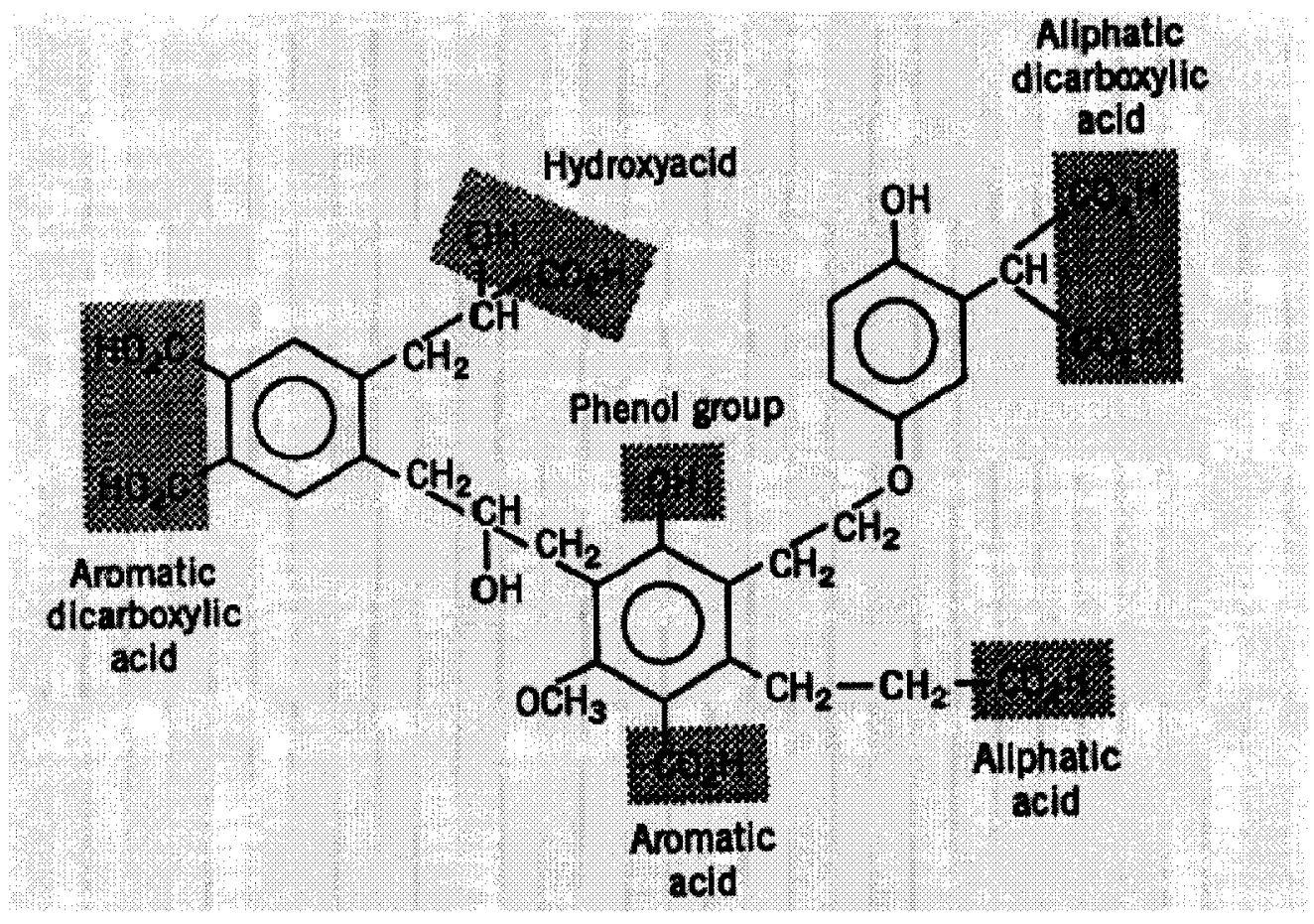

Figure 2 Exemplification of different possible $-\mathrm{OH}$ and $-\mathrm{COOH}$ groups in a hypothetical humic acid polymer [38]. 
Humic substances are organic ligands and play a crucial role in speciation, transport, and deposition of a variety of compounds ranging from metal ions to lipophilic compounds [31-33]. They are the largest fraction of natural organic matter in water. An abundance of experimental evidence suggests that in the aquatic environment, complexation of metal ions by dissolved organic ligands, most of which are represented by humic substances, especially in wetlands, reduces the toxicity of metal species by decreasing the free metal ion concentration [119].

Because of the chemical and steric variety of neighboring functional groups on humic and fulvic acids, there may be a range of affinities (binding energies) for metal ions and for protons, that is, a range of complex formation constants and acidity constants. In addition, electrostatic interactions (repulsion and attraction) between differently charged functional groups influence the acidity and complex formation constants of humic substances. The spread in binding strength of the functional groups in a humic substance is represented by a continuous distribution of the (log of the) equilibrium constants.

Chelating by neighboring carboxyl and phenolic groups is the major mode of metal complexation. Humic substance configuration gradually changes as metal ions find their thermodynamically favored positions within the humic structure, probably involving the formation of relatively stable inner sphere complexes $[124,125]$. The extent of metal-ion binding depends on the ratio of metal ions to humic substances $\left(\left[\mathrm{M}_{T}\right] /\left[\mathrm{L}_{T}\right]\right)$ and $\mathrm{pH}$ $[31,39]$. It is evident that the factors such as the sources of humic substances and the extraction or isolation procedure employed, concentration of humic substances, ionic 
strength of the solution, cation exchange capacity of humus soil, molecular radius, molecular surface area of humic substances, temperature, $\mathrm{pH}$, and method of analysis of the complex may affect the stability constant of the complexes $[38,122]$. The dependence of stability constants on so many factors reinforces the fact that these are conditional stability constants and are valid only for the environmental conditions under which they are determined [122]. Schnitzer and Hansen [123] observed that the stability constants were slightly higher at $\mathrm{pH} 5.0$ than at $\mathrm{pH} 3.5$, which was due to the higher dissociation of functional groups, particularly carboxyl groups, at $\mathrm{pH}$ 5.0. Also, $\mathrm{H}^{+}$and the metal ion compete for binding sites on the ligand and less metal is bound at the lower $\mathrm{pH}$.

As humic substances complexed with metal, their labilities vary accordingly, ranging from fully labile to inert. Their mobility is also variable. The diffusion coefficient of single fulvic molecule is $0.5-3 \times 10^{-10} \mathrm{~m}^{2} \mathrm{~s}^{-1}[34]$, i.e. lower than $D_{M}$ but non-negligible. They may aggregate with other colloids or with themselves at $\mathrm{pH}<6$ and high concentrations, (typically $>50 \mathrm{mg} \cdot \mathrm{ml}^{-1}$ ), and be effectively immobile [40].

\subsection{Chronopotentiometry}

Chronopotentiometry (CP) is the most basic constant current technique. In CP, a current step is applied across an electrochemical cell (without stirring). The current excitation

signal and potential response are shown as a function of time in Figure 3 . The nature of the potential response can be rationalized by considering the concentration profiles of the redox species as a function of time. 


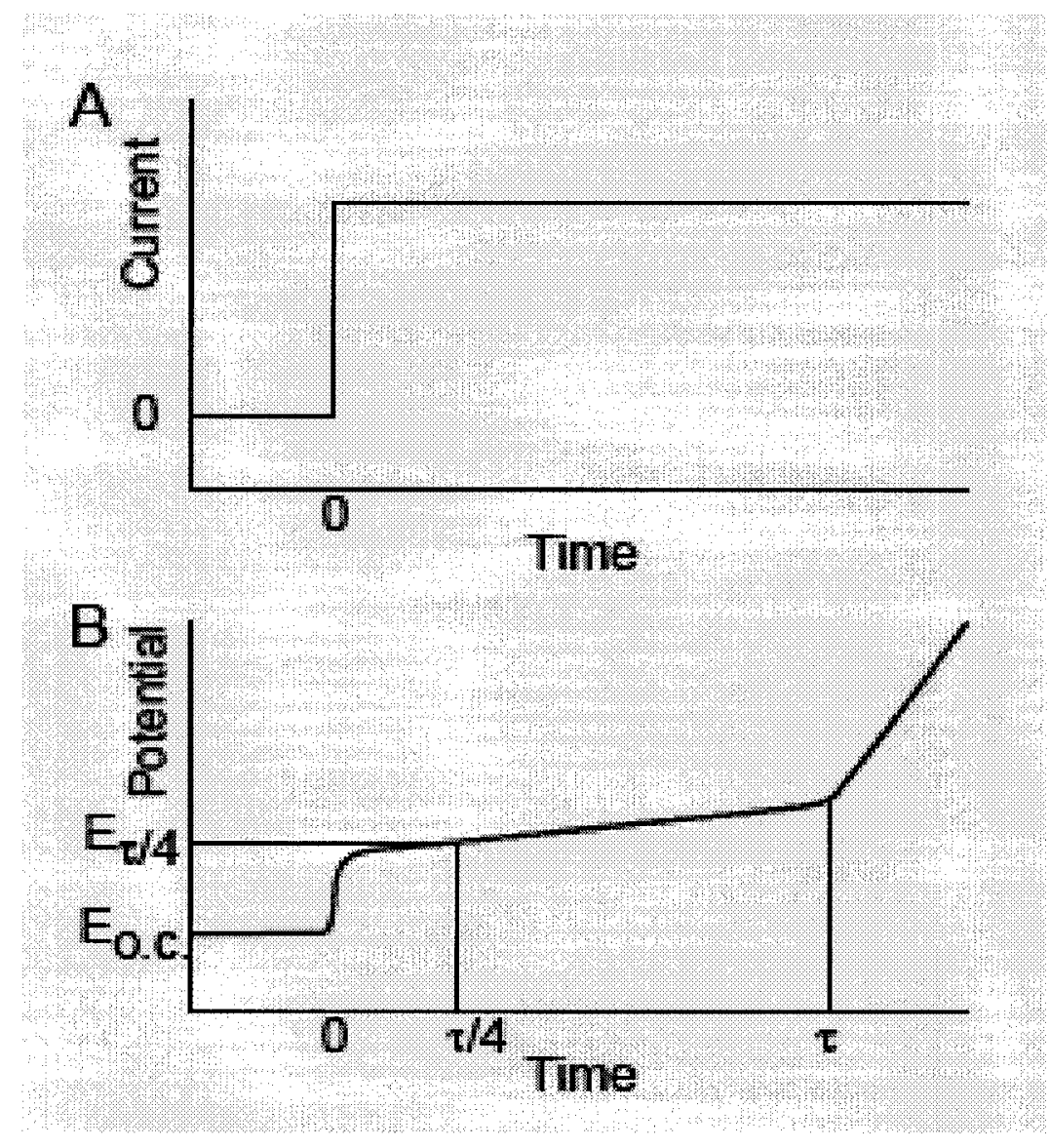

Figure 3 Current excitation (A) and potential response (B) for Chronopotentiometry [41] 
One advantage of all constant current techniques including chronopotentiometry is that the ohmic drop due to solution resistance is constant, as it is equal to the product of the current and the solution resistance. The ohmic distortion can therefore be simply corrected by a constant potential offset. In contrast, in potentiostatic experiments (e.g., cyclic voltammetry), the current, and hence the ohmic drop, varies with potential, and correction is more complicated.

Considering the electron transfer reaction $\mathrm{O}+\mathrm{e}=\mathrm{R}$, the initial potential is the rest potential or the open circuit potential $\left(E_{\text {o.c. }}\right)$. Once the (reducing) current step has been applied, $\mathrm{O}$ is reduced to $\mathrm{R}$ at the electrode surface in order to support the applied current, and the concentration of $\mathrm{O}$ at the electrode surface therefore decreases. The potential is close to the redox potential for $\mathrm{O}+\mathrm{e}=\mathrm{R}$, and its precise value depends upon the Nernst equation:

$$
\mathbf{E}=\mathbf{E}^{0^{\prime}}+\frac{0.059}{n} \log \frac{c_{\mathbf{0}}^{s^{s}}}{\mathbf{c}_{\mathbf{R}}^{\mathbf{s}}}
$$

where $\mathbf{c}_{\mathbf{0}}^{\mathbf{s}}$ and $\mathbf{c}_{\mathbf{R}}^{\mathbf{s}}$ are the surface concentrations of $\mathrm{O}$ and $\mathrm{R}$, respectively. These concentrations vary with time, so the potential also varies with time, which is reflected in the slope of the potential $v s$. time plot at this stage. Once the concentration of $O$ at the electrode surface is zero, the applied current can no longer be supported by this electron transfer reaction, so the potential changes to the redox potential of another electron transfer reaction. If no other analyte has been added to the solution, the second electron transfer reaction will involve reduction of the electrolyte; that is, there is a large change in the potential. 
The time required for the concentration of $\mathrm{O}$ at the electrode surface to reach zero is characterized by time $(\tau)$. The magnitude of $\tau$ depends upon the applied current; for example, an increase in the applied current $i_{s}$ leads to a decrease in $\tau$. The quantitative relationship between $i_{s}$ and $\tau$ is defined by the Sand equation, which corresponds to semiinfinite linear diffusion (large current):

$$
i_{s} \tau^{1 / 2}=\frac{n F A c \pi^{1 / 2} D^{1 / 2}}{2}
$$

where $A$ is the electrode surface area, $c$ is the bulk concentration of the analyte, and $D$ is its diffusion coefficient. The parameter $i_{s} \tau^{1 / 2}$ is a useful diagnostic parameter for $\mathrm{CP}$, as it is constant for redox processes that are not complicated by coupled chemical reactions or adsorption.

One ubiquitous parameter that causes deviations from the ideal behavior represented by the Sand equation is the charging current. Charging current is related to changes in potential, and hence is present throughout all constant current experiments. In addition, since the charging current depends upon the rate of change of potential, the magnitude of the charging current (and hence the fraction of the applied current that is available for the faradaic processes) varies during the experiment.

\subsubsection{Stripping Chronopotentiometry (SCP)}

In recent years, analytical application of SCP has increased, and there is a plethora of publications on analysis of samples containing significant amounts of organic matter, e.g. blood [42,43], urine [44-46], beer [47], wine [48], milk [49], honey [50], mussels [51] 
and natural waters [52-54]. For quantitation of total trace metals in such matrices, results obtained by SCP compare favorably with those from GFAAS $[23,25,55-56]$ or ICP-OES [57], with the advantage of much cheaper instrumentation. Indeed, instrumentation for SCP is simpler than that required for voltammetric methods, and hand-held devices have been developed [58].

As for biological matrices, the purported advantage of SCP over SV methods is that less sample pretreatment is required. For instance, the determination of labile and total copper and lead concentrations in wines has been reported [59].

Stripping chronopotentiometry is also referred to as 'potentiometric stripping analysis' [60]. In SCP, metal ions are reduced at a constant potential during the deposition (accumulation) step for a period of time; the following reoxidation of accumulated metal is carried out by chemical oxidation promoted by a species in solution (usually $\mathrm{Hg}^{2+}$ ) or by application of a constant anodic current. At the beginning of the reoxidation, $E$ decreases greatly from the deposition potential to that given by the equilibrium between the reduced and oxidized forms of the metal on the electrode surface, according to the Nernst equation. As the metal is being stripped to the solution, there is a smooth change in the equilibrium potential but, when the concentration of reduced metal on the electrode surface virtually decreases to zero, there is a dramatic change in the electrode potential, which starts to be determined by a different electrochemical process, or simply approaches the potential of equilibrium between electrode and solution. The time between both sudden potential changes is termed the transition time, $\tau$, which is achieved 
by measuring the area under the peak in the $\mathrm{d} t / \mathrm{d} E$ versus $E$ plot; it is the analytical parameter in SCP.

There are many claims in the literature (based on empirical observations) that SCP is less susceptible to interferences from adsorption of organic compounds on the electrode surface than is SV [61]. A more rigorous understanding of this behavior has recently been developed: determination of transition time from the area under the peak in the inverse of the time derivative of potential $(\mathrm{d} t / \mathrm{d} E)$ versus $E$ plot is the correct strategy for effective elimination of charging current [64]. The area under the baseline corresponds to the time necessary for charging, which is thus effectively eliminated from the analytical signal by this approach.

During the stripping step, at low applied currents, reoxidation occurs slowly (thus the analytical signal is relatively large) and the stripping time regime corresponds to practically complete depletion of the electrode $\left(i_{s} \tau\right.$ constant, $\left.\tau \propto \mathrm{c}\right)$, for which the surface concentration $\mathrm{c}_{\mathrm{M}^{\mathrm{o}}}^{\mathrm{o}}$ is practically the same as the mean bulk concentration of reduced metal in the electrode volume, $c_{M^{o}}^{*}$. This is a most attractive feature because it allows avoiding formulation of the flux, or, for that matter, the concentration gradient of $\mathbf{M}^{\mathbf{o}}$ inside the small spherical electrode volume [62]. The sensitivity and resolution are greatest under conditions that approach complete depletion and SCP in this time regime has sensitivity comparable to that of the more widely exploited differential pulse 
stripping voltammetry (DP-SV) technique [63]. Depletive SCP utilizes small stripping currents, typically in the range of $1-10 \mathrm{~mA} \mathrm{~m}^{-2}$.

In the presence of complexants in solution, it is the ligand-to-metal ratio at the electrode surface during stripping, $\left(c_{\mathrm{L}} / c_{\mathrm{M}}\right)^{\circ}$, (not that in the bulk solution) that governs the stripping peak potential and peak shape. To facilitate data interpretation, experimental conditions should preferably be chosen to avoid saturation of the ligand at the electrode surface [120]. Due to the preconcentration factors inherent in stripping techniques, this implies the need for a relatively large excess of ligand over metal in the bulk solution, combined with deposition time as short as is practicable.

In stripping voltammetry, $\left(c_{\mathrm{L}} / c_{\mathrm{M}}\right)^{\mathrm{o}}$ is dependent on the deposition time [25] and can be calculated via:

$$
\frac{c_{M}^{0}}{c_{M}^{*}}=\frac{3\left(D_{\left.M^{\prime} D_{M^{0}}\right)^{1 / 2} t_{d}}^{\delta_{d^{r}}}\right.}{\delta^{*}}
$$

where $\mathbf{c}_{\mathbf{M}}^{\mathbf{0}}$ is the limiting concentration of metal ion at the electrode surface at the onset of the stripping process, $\mathbf{c}_{\mathbf{M}}^{*}$ is the bulk metal ion concentration, $\mathbf{D}_{\mathbf{M}}$ and $\mathbf{D}_{\mathbf{M}^{\mathbf{0}}}$ are the diffusion coefficients of the metal ion in solution and of the reduced metal in mercury, respectively, $\delta_{\mathrm{d}}$ is the diffusion layer thickness during the deposition step, $r$ is the electrode drop radius, and $t_{\mathrm{d}}$ is the deposition time.

For SCP, the gradients of $\mathrm{M}^{\mathrm{o}}$ (in mercury) and $\mathrm{M}^{2+}$ (in solution) are defined by the applied current and hence $\left(c_{\mathrm{L}} / c_{\mathrm{M}}\right)^{\mathrm{o}}$ is governed by $i_{s}$ and is independent of deposition time [25]: 


$$
\mathbf{c}_{\mathbf{M}}^{\mathbf{o}}-\mathbf{c}_{\mathbf{M}}^{*}=\frac{\left(\boldsymbol{\delta}_{\mathbf{d}} / \mathbf{D}_{\mathbf{M}}\right) \mathbf{i}_{\mathbf{s}}}{\mathbf{n F A}}
$$

It is noteworthy that the $\mathrm{SCP}\left(c_{\mathrm{L}} / c_{\mathrm{M}}\right)^{\circ}$ ratio is defined by the chosen stripping current. Thus, in contrast to SV, it is independent of deposition time. This is of great significance for measurements of very low concentrations (environmentally relevant): in SV, long deposition times (e.g. 10-15 $\mathrm{min}$ ) are typically employed to obtain adequate sensitivity [121]. It must be noted that since the requirement for excess ligand applies strictly to all components of a heterogeneous mixture, it is improbable that an adequate $\left(c_{\mathrm{L}} / c_{\mathrm{M}}\right)^{\circ}$ can be attained with SV under these conditions; the $t_{\mathrm{d}}$ independent nature of the $\operatorname{SCP}\left(c_{\mathrm{L}} / c_{\mathrm{M}}\right)^{\circ}$ thus offers a distinct advantage. The practical limit to the maximum $\left(c_{\mathrm{L}} / c_{\mathrm{M}}\right)^{\circ}$ ratio that can be achieved in SCP for a given bulk ligand concentration is determined by the lowest practically useful $i_{s}$ value.

\subsubsection{Scanned Stripping Chronopotentiometry (SSCP) and Scanned Stripping} Voltammetry (Pseudopolarography or SSV) in Metal Speciation

Pseudopolarography is a method appropriate for distinguishing the labile from the inert complexes of dissolved trace metals with ligands in their natural concentrations [65-89]. It can be particularly applied for the speciation of trace metals that form amalgams, being based on anodic stripping voltammetry or on stripping chronopotentiometry as well [ 62 , 90-92]. A pseudopolarogram, which is similar in shape to the classical polarogram, is the dependence of peak-area of a redox reaction on the deposition potential, changing in subsequent voltammetric measurement cycles $[65,67,68,69,70]$, and reflecting thermodynamic and kinetic properties of metal ions as well as geometric and hydrodynamic characteristics of the working electrode. The main parameters used for the 
speciation of trace metals are the half-wave potential $\left(E_{1 / 2}\right)$ and the limiting current $i^{*}$ or the limiting transition time $\tau^{*}$ (SSCP curve). However, we can benefit from the entire shape of the pseudo-polarographic curve, which provides a scanning image (fingerprint) of the investigated electrochemical reactions. It was reported that thermodynamic stability constant of the inert metal complex can be obtained from the difference between the standard potentials of the redox reactions of the free and the inert complexed metals [72] at low metal concentration levels $\left(<10^{-7} \mathrm{M}\right)$. This theoretical concept was empirically used for the determination of stability constants of inert metal complexes using pseudopolarographic half-wave potentials, and was successfully applied for trace metals speciation of unknown natural aquatic systems $[11,80,88,89]$. From the ratio of the limiting currents of the labile to inert metal complexes (using known side reaction data) the calculation of the stability constant was possible, as well. The parameters relative to the redox reaction, such as the transfer coefficient and the rate constant, could be obtained through the analysis of the shape of pseudopolarographic wave $[93,94]$.

Pseudopolarograms plot the ASV peak current as a function of the applied electrodeposition potential while SSCP curves plot the transition time as a function of the deposition potential, both of them resulting in a sigmoidal dependence in which the potential at half maximum signal can be related to the polarographic half-wave potential. As in direct current polarography (DC-polarography), the limiting current of the pseudopolarogram, or the limiting transition time of SSCP is a linear function of the metal concentration, while their half-wave potentials are independent of it. If the redox reaction is reversible, the pseudopolarographic and SSCP's half-wave potential depend 
on the electrode area, stirring rate and electrolysis time, and shift toward more negative potentials with increasing ligand concentration. Thus, the conditional stability constants of the complexes and their coordination indexes can be calculated by using the DeFord and Hume method [95]:

$$
\begin{aligned}
& \exp \left[-\frac{n F}{R T} \Delta E_{1 / 2}+\ln \frac{i_{M}^{*}}{i_{M+L}^{*}}\right]=\Sigma \beta_{n}[L]^{n} \\
& \exp \left[-\frac{n F}{R T} \Delta E_{1 / 2}+\ln \frac{\tau_{M}^{*}}{\tau_{M+L}^{*}}\right]=\Sigma \beta_{n}[L]^{n} \\
& \Delta E_{1 / 2}=E_{1 / 2}^{M+L}-E_{1 / 2}^{M} \\
& \beta_{n}=\left[M_{n}\right] /[M][L]^{n}
\end{aligned}
$$

$\mathbf{i}_{\mathbf{M}}^{*}$ and $\mathbf{i}_{\mathbf{M}+\mathbf{L}}^{*}$ represent the limiting current of the pseudopolarographic wave of the free and complexed metal, respectively. $\tau_{\mathbf{M}}^{*}$ and $\tau_{\mathbf{M}+\mathbf{L}}^{*}$ represent the limiting transition time of the SSCP wave of the free and complexed metal, respectively. The ratio of these values is a corrective term that takes into account the differences in the diffusion coefficients of the free and complexed metal. $\mathbf{E}_{\mathbf{1} / 2}^{\mathbf{M}+\mathbf{L}}$ and $\mathbf{E}_{1 / 2}^{\mathbf{M}}$ symbolize the pseudopolarographic half-wave potential of the free and complexed metal, respectively. $\mathrm{R}, \mathrm{T}, \mathrm{n}$ and $\mathrm{F}$ have their usual meaning. $\beta_{\mathrm{n}}$ is the cumulative complexation equilibrium constant.

Electrochemical reduction of the metal ion, in systems containing labile complexes, is limited by coupled diffusion of the complex and free metal that can be described by a mean diffusion coefficient defined as [96]: 


$$
\overline{\mathbf{D}}=\left(\mathbf{D}_{\mathbf{M}} \mathbf{c}_{\mathbf{M}}^{*}+\mathbf{D}_{\mathbf{M L}} \mathbf{c}_{\mathbf{M L}}^{*}\right) / \mathbf{c}_{\mathbf{M}, \mathbf{t}}^{*}
$$

where $D_{\mathrm{M}}$ and $D_{\mathrm{ML}}$ are the diffusion coefficients of the metal and of the complex (which is assumed to be equal to the diffusion coefficient of the ligand), respectively, $\mathbf{c}_{\mathbf{M}}^{*}$, $\mathbf{c}_{\mathbf{M L}}^{*}$ and $\mathbf{c}_{\mathbf{M}, \mathbf{t}}^{*}$ are the free, complexed and total bulk metal concentrations, respectively.

\subsection{Objectives of This Thesis}

1 to apply scanned stripping chronopotentiometry (SSCP) to study metal complexation with simple homogeneous ligand and heterogeneous ligand (humic substance) in model solutions;

2 to compare the results obtained by SSCP with those by Pseudopolarography, which employs Differential Pulse Stripping Voltammetry (DP-SV) as a stripping mode in order to evaluate the strengths and weaknesses of SCP;

3 to study and compare the effects of heterogeneity on complexation of selected metals by a well-characterized humic substance, viz. Suwannee River Fulvic Acid (SRFA) by using SSCP and Pseudopolarography;

4 to investigate dilution effects on conditional stability constant of metal complexation with DOC in Copper Cliff Mine effluent water samples by complexometric titration in order to study the practical utility of Stripping Chronopotentiometry (SCP). 
- Chapter 3-

Depletive Stripping Chronopotentiometry and Comparison of Scanned Stripping Chronopotentiometry (SSCP) with Scanned Stripping Voltammetry (SSV or Pseudopolarography) in Homogeneous Complexes Using Static Mercury Drop Electrode 


\subsection{Introduction}

Stripping voltammetry (SV) is of a non-depletive nature and relies on the measurement of a transient current signal that is taken to represent the concentration of the metal accumulated in the electrode volume. As first described quantitatively by De Vries and van Dalen [126,127], and further developed by others [128], complete depletion can be achieved by linear scan SV, at sufficiently low scan rates. However, linear scan voltammetry has relatively low sensitivity.

Depletive Stripping Chronopotentiometry (SCP), a recently developed electroanalytical technique, can overcome the detection step related limitations of SV based on the fact that such conditions approach complete depletion of accumulated metal from the electrode at low stripping current. The depletive SCP regime has greater sensitivity and resolution than does SV. The detection limit of depletive SCP is comparable to that for DP-SV (ca. $0.4 \mathrm{nmol} \mathrm{L}^{-1}$ ) [64]. Besides that, there is general consensus (based on empirical observations) that SCP is less susceptible to interference from adsorbing components than is SV [61,130-132].

Pseudopolarography (scanned stripping voltammetry) has been applied to the characterization of labile $[67,81,82,77-79,129]$ and inert $[11,72,80]$ complexes at low metal concentration levels. The stability constants of the labile metal complexes obtained by pseudopolarography are in very good agreement with the literature data obtained at much higher metal concentration levels $[67,77-79,81]$ using other 'classical' methods, such as polarography and spectrometry. 
In this chapter, the stripping current of SCP is firstly investigated and optimized to achieve complete depletion. The effects of stirring speed and deposition time on the diffusion layer thickness are studied under depletive condition. In order to validate the technique of depletive SCP, the stability constants of homogeneous complexes, i.e. cadmium and lead with pyridine-2, 6-dicarboxylic acid (PDCA) and nitrilo-triacetic acid (NTA) are experimentally determined by using both scanned stripping chronopotentiometry (SSCP) and pseudopolarography with differential pulse stripping voltammetry based on the DeFord-Hume treatment, and the results are compared.

\subsection{Theory}

In stripping techniques at spherical electrodes the limiting current for labile complex systems in the deposition step is

$$
\mathbf{I}_{\mathbf{d}}^{*}=\mathbf{n F A D c _ { M , t } ^ { * }}(\mathbf{1} / \delta+1 / \mathbf{r})
$$

where $D$ is the diffusion coefficient in aqueous solution, $\mathbf{c}_{\mathbf{M}, \mathbf{t}}^{*}$ is the total metal concentration in the bulk solution, $n$ is the number of electrons involved in the process, $F$ is the Faraday constant, $A$ is the electrode area, $\delta$ is the diffusion layer thickness, and $r$ is the radius of the electrode. The diffusion layer thickness depends on the hydrodynamic conditions of the deposition step, which is performed while stirring the solution.

For a macroelectrode, under linear diffusion where $1 / r<<1 / \delta$, the equation reduces to

$$
\mathbf{I}_{\mathbf{d}}^{*}=\mathbf{n F A D c} \mathbf{M}, t^{*} / \delta
$$


In Stripping Chronopotentiometry (SCP) [64], the amount of metal amalgamated during the deposition step, is related to the limiting transition time, $\tau^{*}$, obtained for sufficiently negative deposition potentials by

$$
\tau^{*}=\mathbf{I}_{\mathbf{d}}^{*} \mathbf{t}_{\mathbf{d}} / \mathbf{i}_{\mathbf{s}}
$$

where $i_{s}$ is the stripping current and $t_{\mathrm{d}}$ is the deposition time.

In the presence of ligands, the stability constant of metal complex is defined as

$$
K=\frac{\mathbf{c}_{M L}^{*}}{\mathbf{c}_{M}^{*} \mathbf{c}_{L}^{*}}
$$

Under conditions of sufficient excess of ligand over metal $\left(\mathbf{c}_{\mathbf{L}, \mathbf{t}}^{*} \square \mathbf{c}_{\mathbf{M}, \mathbf{t}}^{*} \Rightarrow \mathbf{c}_{\mathbf{L}}^{*} \cong \mathbf{c}_{\mathbf{L}, \mathbf{t}}^{*}\right)$, it is useful to define

$$
\mathbf{K}^{\prime}=\mathbf{K} \mathbf{c}_{\mathbf{L}, \mathbf{t}}^{*}=\mathbf{c}_{\mathbf{M L}}^{*} / \mathbf{c}_{\mathbf{M}}^{*}
$$

The stability constants of the labile homogeneous complexes can be accurately computed from these SSCP data and pseudopolarography data using an expression for the shift of the half-wave potential, $\Delta E_{\mathrm{d}, 1 / 2}$ (equivalent to the DeFord-Hume expression) [142]:

$$
\begin{aligned}
& \ln \left(1+K^{\prime}\right)=-(\mathbf{n F} / \mathbf{R T}) \Delta \mathbf{E}_{\mathrm{d}, \mathbf{1} / 2}-\ln \left(\mathbf{i}_{\mathbf{M}+\mathbf{L}}^{*} / \mathbf{i}_{\mathbf{M}}^{*}\right) \\
& \ln \left(\mathbf{1}+\mathbf{K}^{\prime}\right)=-(\mathbf{n F} / \mathbf{R T}) \Delta \mathbf{E}_{\mathbf{d}, \mathbf{1} / 2}-\ln \left(\tau_{M+L}^{*} / \tau_{M}^{*}\right)
\end{aligned}
$$

\subsection{Experimental}

\subsubsection{Materials and Reagents}

Standard solutions $(1000 \mu \mathrm{g} / \mathrm{ml})$ of $\mathrm{Pb}$ (II) and Cd (II) were purchased from SCP Science, Montreal, Canada. Ultrapure water of resistivity of $18.2 \mathrm{M} \Omega . \mathrm{cm}$ was obtained from a 
Milli-Q-Plus water purification system (Millipore Corporation). A 2 M stock solution of sodium acetate and a $2 \mathrm{M}$ stock solution of $\mathrm{KNO}_{3}$ were prepared by dissolving an appropriate quantity of sodium acetate trihydrate (ACS grade/BDH) or potassium nitrate (Aldrich) in ultrapure water. The sodium acetate solution and the $\mathrm{KNO}_{3}$ solution were then purified separately by electrolysis at $-1.5 \mathrm{~V} v s$. SCE for at least $48 \mathrm{~h}$ prior to its use. To prevent the impurity metal from returning to the solution, the purified solution was removed while the electrolysis was going on. A 2 M stock solution of acetic acid was prepared by diluting glacial acetic acid (ACS grade/Anachemia) with ultrapure water. All solutions were prepared to contain constant ionic strength of $0.1 \mathrm{M}$ and $\mathrm{pH}$ of 4.8 . A $1 \mathrm{x}$ $10^{-3} \mathrm{M}$ stock solution of PDCA and a $1 \times 10^{-3} \mathrm{M}$ stock solution of NTA were prepared by dissolving an appropriate quantity of pyridine-2, 6-dicarboxylic acid (Aldrich, $>99 \%$, $\mathrm{MW}=167.12)$ or nitrilo-triacetic acid $(\mathrm{BDH},>99 \%, \mathrm{MW}=191.14)$ in ultrapure water.

\subsubsection{Containers and Cleaning Procedure}

All containers used were made of Teflon. After cleaning with ultrapure water, the containers were filled with the cleaning solution containing $10 \%(\mathrm{v} / \mathrm{v})$ nitric acid (AR grade) in ultrapure water and allowed to stand at room temperature for one week. They were further rinsed with ultrapure water five times. Finally, they were filled with ultrapure water, and allowed to stand until use. The water was renewed periodically to ensure continued contact with clean water.

\subsubsection{Apparatus}

An Accumet $20 \mathrm{pH} /$ conductivity meter (Fisher Scientific), fitted with an Accuplast 
combination glass electrode was used to adjust the $\mathrm{pH}$ of the solutions.

Chronopotentiometric and voltammetric measurements were made with a computercontrolled Autolab PGSTAT 30 potentiostat/galvanostat (Eco. Chemie BV, Netherlands), equipped with a Metrohm 663 VA stand (Metrohm, Switzerland). The working electrode was a Static Mercury Drop Electrode (SMDE, Metrohm, Switzerland). The reference electrode was $\mathrm{Ag} / \mathrm{AgCl}$ electrode in a glass tube filled with $3 \mathrm{M} \mathrm{KCl}$ and fitted with a porous Vycor tip (Bioanalytical Systems, Inc., USA). The counter electrode was made of a platinum rod (Metrohm, Switzerland). Analysis of peaks was done using the General Purpose Electrochemical Software v4.9 (Eco Chemie BV, The Netherlands). The data were transferred to a Pentium computer and saved for processing.

\subsubsection{Electrochemical Parameters}

Each sample solution was purged with $\mathrm{N}_{2}$ gas for $10 \mathrm{~min}$ before potential stripping analysis (PSA) method was employed. An oxidizing current, $i_{\mathrm{s}}$ of $1 \times 10^{-9} \mathrm{~A}$ was applied in solution after the deposition and equilibrium periods. The raw signal is the variation of potential with time that is automatically converted to the $\mathrm{d} t / \mathrm{d} E v s$. E format, being the area under the peak at the transition time. The SSCP waves were constructed from a series of individual measurements (peak areas) plotted as functions of the wide range of deposition potentials applied. For each point the potential was held at $E_{\mathrm{d}}$ for the duration of the deposition time of $120 \mathrm{~s}$, after the consequent equilibration time of $20 \mathrm{~s}$ the oxidizing current was applied until a value well past the deposition plateau $(-0.50 \mathrm{~V}$ for $\mathrm{Cd}$ and $-0.25 \mathrm{~V}$ for $\mathrm{Pb}$ ). 
For pseudopolarography measurements, the same sample solution was purged with $\mathrm{N}_{2}$ for $10 \mathrm{~min}$, thereafter determined by differential pulse stripping voltammetry (DP-SV) in the wide range of deposition potentials applied. The experimental conditions are: deposition time $120 \mathrm{~s}$, equilibration time $20 \mathrm{~s}$, initial potential $-1.3 \mathrm{~V}$, end potential $0.1 \mathrm{~V}$, scan rate $0.0102 \mathrm{~V} / \mathrm{s}$.

\subsection{Results and Discussion}

\subsubsection{Stripping Chronopotentiometry Peak}

The detection limit of any technique is determined by its ability to discriminate the analytical signal from the background. For electrochemical methods, decreases in detection limit require improved discrimination of the faradaic signal from the capacitive charging component. Pulse stripping voltammetric methods achieve this by exploiting time-dependent differences.

The slope of the SCP $E$ versus $t$ trace, in the absence of a faradaic process, is determined by the capacitance of the electrode double layer; this slope is modified in the presence of adsorbing species. In many cases the $\mathrm{d} t / \mathrm{d} E$ versus $E$ format allows the capacitive charging current to be effectively eliminated. The area under the peaks in these plots corresponds to the time taken for the faradaic oxidation process; the time necessary for charging corresponds to the area under the baseline (Figure 4). The important point in SCP is that such a straightforward interpretation requires knowledge of the stripping time regime under which the measurements are performed. For example, the poor baselines observed when high stripping currents are employed as a consequence of the ongoing 
faradaic process that follows incomplete depletion of the drop during the transition plateau. For simple systems and complexes with non-distributed stabilities, the peak height, $(\mathrm{d} t / \mathrm{d} E)_{\max }$, can be used in a manner equivalent to the peak area.

Figure 4 presents the direct SCP potential $E v s . t$ trace and the corresponding $(d t / d E) v s . E$ plot at different deposition potentials for Cd(II). For metal complex, ML, which is not directly reducible, the peak will increase from zero to a limiting value over a small range of deposition potential. However, where electrons are added directly to the complex without its initial dissociation in the diffusion layer, direct electrochemical reduction of the complex is known to occur, especially at very negative deposition potentials; the presence of such complexes in a sample can be detected from the effect of deposition potential on transition time or peak current; the peak will hence increase continuously with increasing deposition potential.

\subsubsection{Optimization of the Stripping Current}

In SCP, depending on the magnitude of stripping current $i_{s}$, the conditions prevailing during the stripping step can range from semi-infinite linear diffusion $\left(i_{s} \tau^{1 / 2}\right.$ constant, high stripping current) to the complete depletion limit ( $i_{s} \tau$ constant, low stripping current).

In $i_{s} \tau$ regime (low stripping current), the stripping process takes place at such a low rate that the drop is completely depleted during the transition time. The stripping curve is 

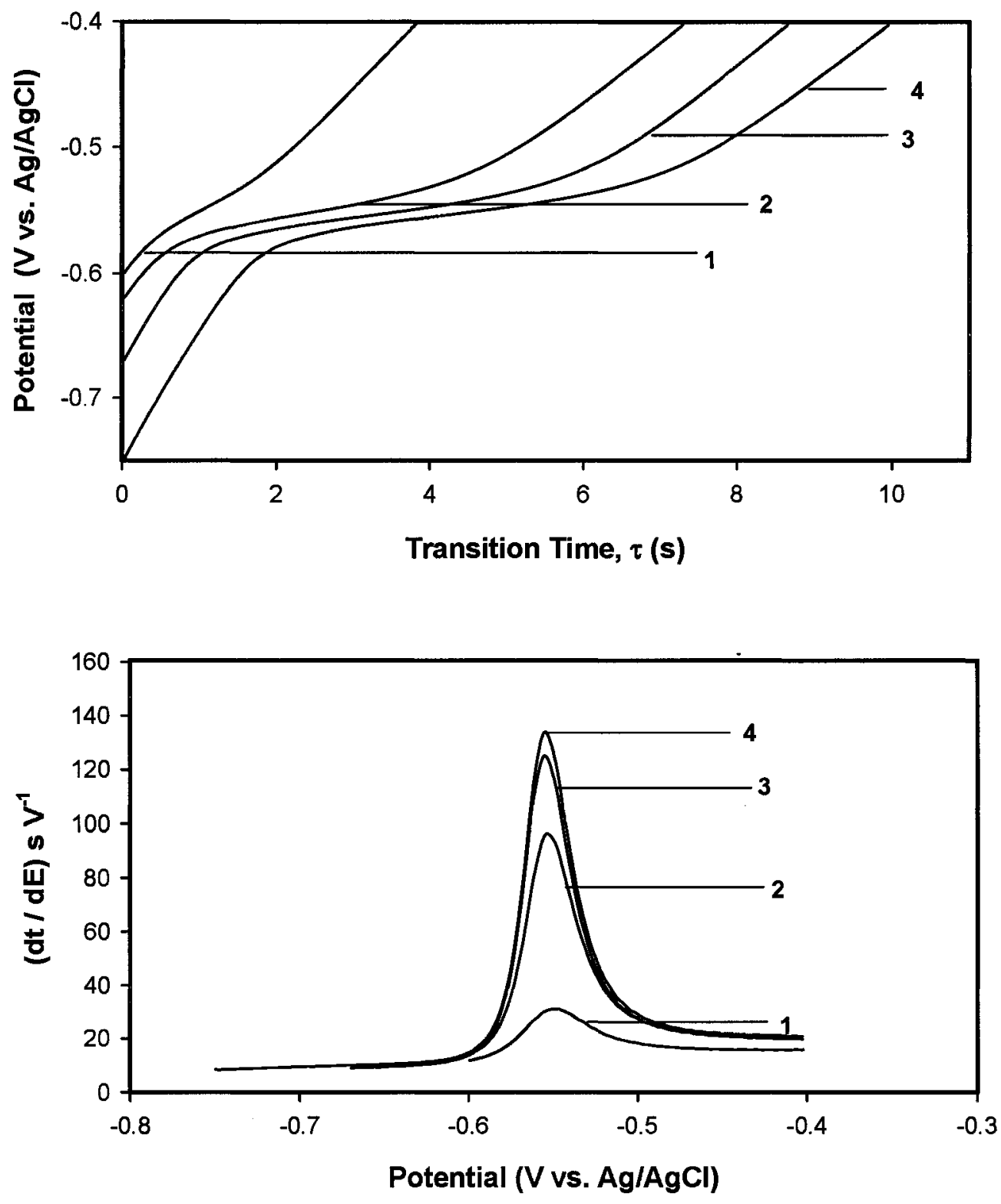

Figure 4 Stripping Chronopotentiometry (SCP) curves for Cd(II) at a SMDE as function of deposition potential: 1. $-0.60 \mathrm{~V} ; 2$ 2. $-0.62 \mathrm{~V} ;$ 3. $-0.67 \mathrm{~V} ; 4$ 4. $-0.75 \mathrm{~V}$. Curves correspond to $2 \times 10^{-7} \mathrm{M} \mathrm{Cd}(\mathrm{II})$, deposition time $120 \mathrm{~s}$, stripping current $1 \mathrm{x}$ $10^{-9} \mathrm{~A}, \mathrm{pH} 4.8 \pm 0.1$, ionic strength $0.1 \mathrm{M}, \mathrm{T}=23 \pm 2{ }^{\circ} \mathrm{C}$. 
described simply by the Faraday Laws, and $\tau$ is directly proportional to $c$ :

$$
\mathbf{i}_{\mathbf{s}} \tau=\mathbf{c}_{\mathbf{M}^{\mathbf{0}}}^{*} \mathrm{nFV}_{\mathrm{drop}}
$$

where $V_{d r o p}$ is the volume of mercury drop electrode, $\tau$ is the transition time.

Theoretically, $\tau$ should increase continually as $i_{s}$ is decreased. There is, however, a practical limit to this effect that is determined by the concentration of traces of dissolved oxygen (or other oxidants). The effect of traces of dissolved oxygen as oxidative flux on the reoxidization of amalgam may not be negligible as the stripping current is sufficiently low. Under conditions of rigorous oxygen exclusion, it is found the lowest utilizable $i_{s}$ under standard conditions to be $1 \times 10^{-9} \mathrm{~A}$ (Figure 5).

The potential at $(\mathrm{d} t / \mathrm{d} E)_{\max }, E_{\mathrm{p}}$, shifts to more positive values as $i_{s}$ increases (Figure 5 ). This result is easily understood by considering the relative concentrations of oxidized and reduced species at the electrode surface during stripping. For a reversible $\mathbf{M}^{\mathrm{n}+} / \mathrm{M}(\mathrm{Hg})$ system, the Nernst equation holds:

$$
\mathbf{E}_{\mathbf{p}}=\mathbf{E}_{\mathrm{o}}^{\prime}+\frac{\mathbf{R T}}{\mathrm{nF}} \ln \left(\frac{\mathbf{c}_{\mathbf{M}^{\mathrm{n}+}}^{*}}{\mathbf{c}_{\mathbf{M}^{\mathrm{p}}}^{*}}\right)
$$

Therefore, as $i_{s}$ increases, the ratio $\mathbf{c}_{\mathbf{M}^{\mathbf{n}+}}{ }^{\mathbf{n}} / \mathbf{c}_{\mathbf{M}^{\mathbf{0}}}$ at the inflection point in the transition plateau will increase $\left(\mathbf{C}_{\mathbf{M}^{\mathbf{n}}+}^{*}\right.$ is the concentration of oxidized metal ion at the mercury drop surface), and $E_{\mathrm{p}}$ will shift to more positive values. 

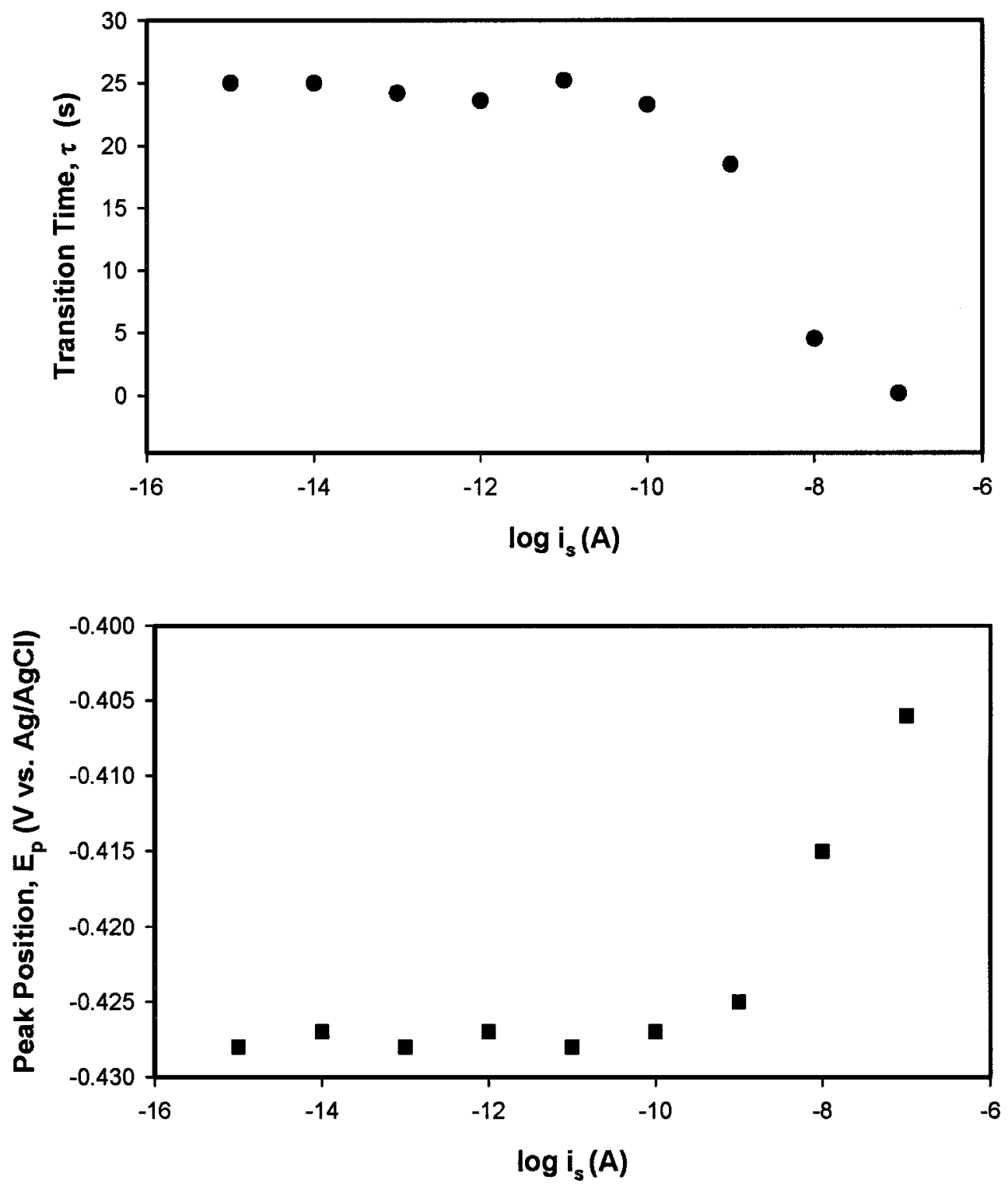

Figure 5 Effects of logarithm of stripping current, $\log i_{\mathrm{s}}$ on transition time, $\tau(\bullet)$ and peak position, $\mathrm{E}_{\mathrm{p}}(\mathrm{\square})$ of $2 \times 10^{-7} \mathrm{M} \mathrm{Pb}$ (II) determined by Stripping Chronopotentiometry (SCP). Deposition potential $-0.6 \mathrm{~V}$, deposition time 180 s, pH $4.8 \pm 0.1$, ionic strength $0.1 \mathrm{M}, \mathrm{T}=23 \pm 1^{\circ} \mathrm{C}$. 


\subsubsection{Diffusion Layer Thickness}

For the complex which is not directly reducible at the electrode, the lability of a complex, determined during the deposition step, depends on the kinetic parameters of the metal complex dissociation, the concentration of excess ligand and the diffusion layer thickness $(\delta)$, which depends on the hydrodynamic conditions and is a function of the rate of stirring of the solution. The larger the value of $\delta$, the longer is the residence time of the complex in the diffusion layer, the greater is the opportunity for dissociation and deposition of metal at the electrode and hence the higher is the fraction of labile metal.

Figure 6 shows that the diffusion layer thickness, $\delta$, decreases with increasing deposition time at slow stirring rate. However, with increasing stirring speed, deposition time seems to have little effect on the diffusion layer thickness, which means it cannot affect the lability of complex under sufficiently stirring conditions. To approach linear diffusion $\delta /$ $r_{0} \ll 1$, faster stirring and larger drop size are recommended.

\subsubsection{Comparison of SSCP with Pseudopolarography}

\subsubsection{Variation of deposition time}

A simplified equation of the half-wave potential for the reversible pseudopolarogram (e.g. $\mathrm{Pb}(\mathrm{II}), \mathrm{Cd}(\mathrm{II}))$ at the mercury drop electrode is given [136]:

$$
E_{1 / 2}=E^{0}+\frac{0.059}{n} \times \log \left(2 r \delta / 3 D t_{d}\right)
$$

where $E^{o}$ is the formal potential, $\delta$ is the diffusion layer thickness, $t_{\mathrm{d}}$ is the deposition time, other symbols have been defined previously. 


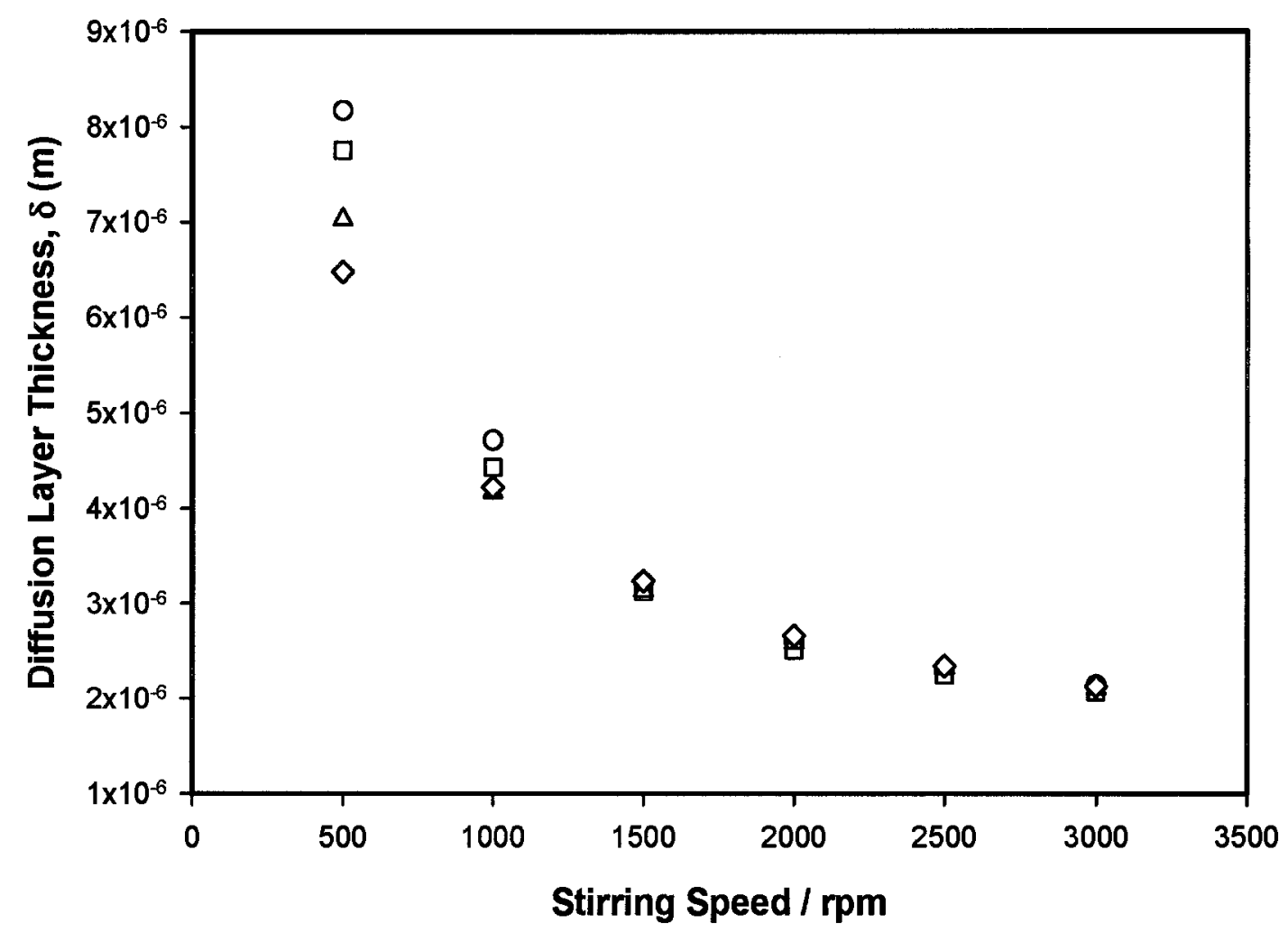

Figure 6 Variation of diffusion layer thickness, $\delta$, of $2 \times 10^{-7} \mathrm{M} \mathrm{Pb}$ (II) with the stirring speed determined by SCP at a $\operatorname{SMDE}\left(\mathrm{r}_{\mathrm{o}}=2.03 \times 10^{-4} \mathrm{~m}\right)$. The curves correspond to different deposition times: $180 \mathrm{~s}(0), 360 \mathrm{~s}(\square), 600 \mathrm{~s}(\Delta), 900 \mathrm{~s}$ $(\diamond)$. Deposition potential $-0.65 \mathrm{~V}$, stripping current $1 \times 10^{-9} \mathrm{~A}, \mathrm{pH} 4.8 \pm 0.1$, ionic strength $0.1 \mathrm{M}, \mathrm{T}=23 \pm 2{ }^{\circ} \mathrm{C}$. 
Figure 7 illustrates the effect of deposition time on SSCP curve of $2 \times 10^{-7} \mathrm{~mol} \mathrm{~L}^{-1} \mathrm{~Pb}$ (II). The half-wave potential shifts to more negative values with increasing deposition time under sufficiently stirred hydrodynamic condition.

\subsubsection{Labile complexes: $C d(I I)-P D C A$ and $P b(I I)-P D C A$}

$\mathrm{Cd}(\mathrm{II})-\mathrm{PDCA}, \mathrm{Pb}$ (II)-PDCA complexes are simple labile, reversible systems for which $\mathrm{D}_{\mathrm{ML}}=\mathrm{D}_{\mathrm{M}}$. For Cd(II)-PDCA, there is neither adsorption of free ligand on the electrode nor adsorption of the complex [22,24]. For $\mathrm{Pb}(\mathrm{II})-\mathrm{PDCA}$, there is no adsorption of free ligand, but the complex does adsorb over the potential range of $\mathrm{Pb}^{\circ}$ oxidation [22]. Depletive SCP measurements are however not affected by these adsorption processes [22-24].

To avoid saturation of the ligand at the electrode surface of the electrode during stripping, there should be sufficient ligand excess. Both effects, $D_{M L}$ lower than $D_{M}$ and a slow kinetics of the complex dissociation, may lead to a decrease in the peak height. In these two cases (Figure 8, Figure Al(APPENDIX)), much higher concentration of PDCA restrains the dissociation of the complexes, the $\mathrm{Pb}(\mathrm{II})$-PDCA complex adsorbed on the electrode impedes the reduction of $\mathrm{Pb}(\mathrm{II})$, hence leads to ineffective deposition, and contributes the less labile species.

Figures 9 and A2 (APPENDIX) present the pseudopolarograms of Cd(II)-PDCA and $\mathrm{Pb}(\mathrm{II})-\mathrm{PDCA}$ complexes stripped by $\mathrm{DP}-\mathrm{SV}$, which prove the ligand saturation and the induced metal adsorption to the electrode, as reported in the literatures [21-23]. 


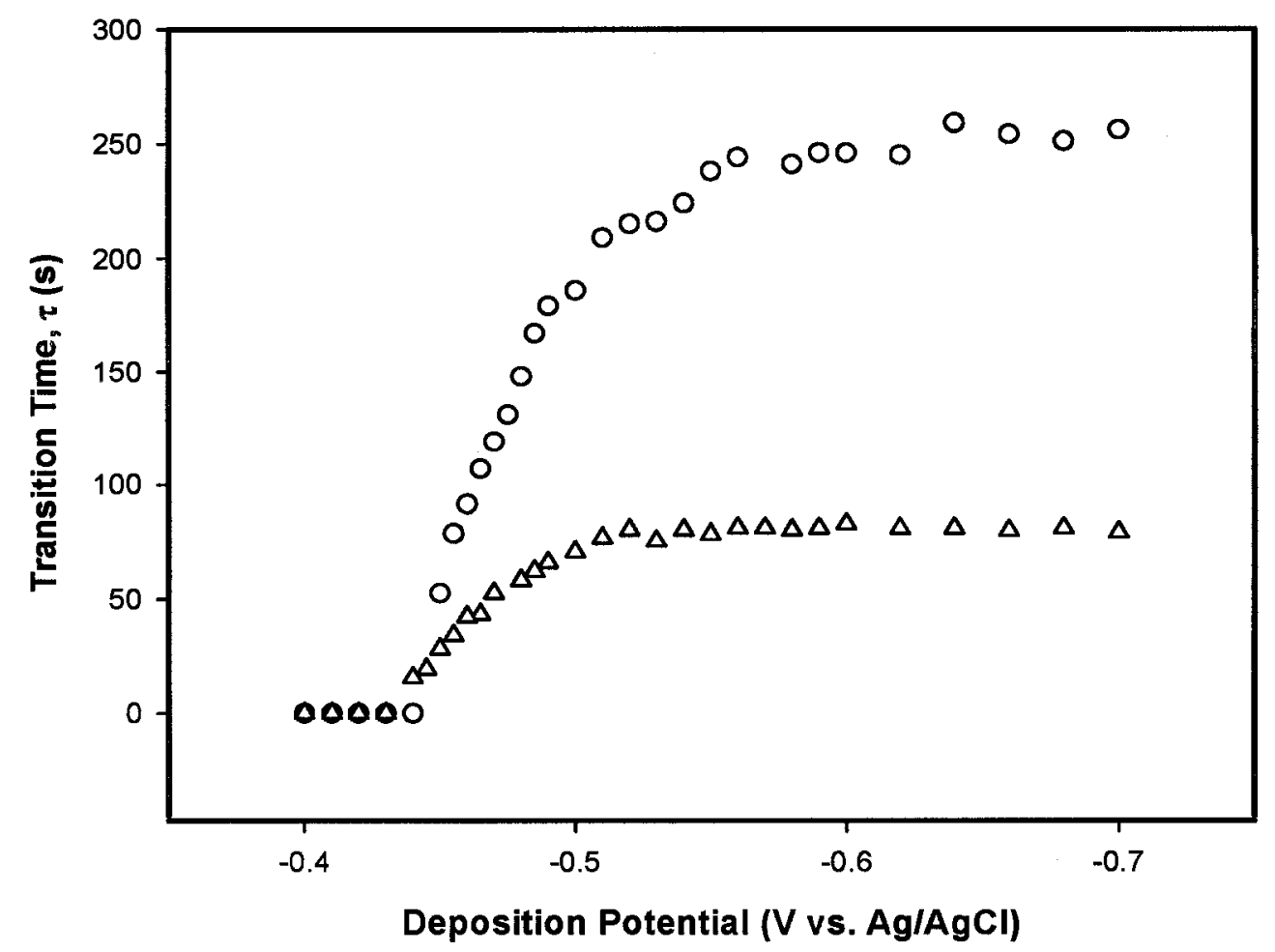

Figure 7 Experimentally determined SSCP curves of $5 \times 10^{-7} \mathrm{M} \mathrm{Pb}(\mathrm{II})$ at two different deposition times, $(\Delta) 60 \mathrm{~s}$ and $(\circ) 240 \mathrm{~s}$. Stripping current $1 \times 10^{-9} \mathrm{~A}$, stirring speed $2000 \mathrm{rpm}$, ionic strength $0.1 \mathrm{M}, \mathrm{pH} 4.8 \pm 0.1, \mathrm{~T}=23 \pm 2{ }^{\circ} \mathrm{C}$. 


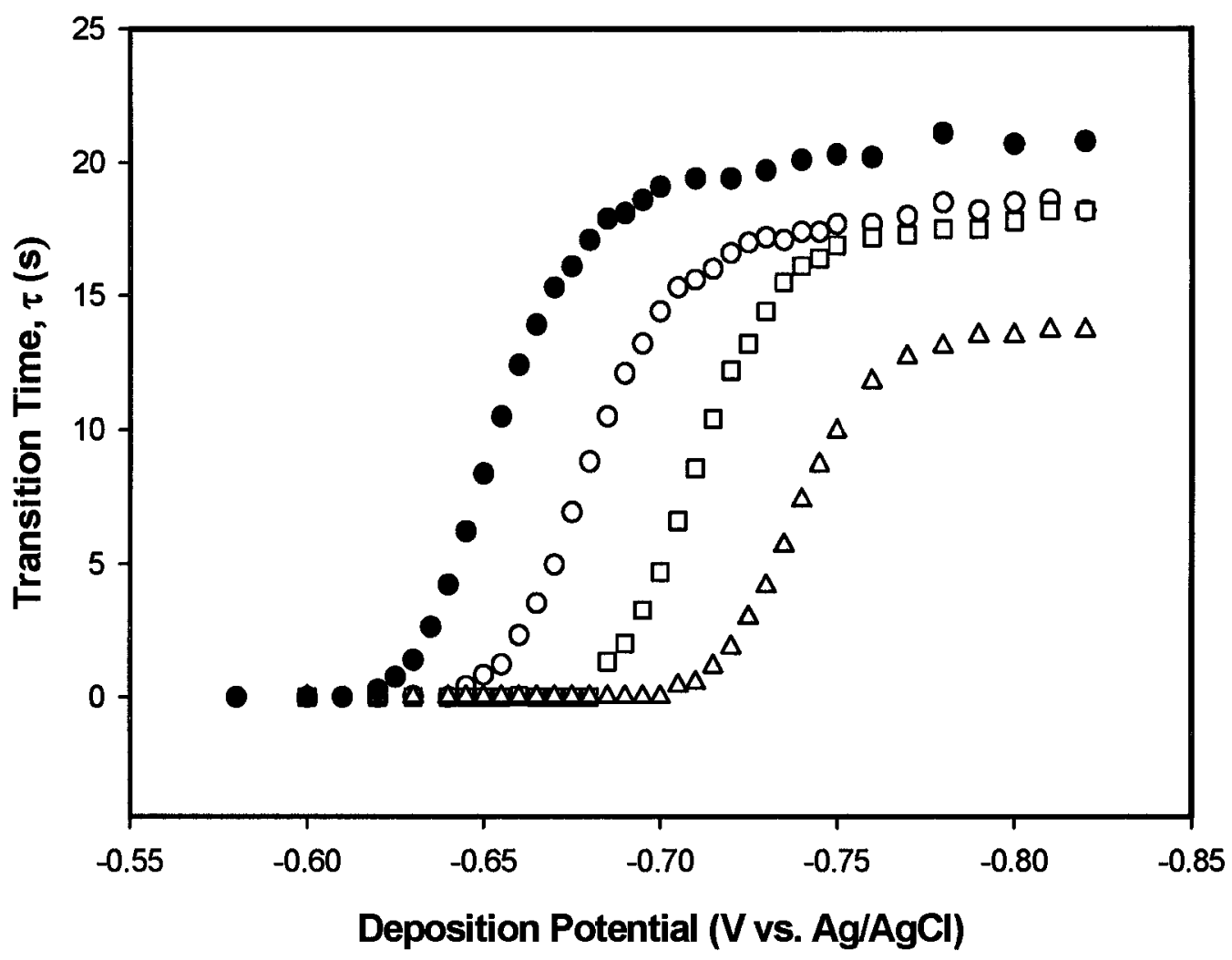

Figure 8 Experimentally determined depletive SSCP curves for $\mathrm{Cd}(\mathrm{II})$ in the presence of different concentrations of PDCA at SMDE. Curves correspond to ( $\bullet$ ) $[\mathrm{Cd}(\mathrm{II})]=2 \times 10^{-7} \mathrm{M} ;(\mathrm{O})[\mathrm{Cd}(\mathrm{II})]=2 \times 10^{-7} \mathrm{M},[\mathrm{PDCA}]=2 \times 10^{-6} \mathrm{M}$; (口) $[\mathrm{Cd}(\mathrm{II})]=2 \times 10^{-7} \mathrm{M},[\mathrm{PDCA}]=2 \times 10^{-5} \mathrm{M} ;(\Delta)[\mathrm{Cd}(\mathrm{II})]=2 \times 10^{-7} \mathrm{M}$, $[\mathrm{PDCA}]=1 \times 10^{-4} \mathrm{M}$. Deposition time $120 \mathrm{~s}$, stripping current $1 \times 10^{-9} \mathrm{~A}$, ionic strength $0.1 \mathrm{M}, \mathrm{pH} 4.8 \pm 0.1, \mathrm{~T}=23 \pm 2{ }^{\circ} \mathrm{C}$. 


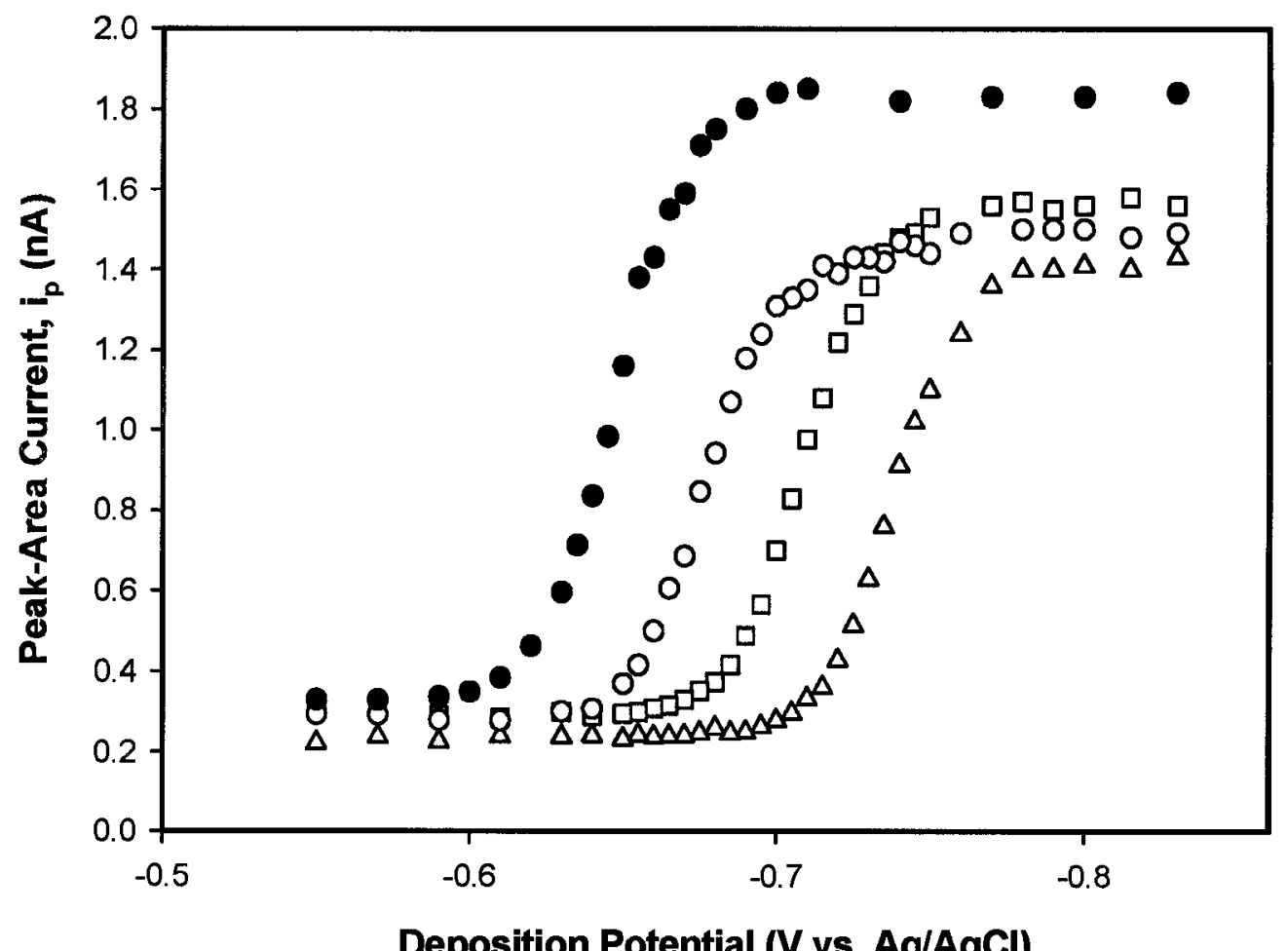

Figure 9 Experimentally determined pseudopolarograms for $\mathrm{Cd}(\mathrm{II})$ in the presence of different concentrations of PDCA at SMDE. Curves correspond to $(\bullet)$ [Cd(II)] $=2 \times 10^{-7} \mathrm{M} ;(\mathrm{O})[\mathrm{Cd}(\mathrm{II})]=2 \times 10^{-7} \mathrm{M},[\mathrm{PDCA}]=2 \times 10^{-6} \mathrm{M} ;(\square)[\mathrm{Cd}(\mathrm{II})]=2$ x $10^{-7} \mathrm{M},[\mathrm{PDCA}]=2 \times 10^{-5} \mathrm{M} ;(\Delta)[\mathrm{Cd}(\mathrm{II})]=2 \times 10^{-7} \mathrm{M},[\mathrm{PDCA}]=1 \times 10^{-4}$ M. Deposition time $120 \mathrm{~s}$, scan rate $0.0102 \mathrm{~V} / \mathrm{s}$, ionic strength $0.1 \mathrm{M}, \mathrm{pH} 4.8$ $\pm 0.1, \mathrm{~T}=23 \pm 2{ }^{\circ} \mathrm{C}$. 


\subsubsection{Quasi-labile complexes: $C d(I I)-N T A$ and $P b(I I)-N T A$}

The electrochemical behaviors of the Cd(II)-NTA and Pb(II)-NTA systems have been extensively studied [137-140]. The voltammogram (Figure 10 and Figure A3 (APPENDIX)) exhibit two waves: (i) the one at the more positive potential involves the charge transfer process (reversible):

$$
\mathrm{Cd}^{2+}+2 \mathrm{e}^{-} \rightarrow \mathrm{Cd}^{0}
$$

which corresponds to the diffusion limiting current due to free metal ions plus the kinetic current arising from dissociation of the complex. Complex dissociation can occur via two parallel reactions:

$$
\begin{gathered}
\mathrm{CdNTA} \leftarrow \frac{\mathrm{k}_{1}}{\leftarrow} \rightarrow \mathrm{Cd}^{2+}+\mathrm{NTA}^{3-} \\
\mathrm{CdNTA} \mathrm{T}^{-}+\mathrm{H}^{+} \underset{\leftarrow}{\leftarrow} \frac{\mathrm{k}_{2}}{\mathrm{k}} \rightarrow \mathrm{Cd}_{-2}^{2+}+\mathrm{HNTA}^{2-}
\end{gathered}
$$

(ii) a second wave at more negative potential arises from (irreversible) direct reduction of the complex (and its height is thus controlled by the diffusion coefficient for the complex): $\mathrm{ML}+\mathrm{ne}^{-} \rightarrow \mathrm{M}(\mathrm{Hg})+\mathrm{L}^{\mathrm{n}-}$. Below pH ca. 5, the direct dissociation of the Cd(II)-NTA complex via Eq. 3.12 becomes slower than the acid-assisted path of Eq. 3.13 , the rates being $k_{1}$ in the range $1-3 \mathrm{~s}^{-1}$, and $k_{2} 6.5 \times 10^{4}-1.5 \times 10^{6} \mathrm{dm}^{3} \mathrm{~mol}^{-1} \mathrm{~s}^{-1}$ [138].

The SSCP results (Figure 10 and Figure A3 (APPENDIX)) of Cd(II)-NTA and Pb(II)NTA agree with those of the pseudopolarographic results (Figure 11 and Figure A4 (APPENDIX)). 
For totally irreversible reduction of the complex species ML, i.e. Cd-NTA and Pb-NTA, the half-wave potential is independent of the ligand concentration [140], as shown in Figures 10, 11, A3 (APPENDIX), A4 (APPENDIX):

$$
E_{1 / 2}=E^{0}-(R T / n F) \ln K+(R T / \mathbf{a n F}) \ln \left(k_{s} / D\right)+(R T / \mathbf{a n F}) \ln (\delta)
$$

where $E^{0}$ is standard potential of the redox reaction, $K$ is stability constant of the complex, $\alpha$ is charge transfer coefficient, $k_{\mathrm{s}}$ is standard rate constant, $\delta$ is diffusion layer thickness, other symbols have their usual meaning.

The limiting transition time, $\tau^{*}$, of SSCP is proportional to the products of the concentrations of reacting species with their diffusion coefficients.

\subsubsection{Reversibility of the electrode reaction}

The reversibility of the studied systems could be examined by means of a logarithmic analysis of the SSCP curves and pseudopolarograms, based on the expression:

$$
\begin{aligned}
& \ln \left[\left(\tau^{*}-\tau\right) / \tau\right]=\frac{n F}{R T} E_{d}-\frac{n F}{R T} E_{d, 1 / 2} \\
& \ln \left[\left(i^{*}-i\right) / i\right]=\frac{n F}{R T} E_{d}-\frac{n F}{R T} E_{d, 1 / 2}
\end{aligned}
$$

$\tau, i$ were the SCP transition time or ASV peak current obtained at each deposition potential $E_{\mathrm{d}}$. When plotting $\ln \left[\left(\tau^{*}-\tau\right) / \tau\right]$ or $\ln \left[\left(i^{*}-i\right) / i\right]$ vs. $E_{\mathrm{d}}$, where the limiting transition time $\tau^{*}$ and the limiting current $i^{*}$ were estimated as the difference between the top and the bottom of the SSCP waves and pseudopolarograms, respectively, for a reversible system, a straight line with a slope of approximately $38.9 \times \mathrm{x} \mathrm{V}^{-1}$ is expected. 


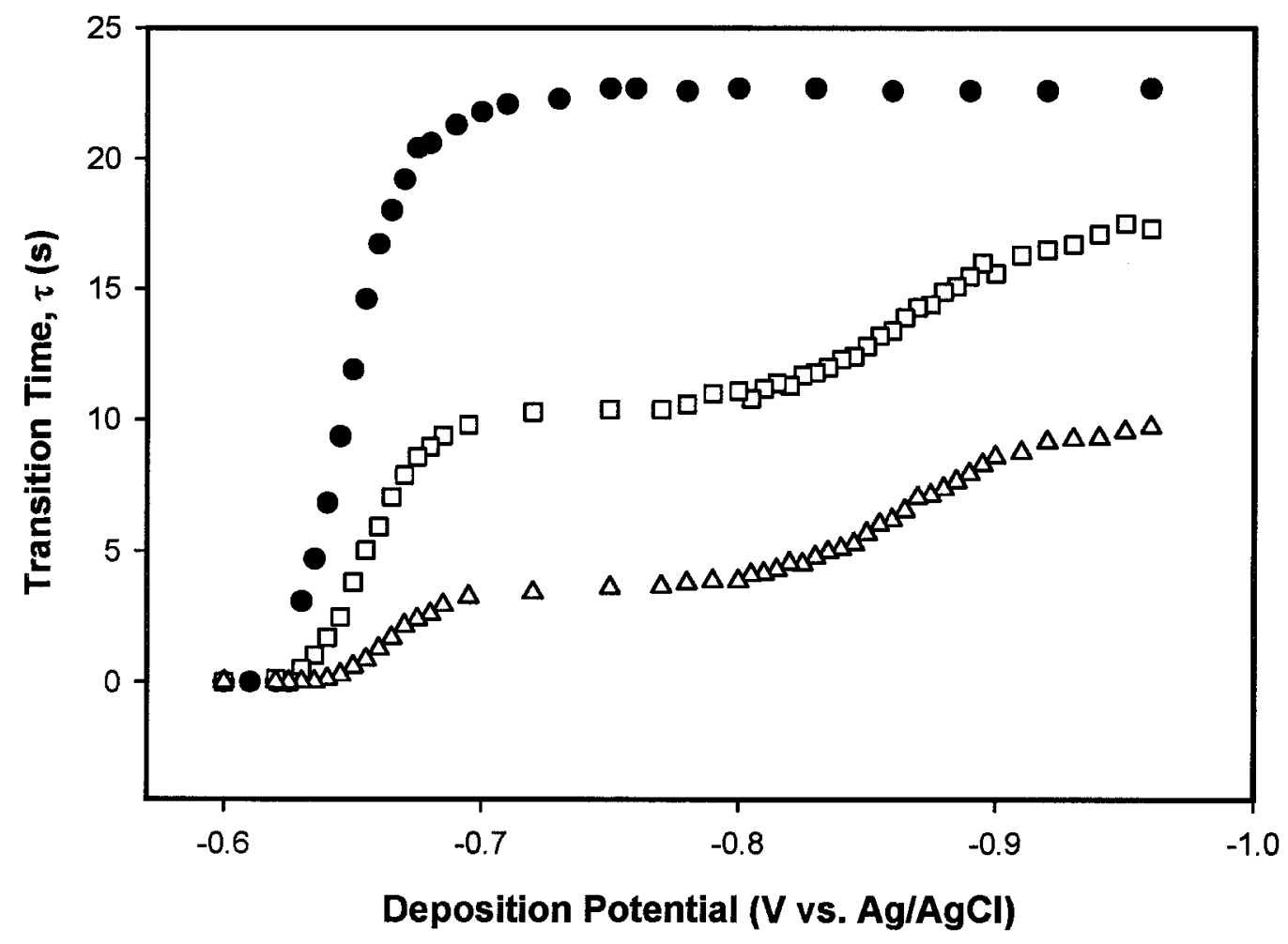

Figure 10 Experimentally determined depletive SSCP curves for Cd(II) in the presence of different concentrations of NTA at SMDE. Curves correspond to (•) $[\mathrm{Cd}(\mathrm{II})]=2 \times 10^{-7} \mathrm{M} ;($ ( $)[\mathrm{Cd}(\mathrm{II})]=2 \times 10^{-7} \mathrm{M},[\mathrm{NTA}]=2 \times 10^{-5} \mathrm{M} ;(\Delta)$ $[\mathrm{Cd}(\mathrm{II})]=2 \times 10^{-7} \mathrm{M},[\mathrm{NTA}]=1 \times 10^{-4} \mathrm{M}$. Deposition time $120 \mathrm{~s}$, stripping current $1 \times 10^{-9} \mathrm{~A}$, ionic strength $0.1 \mathrm{M}, \mathrm{pH} 4.8 \pm 0.1, \mathrm{~T}=23 \pm 2{ }^{\circ} \mathrm{C}$. 


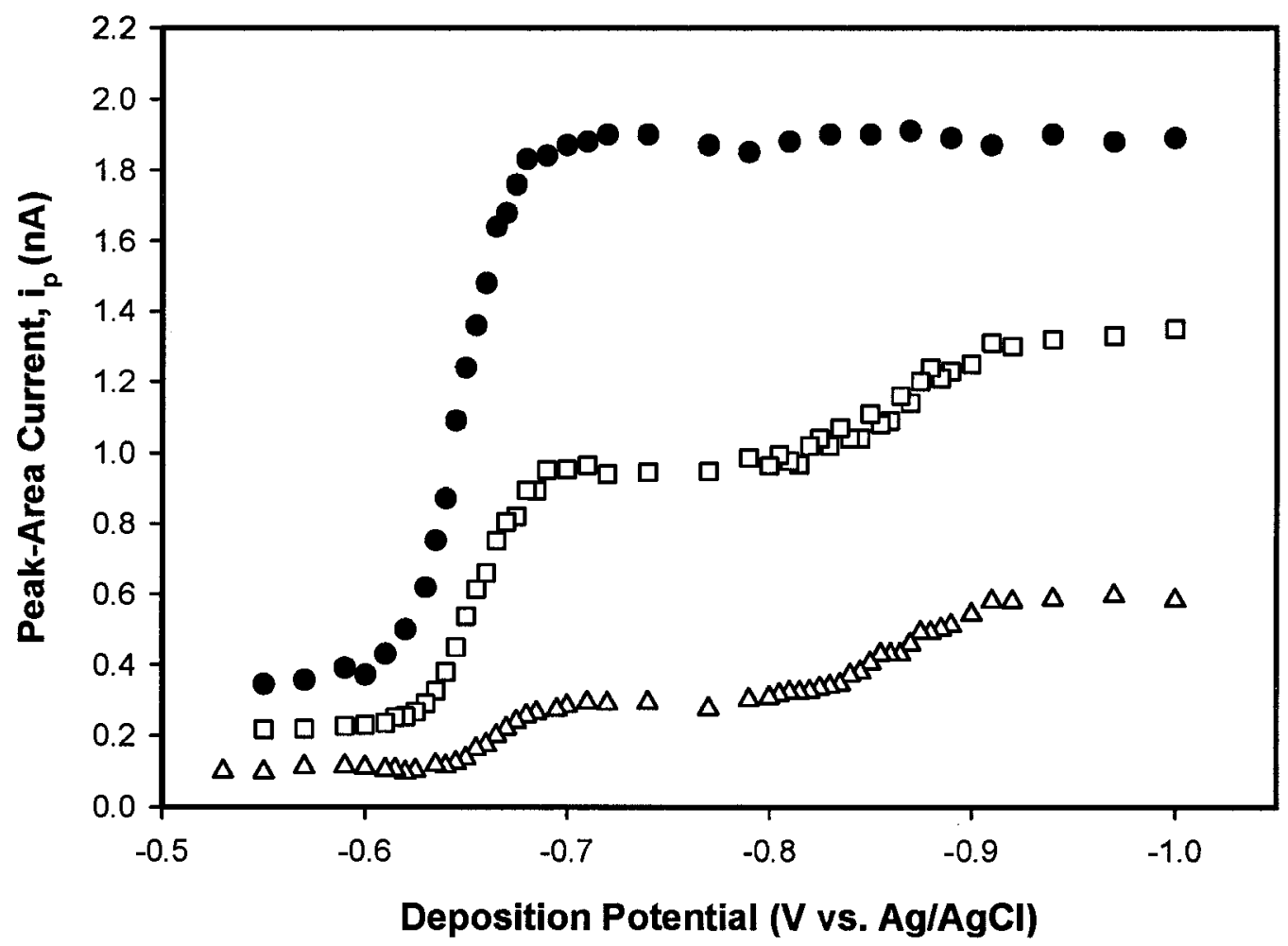

Figure 11 Experimental determined pseudopolarograms of $\mathrm{Cd}(\mathrm{II})$ in the presence of different concentrations of NTA at SMDE. Curves correspond to (•) $[\mathrm{Cd}(\mathrm{II})]=2 \times 10^{-7} \mathrm{M} ;(\square)[\mathrm{Cd}(\mathrm{II})]=2 \times 10^{-7} \mathrm{M},[\mathrm{PDCA}]=2 \times 10^{-5} \mathrm{M} ;(\Delta)$ $[\mathrm{Cd}(\mathrm{II})]=2 \times 10^{-7} \mathrm{M},[\mathrm{PDCA}]=1 \times 10^{-4} \mathrm{M}$. Deposition time $120 \mathrm{~s}$, scan rate $0.0102 \mathrm{~V} / \mathrm{s}$, ionic strength $0.1 \mathrm{M}, \mathrm{pH} 4.8 \pm 0.1, \mathrm{~T}=23 \pm 2^{\circ} \mathrm{C}$. 
Non-linear relationships or slopes different from the expected value are considered as irreversible systems. After verifying the reversibility of the system, half-wave potential was calculated as $E_{1 / 2}=-$ intercept $/$ slope [143]. The half-wave potential can also be obtained from fitting the SSCP curve or pseudopolarogram with Sigma Plot software.

Based on the results obtained from Figures 12-15 (Figure A5-A8 (APPENDIX)), PDCA has no affect on the reversibility of $\mathrm{Cd}(\mathrm{II})$ and $\mathrm{Pb}$ (II) electrode reaction with the slope of $38.9 \mathrm{~V}^{-1}$. However, the electrode reaction of $\mathrm{Cd}(\mathrm{II})$ and $\mathrm{Pb}(\mathrm{II})$ becomes irreversible in the presence of NTA due to the reduction of the complexes on the electrode. The results obtained from SSCP agree well with those from pseudopolarography, as well as with the literature values.

The stability constants of Cd(II)-PDCA，Pb(II)-PDCA，Cd(II)-NTA，Pb(II)-NTA complexes computed from SSCP and pseudopolarography experimental data using the equation equivalent to the DeFord-Hume expression are presented in Table 3. 


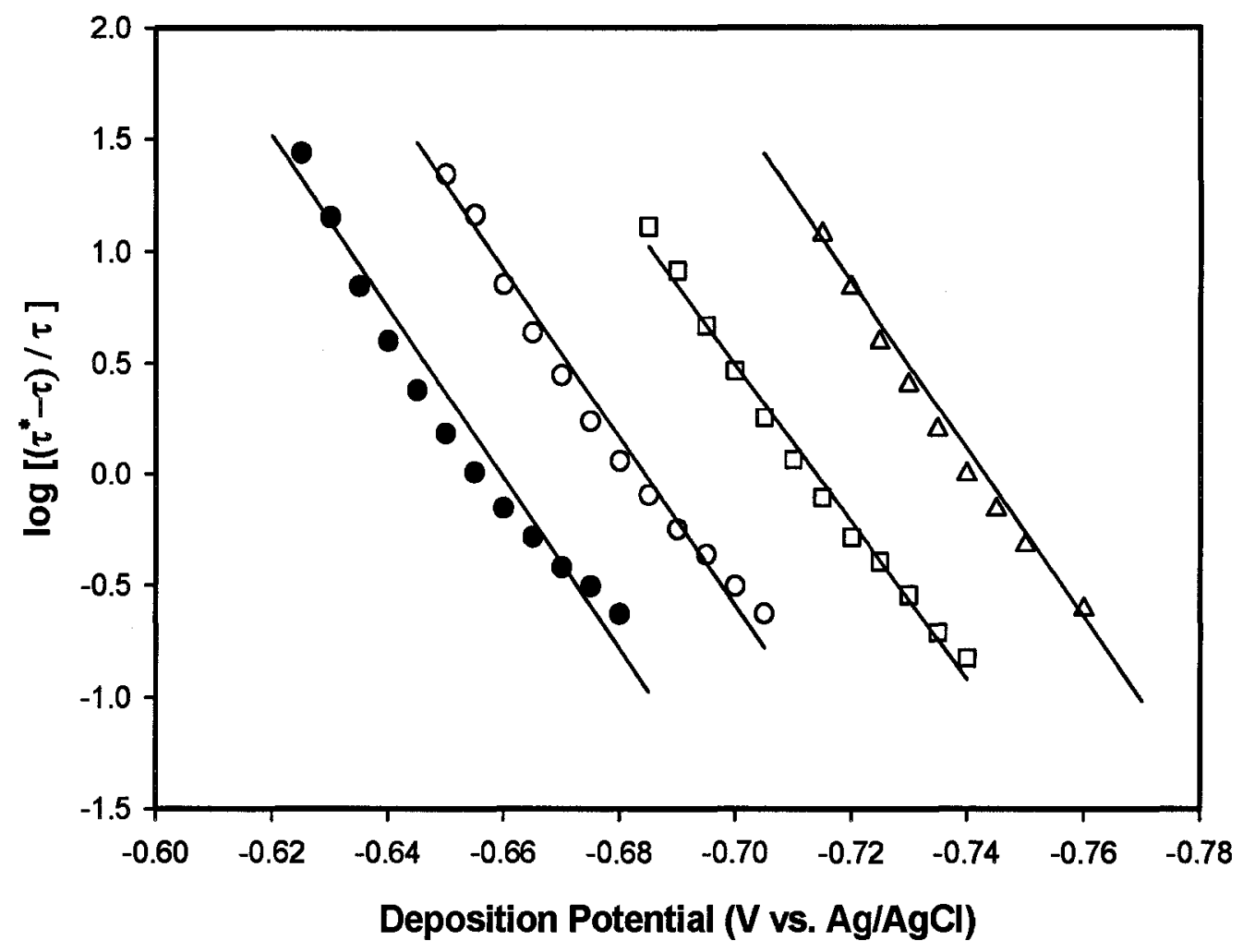

Figure 12 Log analysis of SSCP curves for $\mathrm{Cd}(\mathrm{II})$ in the presence of different concentrations of PDCA shown in Figure 8. Lines are shown for $(\bullet) 2 \times 10^{-7}$ M Cd(II); (O) $2 \times 10^{-7} \mathrm{M} \mathrm{Cd(II),} 2 \times 10^{-6} \mathrm{M}$ PDCA; () $2 \times 10^{-7} \mathrm{M} \mathrm{Cd(II),} 2$ x $10^{-5} \mathrm{M} \mathrm{PDCA} ;(\Delta) 2 \times 10^{-7} \mathrm{M} \mathrm{Cd}(\mathrm{II}), 1 \times 10^{-4} \mathrm{M}$ PDCA. Solid lines indicate the regions of steepest slope at the foot of the waves with slope 38.9 $\mathrm{V}^{-1}$ 


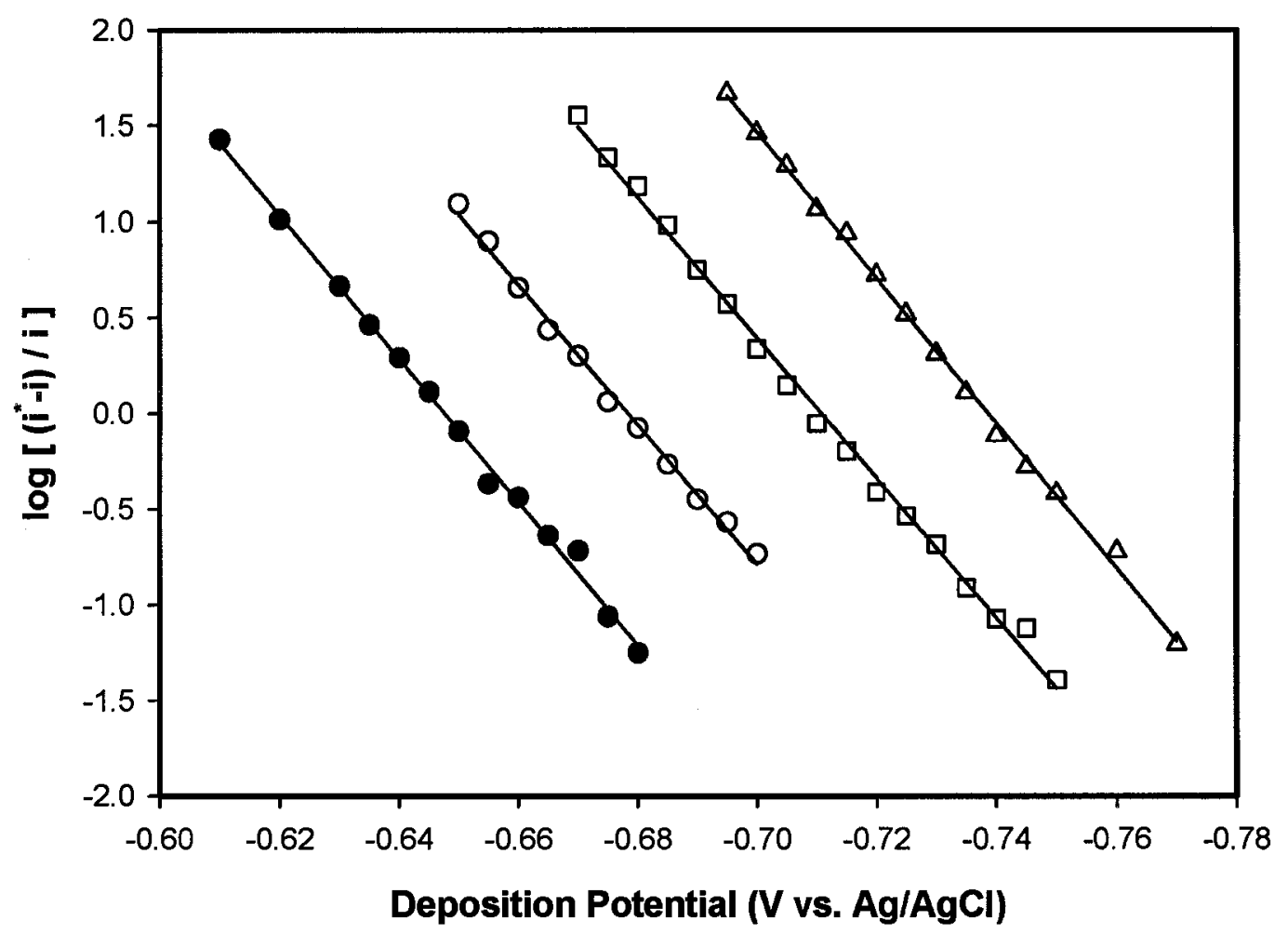

Figure 13 Log analysis of pseudopolarograms for $\mathrm{Cd}(\mathrm{II})$ in the presence of different concentrations of PDCA shown in Figure 9. Lines are shown for $(\bullet) 2 \times 10^{-7}$ M Cd(II); (O) $2 \times 10^{-7} \mathrm{M} \mathrm{Cd(II),} 2 \times 10^{-6} \mathrm{M}$ PDCA; () $2 \times 10^{-7} \mathrm{M} \mathrm{Cd(II),} 2$ x $10^{-5} \mathrm{M}$ PDCA; $(\Delta) 2 \times 10^{-7} \mathrm{M} \mathrm{Cd}(\mathrm{II}), 1 \times 10^{-4} \mathrm{M}$ PDCA. Solid lines indicate the regions of steepest slope at the foot of the waves with slope $38.9 \mathrm{~V}^{-1}$. 


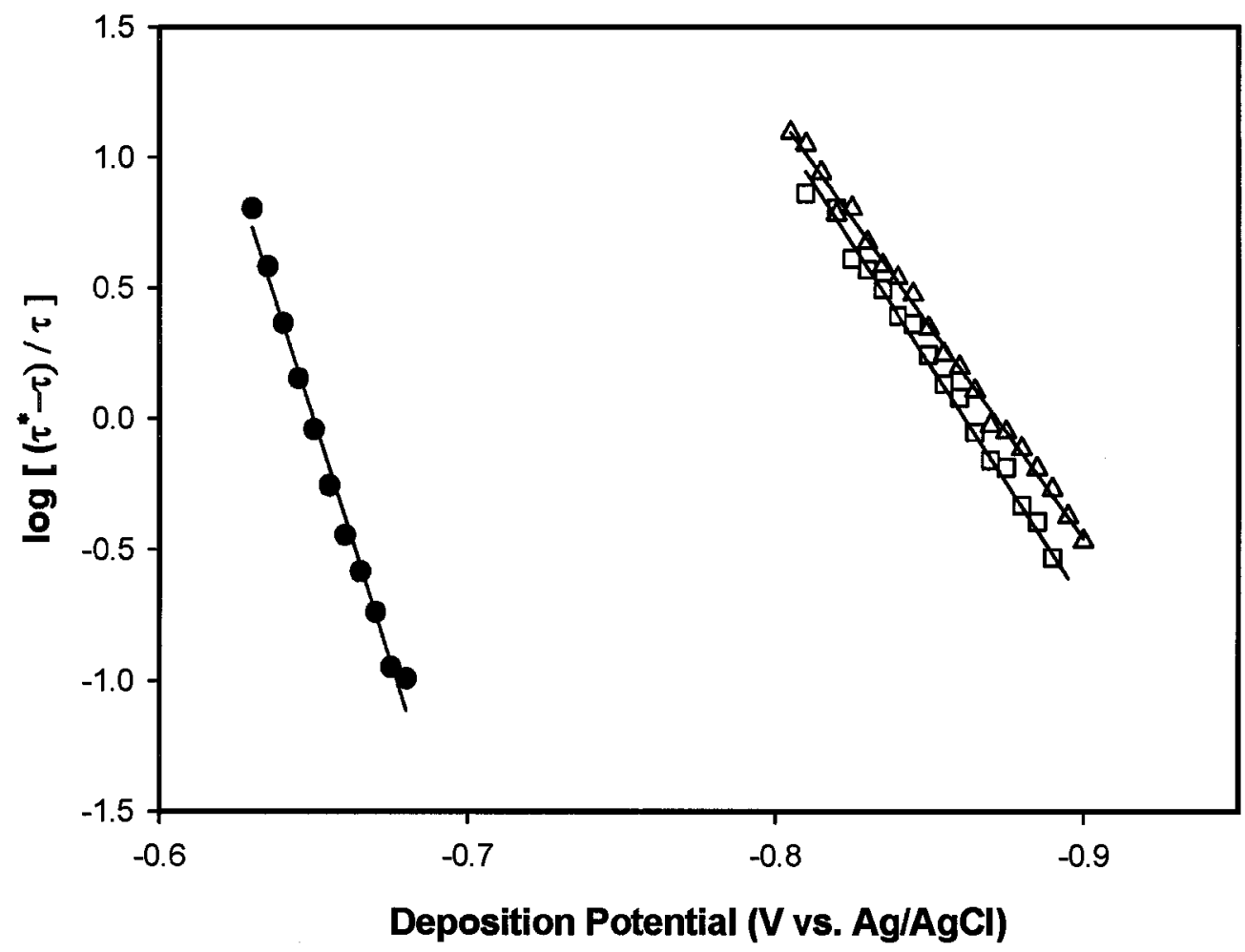

Figure $14 \mathrm{Log}$ analysis of SSCP curves for Cd(II) in the presence of different concentrations of NTA shown in Figure 10. Lines are shown for $(\bullet) 2 \times 10^{-7}$ M Cd(II); (口) $2 \times 10^{-7} \mathrm{M} \mathrm{Cd(II),} 2 \times 10^{-5} \mathrm{M} \mathrm{NTA;}(\Delta) 2 \times 10^{-7} \mathrm{M} \mathrm{Cd}(\mathrm{II}), 1 \mathrm{x}$ $10^{-4} \mathrm{M}$ NTA. Solid lines indicate the regions of steepest slope at the foot of the waves. 


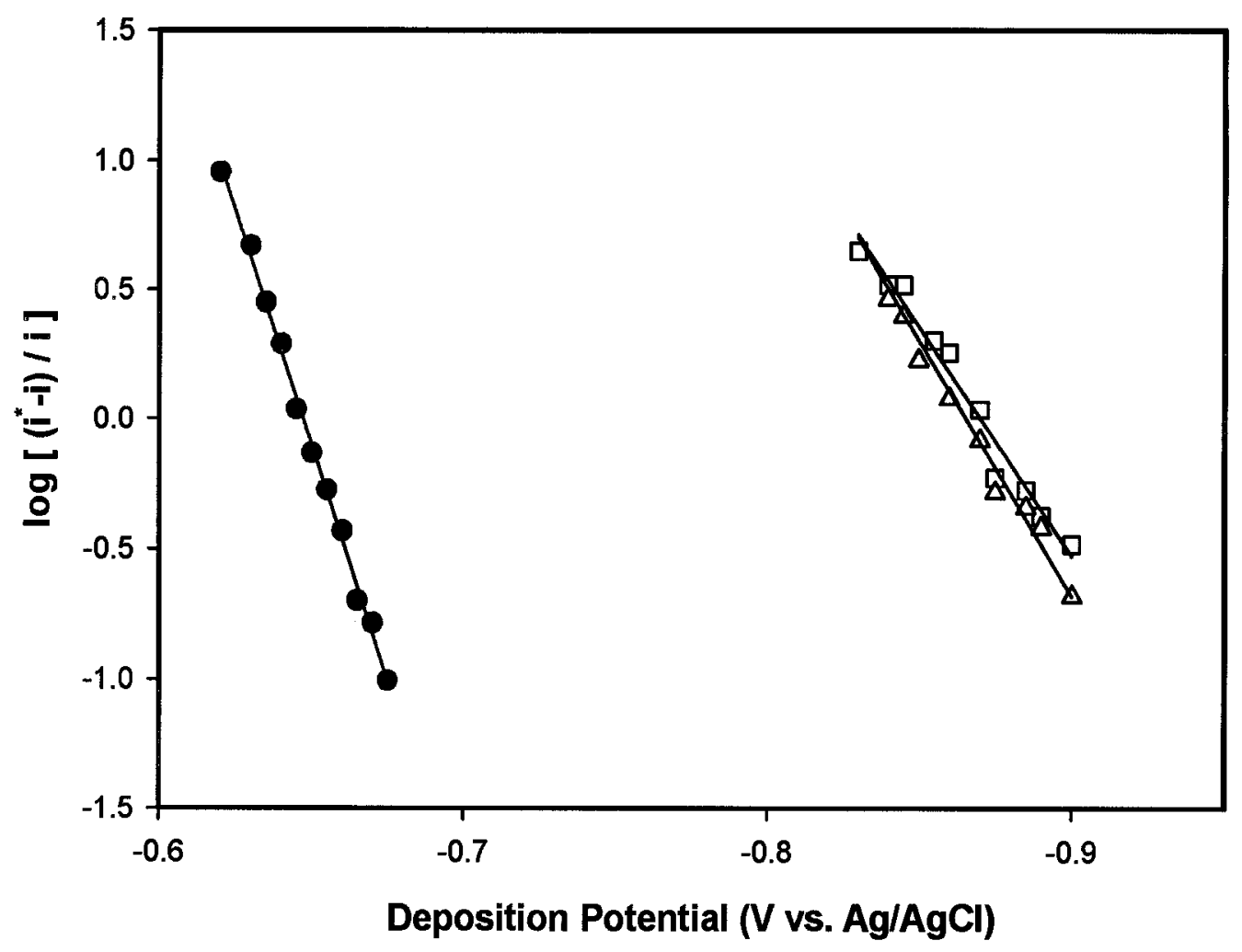

Figure 15 Log analysis of pseudopolarograms for $\mathrm{Cd}(\mathrm{II})$ in the presence of different concentrations of NTA shown in Figure 11. Lines are shown for $(\bullet) 2 \times 10^{-7}$ M Cd(II); ( $\square) 2 \times 10^{-7} \mathrm{M} \mathrm{Cd}(\mathrm{II}), 2 \times 10^{-5} \mathrm{M}$ NTA; ( $\left.\Delta\right) 2 \times 10^{-7} \mathrm{M} \mathrm{Cd}(\mathrm{II}), 1 \times$ $10^{-4} \mathrm{M}$ NTA. Solid lines indicate the regions of steepest slope at the foot of the waves. 
Table 3 Comparisons of experimentally determined stability constants (log K) of homogenous metal complexes by Scanned Stripping Chronopotentiometry and Pseudopolargraphy with literature values

\begin{tabular}{cccc}
\hline Complex & Literature value [141] & $\begin{array}{c}\text { Scanned Stripping } \\
\text { Chronopotentiometry }\end{array}$ & $\begin{array}{c}\text { Pseudo- } \\
\text { polargraphy }\end{array}$ \\
\hline $\mathrm{Pb}$ (II)-NTA & 11.34 & $11.88 \pm 0.10$ & $12.21 \pm 0.25$ \\
$\mathrm{Cd}(\mathrm{II})-\mathrm{NTA}$ & 9.78 & $9.57 \pm 0.09$ & $10.22 \pm 0.24$ \\
$\mathrm{~Pb}(\mathrm{II})-\mathrm{PDCA}$ & 8.66 & $8.15 \pm 0.01$ & $8.09 \pm 0.01$ \\
$\mathrm{Cd}(\mathrm{II})-\mathrm{PDCA}$ & 6.75 & $7.00 \pm 0.05$ & $6.94 \pm 0.03$ \\
\hline
\end{tabular}


- Chapter 4-

Depletive Scanned Stripping Chronopotentiometry: Study of Heterogeneous Complexant, Suwannee River Fulvic Acid, on Metal Speciation Described by Differential Equilibrium Functions Using Static Mercury Drop Electrode 


\subsection{Introduction}

Humic substances (HS), one group of natural ligands, are ubiquitous in environmental and biological media, where they play a crucial role in the maintenance of life by acting as metal ion buffers over wide ranges of concentration and $\mathrm{pH}$ [144]. The heterogeneity of HS, which contain both 'hard' (e.g. carboxyl, phenolic) and 'soft' (e.g. amino, sulphydryl) complexing sites, makes the reliable quantification and prediction of metal ion complexation a challenging task because of the distributed stability constants and dissociation rate constants of their complexes. The apparent stability and lability of metal complexes with HS is strongly dependent on the metal to ligand ratio [144]. It is therefore desirable to make measurements under environmentally relevant conditions, i.e. low metal ion concentrations.

There are numerous literature reports on the potential and time dependence of adsorption of fulvic acid (FA) onto mercury [144-147,154,] and consequent adsorption of metal ions $[87,148,149,155]$. These macromolecular heterogeneous ligands and the metal complex species adsorb on electrode surface over a wide range potential and $\mathrm{pH}$ range. Besides, the condition for sufficient ligand excess strictly applies to every component of the heterogeneous mixture [12].

SCP under complete depletion has the lowest requirement for excess ligand, compared with other stripping voltammetry. The stripping peaks of SCP become significantly broader in the presence of FA, probably contributed by ligand heterogeneity. Use of SCP 
peak area, rather than peak height, allows correct quantitation of systems in which peak broadening has occurred [22].

In this chapter, the attention has been paid to application of Scanned Stripping Chronopotentiometry (SSCP) to determine stability constants, heterogeneities and diffusion coefficients of heterogeneous complexes, i.e. lead, cadmium and zinc in the presence of different concentrations of Suwannee River Fulvic Acid (SRFA) in acidic model solutions. Pseudopolarography with DP-SV measurement has also been made in the same solutions and the results were compared with those obtained from SSCP.

\subsection{Theory}

\subsubsection{Scanned Stripping Chronopotentiometry for Heterogeneous Complexants: Humic} Substances

Analogous to d.c. polarography, an s-shaped, polarogram-like curve between the transition time or stripping current and the corresponding deposition potential is obtained for studying metal speciation at much lower concentrations $\left(10^{-7}-10^{-9} \mathrm{M}\right)$ by Scanned Stripping Chronopotentiometry (SSCP) or Pseudopolarography (Scanned Stripping Voltammetry, SSV), as shown in Figure 16. For simple, labile complexes, the half-wave potential is shifted to a more negative deposition potential relative to that for free metal ion. The s-shaped wave for a solution containing 'simple', homogeneous ligand is described by DeFord and Hume equation:

$$
\mathbf{E}_{\mathbf{d}}=\underbrace{\mathbf{E}_{\mathbf{0}}+\frac{\mathbf{R T}}{\mathbf{n F}} \ln \left(\frac{1}{a} \sqrt{\frac{D_{\mathbf{R}}}{D_{\mathbf{M L}}}}\right)}_{\mathbf{E}_{\mathbf{d}, 1 / 2}}+\frac{\mathbf{R T}}{\mathbf{n F}} \ln \left(\frac{1-\tau / \tau^{*}}{\tau / \tau^{*}}\right)
$$


where $E_{0}$ is the normal redox potential (V), $n$ is the number of electrons exchanged, $\alpha$ is the degree of the complexation of the metal, $D_{R}$ is the diffusion coefficient of the reduced form in mercury, $D_{M L}$ is the diffusion coefficient of complexes, $\tau^{*}$ is the limiting transition time, other symbols have their usual meaning. $E_{d, 1 / 2}=E_{d}$ when $\tau=\tau^{*} / 2$.

For heterogeneous organic complexants, i.e. fulvic acid (FA), a flattening of the pseudopolarographic wave relative to the homogeneous case is observed (Figure 16). This effect can be ascribed to ligand heterogeneity if it is found to be independent of deposition time and electrode size $[91,152,153]$. Filella et al. derived an equation to describe the shape of a polarographic wave in the presence of heterogeneous complexants [150], which may be applied to SSCP and pseudopolarographic waves:

$$
\begin{aligned}
& \mathbf{E}_{\mathrm{d}}=\underbrace{\mathbf{E}_{\mathbf{0}}+\frac{\mathbf{R T}}{\mathbf{n F}} \ln \left[\frac{1}{\mathbf{A}^{1 / \Gamma} \mathbf{c}_{\mathrm{L}}}\left(\frac{\mathbf{c}_{\mathbf{M}}}{\mathbf{c}_{\mathrm{L}}}\right)^{(1-\Gamma) / \Gamma}\left(\frac{\mathrm{D}_{\mathrm{R}}}{\mathrm{D}_{\mathrm{ML}}}\right)^{1 / 2}\right]}_{\text {const. } \mathrm{E}_{\mathrm{d}, 1 / 2}}+\frac{\mathbf{R T}}{\mathbf{n F}} \ln \left[\frac{\left(1-\tau / \tau^{*}\right)^{1 / \Gamma}}{\tau / \tau^{*}}\right] \\
& \mathbf{E}_{d}=\underbrace{E_{0}+\frac{R T}{n F} \ln \left[\frac{1}{A^{1 / \Gamma} c_{L}}\left(\frac{c_{M}}{c_{L}}\right)^{(1-\Gamma) / \Gamma}\left(\frac{D_{R}}{D_{M L}}\right)^{1 / 2}\right]}_{\text {const. } E_{d, 1 / 2}}+\frac{R T}{n F} \ln \left[\frac{\left(1-i / i^{*}\right)^{1 / \Gamma}}{i / i^{*}}\right]
\end{aligned}
$$

In Equation 4.2, $\mathrm{A}$ is Freundlich constant, $\mathrm{c}_{\mathrm{M}}$ and $\mathrm{c}_{\mathrm{L}}$ is the concentrations of $\mathbf{M}$ and $\mathrm{L}$ in the bulk solution, respectively. $\Gamma$ is a parameter that reflects the degree of heterogeneity of the system, referring to both the physical and chemical properties and should be independent of experimental conditions. All other have been defined previously. For $[\mathrm{M}]_{\mathrm{b}}$ $\gg[\mathrm{M}], \Gamma$ may have another meaning to express the complexation buffer intensity of the system, $\beta[156]$ : 


$$
\Gamma \approx \frac{1}{[M]_{b}} \frac{d[M]_{b}}{d \log [M]}=\frac{\beta}{[M]_{b}}
$$

$[\mathrm{M}]_{\mathrm{b}}$ and $[\mathrm{M}]$ stand for the concentrations of the bound and the free metal ion, respectively. $\Gamma$ always lies in the range $0.3-0.7$. The meaning of $\Gamma$ and its constancy make it a very important parameter for describing heterogeneous complexant properties.

Comparison of Equation 4.1 with Equation 4.2 reveals that the DeFord and Hume equation is a special case of Equation 4.2 under the condition of a simple, homogeneous ligand $(\Gamma=1)$.

\subsubsection{Differential Equilibrium Function}

The thermodynamic binding properties of heterogeneous complexants, such as humic substances for a particular metal ion can be described by Differential Equilibrium Function (DEF) $[158,162,176,177]$ :

$$
\log \theta=\Gamma \log K_{0}^{*}-\Gamma \log K^{*}
$$

$\theta$ is degree of occupation of all site types $\left(=[\mathrm{M}]_{\mathrm{b}} / \mathrm{c}_{\mathrm{S}}\right), \mathbf{K}_{\mathbf{0}}^{*}$ is a constant and the value of $\mathbf{K}^{*}$ when $\theta=1 . \mathbf{K}^{*}$ is the Differential Function Parameter, which is a mathematically well defined weighted average of all the thermodynamic equilibrium constants of the complexes formed between $\mathbf{M}$ and site type; it is a much more meaningful and useful parameter [156].

The constant, $\alpha$, is related to $\mathbf{K}_{\mathbf{0}}^{*}$ by Equation 4.6 [150]: 


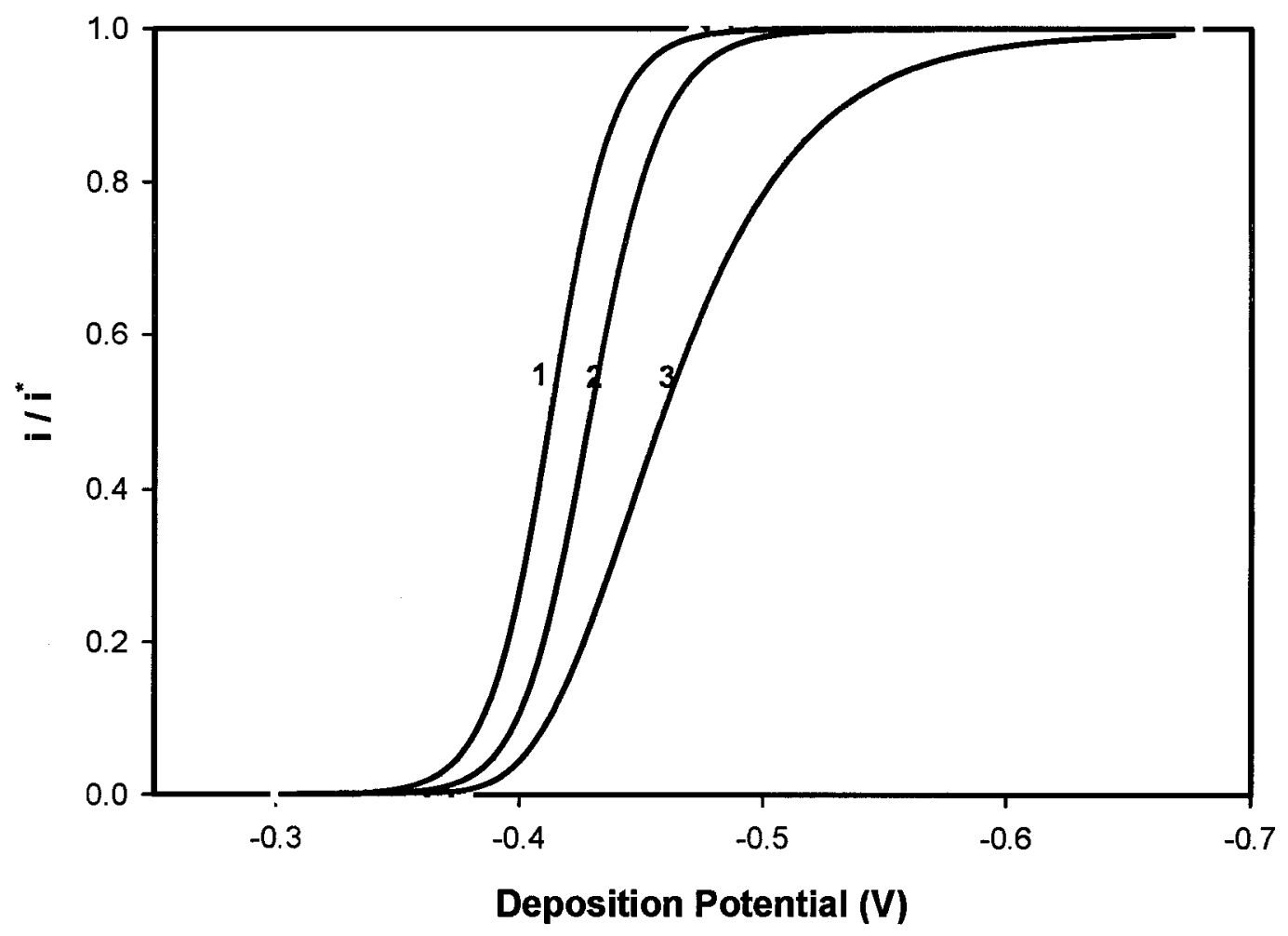

Figure 16 Simulated pseudopolarographic curves for the reduction of $M$ under noncomplexing conditions (curve 1), in the presence of a simple ligand (Eqn. 4.1; curve 2) and in the presence of a heterogeneous complexant (Eqn. 4.2, $\Gamma=$ 0.3 ; curve 3$), i^{*}$ is the limiting current for the labile system [150]. 


$$
\alpha=c_{L} \frac{K_{0}^{*} \Gamma}{1-\Gamma}\left(\frac{c_{L}}{c_{M}}\right)^{(1-\Gamma) / \Gamma}
$$

$\alpha$ can be determined from the shift of the SSCP wave of heterogeneous complexes relative to that of the metal aqua complex by Equation 4.7, similar to the treatment of pseudopolargram (Equation 4.8)[95]:

$$
\begin{aligned}
& \ln \alpha=\frac{R T}{n F}\left(E_{1 / 2}-E_{M L, 1 / 2}\right)+\ln \left(\frac{\tau^{*}}{\tau_{M L}^{*}}\right) \\
& \ln \alpha=\frac{R T}{n F}\left(E_{1 / 2}-E_{M L, 1 / 2}\right)+\ln \left(\frac{i^{*}}{i_{M L}^{*}}\right)
\end{aligned}
$$

$E_{1 / 2}$ is the half-wave potential in the absence of ligand, $E_{M L, 1 / 2}$ is the half-wave potential in the presence of ligand, $\tau^{*}$ and $i^{*}$ is the limiting transition time and the limiting peak current in the absence of ligand, $\tau_{\mathbf{M L}}^{*}$ and $\mathbf{i}_{\mathbf{M L}}^{*}$ is the limiting transition time and the limiting peak current in the presence of ligand.

\subsubsection{Diffusion Coefficient}

The determination of the diffusion coefficient of the heterogeneous complex presents a serious problem because of the polydisperse nature of the heterogeneous complexants [159], which results in a distribution of diffusion coefficients. The mean diffusion coefficient can be calculated from the transition times or the peak currents obtained in the presence $\left(\tau_{M L}\right)$ and absence $\left(\tau_{M}\right)$ of a complexing ligand for the same total metal concentration:

$$
\frac{\tau_{\mathbf{M L}}^{*}}{\tau_{\mathbf{M}}^{*}}=\left(\frac{\overline{\mathbf{D}}}{\mathbf{D}_{\mathbf{M}}}\right)^{\mathbf{p}}
$$




$$
\frac{\mathbf{i}_{\mathbf{M L}}^{*}}{\mathbf{i}_{\mathbf{M}}^{*}}=\left(\frac{\overline{\mathbf{D}}}{\mathbf{D}_{\mathbf{M}}}\right)^{\mathbf{p}}
$$

where $\mathrm{p}$ is a hydrodynamic parameter, related to the mass transport in the system. For a macro-electrode it assumes a value between $1 / 2$ and $2 / 3$ [160]. For my calculation, $p=$ 2/3 was chosen, which corresponds to laminar convective diffusion.

\subsection{Experimental}

\subsubsection{Materials and Reagents}

Standard solutions $(1000 \mu \mathrm{g} / \mathrm{ml})$ of $\mathrm{Pb}(\mathrm{II}), \mathrm{Cd}(\mathrm{II})$ and $\mathrm{Zn}$ (II) were purchased from SCP Science, Montreal, Canada. Ultrapure water of resistivity of $18.2 \mathrm{M} \Omega . \mathrm{cm}$ was obtained from a Milli-Q-Plus water purification system (Millipore Corporation, USA), fitted with an organic purification column to remove organic matter. A $2 \mathrm{M}$ stock solution of sodium acetate and a $2 \mathrm{M}$ stock solution of $\mathrm{KNO}_{3}$ were prepared by dissolving an appropriate quantity of sodium acetate trihydrate (ACS grade/BDH) or potassium nitrate (Aldrich) in ultrapure water. The sodium acetate solution and the $\mathrm{KNO}_{3}$ solution were then purified separately free of metal by electrolysis at $-1.5 \mathrm{~V} v s$. SCE for at least $48 \mathrm{~h}$ prior to its use. To prevent the impurity metal from dissolving back to the solution, the purified solution was removed when the electrolysis was going on. A $2 \mathrm{M}$ stock solution of acetic acid was prepared by diluting glacial acetic acid (ACS grade/Anachemia) with ultrapure water. An ionic strength of $0.1 \mathrm{M}$ and $\mathrm{pH}$ of 4.8 were used all through the experiments. The Suwannee River Fulvic Acid (SRFA), with Cat. No. 1S101F, was obtained from International Humic Substances Society (IHSS, USA). The concentrations of carboxylic and phenolic groups in the Suwannee River FA are 11.44 and $2.91 \mathrm{mmol} / \mathrm{g}$, respectively 
[151]. A stock solution of SRFA was prepared by dissolving $0.0664 \mathrm{~g}$ of freeze-dried SRFA in $50.0 \mathrm{ml}$ of ultrapure water.

\subsubsection{Suwannee River Fulvic Acid Model Solutions}

Two model solutions were prepared in ultrapure water containing different concentrations of Suwannee River Fulvic Acid ( $8 \times 10^{-5}$ mol. $\mathrm{L}^{-1}$ and $\left.2 \times 10^{-4} \mathrm{~mol}_{\mathrm{L}} \mathrm{L}^{-1}\right)$ and equal-molar concentrations of $\mathrm{Mn}(\mathrm{II}), \mathrm{Co}(\mathrm{II}), \mathrm{Ni}(\mathrm{II}), \mathrm{Cu}(\mathrm{II}), \mathrm{Zn}(\mathrm{II}), \mathrm{Cd}(\mathrm{II})$ and $\mathrm{Pb}(\mathrm{II})$; the concentration for each of them was $2 \times 10^{-7}$ mol. $\mathrm{L}^{-1}$. The $\mathrm{pH}$ of the fulvic acid model solutions were adjusted to $4.8 \pm 0.1$ with $\mathrm{HAc} / \mathrm{NaAc}$ buffer, and then the samples were left overnight for equilibrium $(12 \mathrm{~h})$.

\subsubsection{Apparatus}

The apparatus has been described in section 3.2.3

\subsubsection{Electrochemical Parameters}

Each sample solution was purged with $\mathrm{N}_{2}$ gas for $10 \mathrm{~min}$ before the Potential Stripping Analysis (PSA) method was employed. An oxidizing current, $i_{\mathrm{s}}$ of $1 \times 10^{-9} \mathrm{~A}$ was applied in solution after the deposition and equilibrium periods. The raw signal is the variation of potential with time that is automatically converted to the $\mathrm{d} t / \mathrm{d} E v s$. E format, being the area under the peak at the transition time. The SSCP waves were constructed from a series of individual measurements (peak areas) plotted as functions of the wide range of deposition potentials applied. For each point, the potential was held at $E_{\mathrm{d}}$ for the duration of the deposition time of $120 \mathrm{~s}$, after a quiescent period of $20 \mathrm{~s}$ the oxidizing current was 
applied until a value well past the deposition plateau $(-0.25 \mathrm{~V}$ for $\mathrm{Pb}, \mathrm{Cd}$ and $\mathrm{Zn})$.

For pseudopolarography measurements, the same sample solution was purged with $\mathrm{N}_{2}$ for $10 \mathrm{~min}$, thereafter determined by Differential Pulse Stripping Voltammetry (DP-SV) at the wide range of deposition potentials applied. The experiment conditions are: deposition time $120 \mathrm{~s}$, equilibration time $20 \mathrm{~s}$, initial potential $-1.3 \mathrm{~V}$, end potential $0.1 \mathrm{~V}$, modulation time $0.05 \mathrm{~s}$, interval time $0.5 \mathrm{~s}$, step potential $0.0051 \mathrm{~V}$, modulation amplitude $0.02502 \mathrm{~V}$, scan rate $0.0102 \mathrm{~V} / \mathrm{s}$.

\subsubsection{Data Analysis}

The experiment data were fitted to Equation 4.1 using a commercial software program, NLREG v5.2 (Phillip H. Sherrod, Brentwood, TN, USA)

\subsection{Results and discussion}

\subsubsection{SSCP}

With the addition of SRFA to a solution of metal ions, the signal decreased at each deposition potential. This is because the complexes become less labile and have lower diffusion coefficients than the free metal ion (Figure 17 for $\mathrm{Pb}$ (II), Figure $\mathrm{B} 1$ for $\mathrm{Cd}(\mathrm{II})$ (APPENDIX), Figure B2 for $\mathrm{Zn}(\mathrm{II})$ (APPENDIX)). The further decrease in peak area that occurs at higher SRFA concentrations might represent some loss of lability in this system [22].

\subsubsection{Heterogeneity}


Figure 17 shows that in the presence of SRFA, the SSCP wave of Pb(II) was flattened and spread out along the Deposition potential axis, which reflects greater heterogeneity ( $\Gamma$ decrease) as compared to the homogeneous case. As the total metal amount was depleted from the electrode surface, the stronger sites of SRFA near the electrode surface became free and therefore active in controlling the free metal ion concentration. After the stronger sites of SRFA near the electrode surface were occupied with the stripped metal, the weaker sites might join to control the metal concentration, which reflected the change of heterogeneity. With increasing depletion of the metal at the electrode surface, this effect became progressively more pronounced, resulting in greater flattening and elongation of the SSCP wave. This effect is more apparent in SSCP than pseudopolarography because of its depletive nature.

It can be seen from Figure 17, B1 (APPENDIX), B2 (APPENDIX) that the extent of this flattening depends on the metal ion involved and follows the order $\mathrm{Pb}$ (II) $>\mathrm{Cd}$ (II) $>$ $\mathrm{Zn}(\mathrm{II})$, which corresponds to the varied heterogeneity, $\Gamma$, of the metal complex system. These parameters are in broad agreement with the literatures values, which reported the heterogeneity order of $\mathrm{Pb}(\mathrm{II})>\mathrm{Cd}$ (II) [164-168]. In the presence of sufficiently excess complexing ligand, $\Gamma$ is independent of the metal-to-ligand ratio. Different experimental conditions may look at different parts of the same distribution, which may be more or less sensitive to to $\Gamma$.

\subsubsection{Stability constant and ionic potential}


The slopes of $\mathrm{Pb}(\mathrm{II})$ and $\mathrm{Cd}(\mathrm{II})$ shift to more negative potential with increasing concentration of fulvic acid, as shown in Figure 17 and Figure B1 (APPENDIX), which reflect more stable metal complexes formed with higher apparent stability constants at lower metal loading presented in Table 4. This occurs because weaker sites start to contribute to metal complexation at higher loadings, whereas stronger binding sites are preferred at lower metal ion loadings $[169,170]$.

Figure B2 (APPENDIX) shows that Zn(II) has weak binding with SRFA: less shift of the slope and the complexes behave similar to homogeneous systems under those two metal loading conditions.

The apparent stability and kinetic lability of complexes depend on the heterogeneity $\Gamma$, the metal ion loading, the time-scale of the technique, and the water exchange rate for the metal ion [176].

Because Fulvic Acid molecules are prone to aggregate in acidic condition (pH 4.8 under this experiment conditions), metal-fulvic acid binding is expected to more covalent. This effect probably results from mutual cation and anion polarization, which favors the combination of large, polarizable metal ions, such as $\mathrm{Pb}(\mathrm{II})$ with soft (polarizable) ligand, such as nitrogen-containing, sulphur-containing minor binding sites of the FA. The binding energy of the metal ions is expected to depend on their ionic potential $\left(\mathrm{z}^{2} / \mathrm{r}\right)$ [171]. The ionic potentials are: $\mathrm{z}^{2} / \mathrm{r}=0.030 \mathrm{pm}^{-1}$ for $\mathrm{Pb}(\mathrm{II}), \mathrm{z}^{2} / \mathrm{r}=0.037 \mathrm{pm}^{-1}$ for $\mathrm{Cd}(\mathrm{II})$, and $\mathrm{z}^{2} / \mathrm{r}=0.046 \mathrm{pm}^{-1}$ for $\mathrm{Zn}(\mathrm{II})$. Lower ionic potential results in lower electrostatic 
interactions between metal and ligand, and hence in lower electrostatic binding energy. The covalent character becomes less with increasing the ionic potential of metal cation. This was observed by Fasfous et al. [172] for $\mathrm{Zn}$ (II), $\mathrm{Cd}(\mathrm{II})$ and $\mathrm{Pb}$ (II) complexes with Laurentian fulvic acid. For simple ligands consisting of O-donors, $\mathrm{N}$-and S-donors, the order of stability of complex formation is typically $\mathrm{Pb}(\mathrm{II})>\mathrm{Cd}(\mathrm{II})$ [174].

\subsubsection{Diffusion coefficients}

The determination of the diffusion coefficient of the complex presents a problem because of the polydisperse nature of humic substances [159]. There is therefore a lack of data on diffusion coefficients for heterogeneous complexes in natural waters [40]. As a rough approximation, the metal complexes of individual molecules of a given group of heterogeneous complexants (e.g. metal-fulvic acid complexes) are often assumed to have similar size and a single diffusion coefficient [175]. Table 4 lists the average diffusion coefficients of $\mathrm{Zn}$ (II)-FA, Cd(II)-FA and $\mathrm{Pb}$ (II)-FA complexes. The diffusion coefficients $\mathrm{D}_{\mathrm{ML}}$ of complexes are obtained by fitting the observed curves and solving Equation 4.9 using the reported diffusion coefficients for the free metal ions $\left(D_{\mathrm{Pb}}=8.28 \times 10^{-10} \mathrm{~m}^{2} \mathrm{~s}^{-1}\right.$, $D_{C d}=6.90 \times 10^{-10} \mathrm{~m}^{2} \mathrm{~s}^{-1}, \mathrm{D}_{\mathrm{Zn}}=6.38 \times 10^{-10} \mathrm{~m}^{2} \mathrm{~s}^{-1}$ [173]). $\mathrm{D}_{\mathrm{ML}}$ has much lower values than the corresponding $\mathrm{D}_{\mathrm{M}}$, indicating that the complexes with fulvic acid are significantly larger than the metal aqua complexes [173]. 


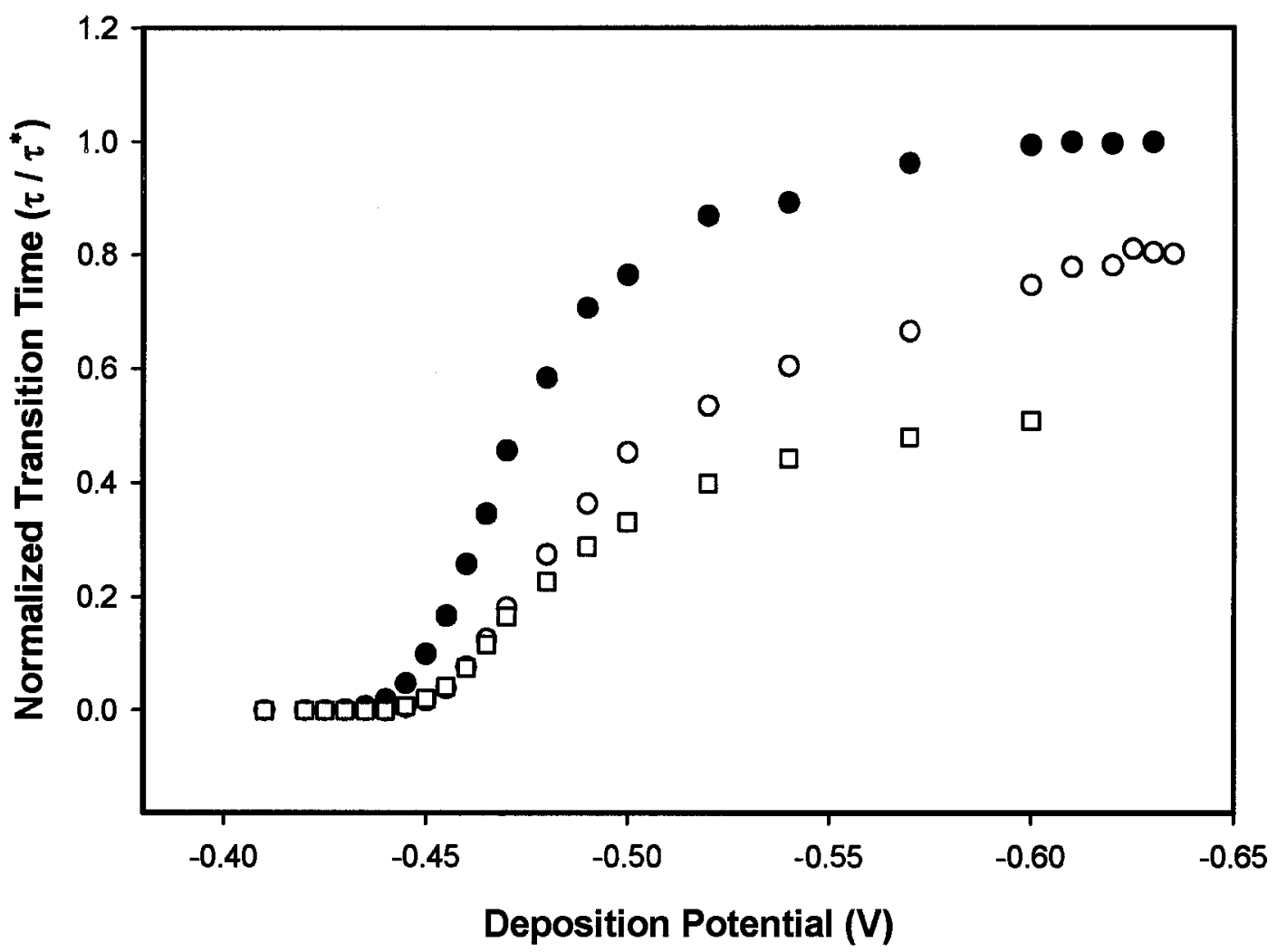

Figure 17 Experimentally determined depletive SSCP curves for $\mathrm{Pb}(\mathrm{II})$ in the presence of different concentrations of SRFA at SMDE. Curves correspond to $(\bullet) 2 \mathrm{x}$ $10^{-7} \mathrm{M} \mathrm{Pb}(\mathrm{II}) ;(\mathrm{O}) 2 \times 10^{-7} \mathrm{M} \mathrm{Pb}(\mathrm{II}), 8 \times 10^{-5} \mathrm{M} \mathrm{SRFA}$; (口) $2 \times 10^{-7} \mathrm{M} \mathrm{Pb}(\mathrm{II})$, $2 \times 10^{-4} \mathrm{M}$. Deposition time $120 \mathrm{~s}$, stripping current $1 \times 10^{-9} \mathrm{~A}$, ionic strength $0.1 \mathrm{M}, \mathrm{pH} 4.8 \pm 0.1, \mathrm{~T}=23 \pm 2^{\circ} \mathrm{C}$. 
The parameters $\Gamma$ and $\tau^{*}$ were determined by fitting the SSCP curve to Equation 4.2 [161]. The regression analysis relied on data points only from the rising portion of the polarographic wave. Equations $4.5[31,162,163], 4.6$ and $4.7[95,150]$ were proposed for calculating the average stability constant $\mathrm{K}^{*}$ of $\mathrm{M}(\mathrm{II})-\mathrm{SRFA}$ complexes. All the calculated results are presented in Table 4 below.

Table 4 Complexation parameters of $2 \times 10^{-7} \mathrm{~mol} \mathrm{~L}^{-1} \mathrm{M}(\mathrm{II})$ in the presence of Suwannee River Fulvic Acid (SRFA) determined by depletive SSCP.

\begin{tabular}{cccccc}
\hline Metal(II) & $\mathbf{c}_{\text {SRFA }}\left(\mathbf{m o l L}^{-1}\right)$ & $\boldsymbol{\Gamma}$ & $\log \mathbf{K}^{*}$ & $\tau / \tau^{*}$ & $\overline{\mathbf{D}}_{\mathbf{M L}} / \mathbf{1 0}^{-10}\left(\mathrm{~m}^{2} \mathrm{~s}^{-1}\right)$ \\
\hline $\mathrm{Zn}$ & $8 \times 10^{-5}$ & $0.96 \pm 0.04$ & $5.54 \pm 0.16$ & 0.96 & $6.00 \pm 0.41$ \\
$\mathrm{Zn}$ & $2 \times 10^{-4}$ & $0.95 \pm 0.02$ & $6.57 \pm 0.30$ & 0.98 & $6.19 \pm 0.14$ \\
$\mathrm{Cd}$ & $8 \times 10^{-5}$ & $0.90 \pm 0.04$ & $5.92 \pm 0.08$ & 0.78 & $4.75 \pm 0.33$ \\
$\mathrm{Cd}$ & $2 \times 10^{-4}$ & $0.77 \pm 0.03$ & $6.63 \pm 0.08$ & 0.62 & $3.37 \pm 0.35$ \\
$\mathrm{~Pb}$ & $8 \times 10^{-5}$ & $0.49 \pm 0.11$ & $7.15 \pm 0.26$ & 0.80 & $5.92 \pm 0.23$ \\
$\mathrm{~Pb}$ & $2 \times 10^{-4}$ & $0.36 \pm 0.06$ & $7.22 \pm 0.06$ & 0.49 & $2.84 \pm 0.18$ \\
\hline
\end{tabular}

\subsubsection{Pseudopolarography}

It is well known that the metal ion concentration at the electrode surface during the stripping step is much larger than that in the bulk solution. Although this surface concentration effect is of no particular importance in the case of an uncomplexing medium, it may drastically influence the ligand-to-metal concentration ratio in a 
complexing medium. Under non-depletive conditions (i.e. most of the stripping voltammetry, such as DP-SV), the concentration gradient of $\mathrm{M}$ at the electrode surface will be hence modified, as well as the shape of the current/potential curve. Obviously, this effect can be negligible when the bulk ligand concentration is so large that it is in great excess even at the electrode surface during the stripping step. Unfortunately, this is not the case for many ligands found in natural water systems.

In most complexing media, the ligand/metal ratio in the bulk solution must be larger than 1000 in order to avoid the surface effect [13]. When this condition was not met, the currents measured were at least $30 \%$ below those that should be obtained in the absence of the surface effect. An even larger discrepancy was obtained when the diffusion coefficient of the complex was lower than that of the free metal ion, i.e. $D_{M-F A}<D_{M}$. Because the importance of this surface effect would vary along the pseudopolarogram, it may be expected that not only the limiting current, but also $E_{1 / 2}$ and the slope might be modified. The pseudopolarographic results of my experiment at low concentration of fulvic acid, especially for Cd(II) (Figure B3 (APPENDIX)) confirmed this.

At the same time, the attempt to interpret the data was more confused by the induced metal adsorption, which could become deteriorated by the sufficiently excess ligand requirement. In fact, when the concentration of fulvic acid was 1000 times higher than that of the metal ion, the induced metal adsorption occurred for all these three metal to different extents. In contrast to SSCP, the pseudopolarograms (SSV curves) cannot 
therefore be assigned any meaning due to the concomitant competing influences of induced metal adsorption and ligand saturation at the electrode surface.

The complexation parameters were also calculated by solving Differential Equilibrium Function (DEF) based on the pseudopolarographic data and were presented in Table 5. The heterogeneity parameters follow the order of $\mathrm{Pb}(\mathrm{II})>\mathrm{Cd}(\mathrm{II}) \approx \mathrm{Zn}(\mathrm{II})$, which partly agrees with that obtained by SSCP. The order of stability constants for these three metal complexes systems is consistent with those predicted by SSCP.

Table 5 Complexation parameters of $2 \times 10^{-7} \mathrm{~mol} \mathrm{~L}^{-1} \mathrm{M}(\mathrm{II})$ in the presence of Suwannee River Fulvic Acid (SRFA) determined by pseudopolarography.

\begin{tabular}{cccccc}
\hline Metal(II) & C SRFA $\left(\mathrm{molL}^{-1}\right)$ & & & & \\
& & $\boldsymbol{\Gamma}$ & $\log \mathbf{K}^{*}$ & $\tau / \tau^{*}$ & $\overline{\mathbf{D}}_{\mathbf{M L}} / 10^{-10}\left(\mathbf{m}^{2} \mathbf{s}^{-1}\right)$ \\
\hline $\mathrm{Zn}$ & $8 \times 10^{-5}$ & $0.89 \pm 0.05$ & $5.62 \pm 0.03$ & 0.96 & $6.00 \pm 0.32$ \\
$\mathrm{Zn}$ & $2 \times 10^{-4}$ & $0.89 \pm 0.05$ & $5.56 \pm 0.04$ & 0.86 & $5.09 \pm 0.13$ \\
$\mathrm{Cd}$ & $8 \times 10^{-5}$ & $0.91 \pm 0.04$ & $5.68 \pm 0.01$ & 0.85 & $5.41 \pm 0.29$ \\
$\mathrm{Cd}$ & $2 \times 10^{-4}$ & $0.90 \pm 0.01$ & $5.73 \pm 0.02$ & 0.89 & $5.79 \pm 0.05$ \\
$\mathrm{~Pb}$ & $8 \times 10^{-5}$ & $0.81 \pm 0.06$ & $5.84 \pm 0.02$ & 0.85 & $6.49 \pm 0.23$ \\
$\mathrm{~Pb}$ & $2 \times 10^{-4}$ & $0.63 \pm 0.05$ & $6.17 \pm 0.09$ & 0.76 & $5.49 \pm 0.67$ \\
\hline
\end{tabular}

Compared with pseudopolarography, such as Figure 18 for $\mathrm{Pb}(\mathrm{II})-\mathrm{SRFA}$, the complexes look to be more stable and less labile in SSCP determination. 


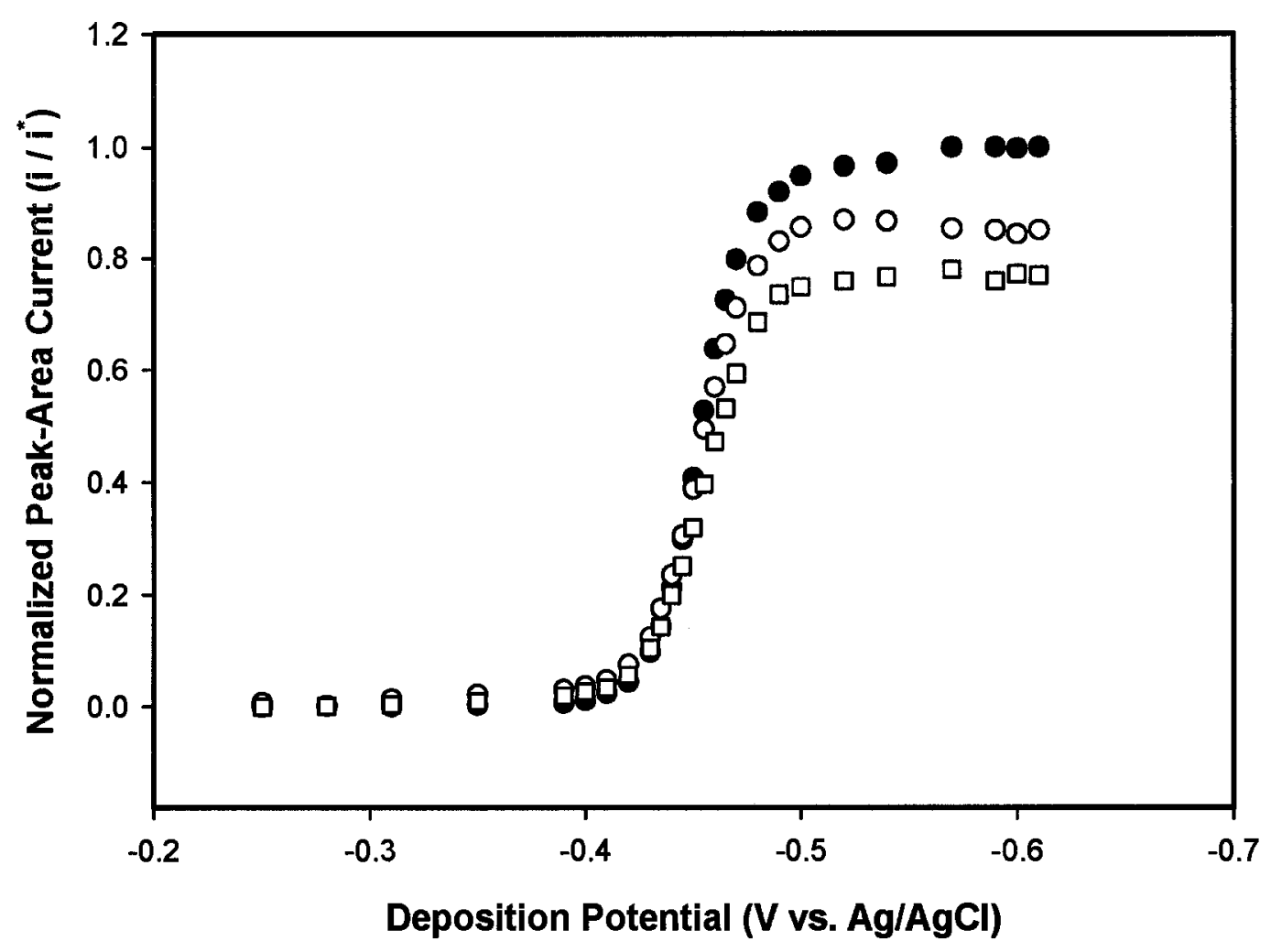

Figure 18 Experimentally determined pseudopolarograms for $\mathrm{Pb}$ (II) in the presence of different concentrations of SRFA at SMDE. Curves correspond to (•) $2 \mathrm{x}$ $10^{-7} \mathrm{M} \mathrm{Pb}(\mathrm{II}) ;(\circ) 2 \times 10^{-7} \mathrm{M} \mathrm{Pb}(\mathrm{II}), 8 \times 10^{-5} \mathrm{M} \mathrm{SRFA}$; (口) $2 \times 10^{-7} \mathrm{M} \mathrm{Pb}(\mathrm{II})$, $2 \times 10^{-4}$ M SRFA. Deposition time $120 \mathrm{~s}$, scan rate $0.0102 \mathrm{~V} / \mathrm{s}$, ionic strength $0.1 \mathrm{M}, \mathrm{pH} 4.8 \pm 0.1, \mathrm{~T}=23 \pm 2^{\circ} \mathrm{C}$. 
- Chapter 5-

Complexometric Titration of Copper Cliff Mine Effluent

Waters by Depletive Stripping Chronopotentiometry to Study

the Effects of Dilution on the Stability Constants of Zn(II)- and

Cd(II)-DOC Complexes 


\subsection{Introduction}

Natural waters contain a diversity of ligands that complex metal ions, among which are major and trace inorganic ligands $[178,179]$, synthetic chelators [180], humic substances [181], colloids [182], and microbial chelators [183]. The chemical form of metal ions is governed by physico-chemical factors (e.g., salinity, $\mathrm{pH}$, hardness, and dissolved organic matter (DOM)) that prevail in the local environment [201]. While the coordination equilibria of major inorganic and synthetic ligands can be modeled accurately using critically reviewed stability constants [178], those of natural organic ligands cannot since their concentrations and stability constants are difficult to characterize.

Complexometric titrations followed with instrumental methods have potential application to the analysis of very dilute solutions such as those encountered in natural waters [184] There are two titration methodologies which can be employed to study metal complexation using equilibrium approach. One is adding complexant to a water sample containing fixed concentration of trace metal. The other is adding metal ion to a water sample containing fixed concentration of complexants, which is preferably utilizable for surface waters with constant but unknown ligand concentration.

Stripping chronopotentiometry (SCP) performed under conditions approaching complete depletion has good sensitivity as well it is essentially free from adsorption effect [185], which may make it more favorable for the complexometric titration of dissolved organic carbon (DOC) in real water samples. 
This chapter applies depletive stripping chronopotentiometry (SCP) technique following complexometric titration to investigate the effects of dilution on the conditional stability constants of metal-DOC complexes in Copper Cliff Mine effluents waters, Sudbury, ON. This has never been reported before and it is the first attempt to apply SCP to real samples.

\subsection{Theory}

In general, titrations are employed, i.e. a measurement is made on the natural sample with very low concentration of specific metal, then increments of metal ions are added, and the stability constant, $\mathrm{K}$, and the corresponding apparent ligand concentration, $\mathrm{L}$, are obtained from the resulting titration curve.

For simplicity, it is assumed that (1) DOC be regarded as a single ligand L and it give an average stability constant rather than a range of stability constants; (2) DOC forms 1:1 complex, ML with the metal ion. The conditional stability constant, $\mathbf{K}_{\mathbf{M}_{\mathbf{L}} \mathbf{L}}$ is given by

$$
\mathbf{K}_{\mathbf{M}^{\prime} \mathbf{L}}=[\mathbf{M L}] /\left(\left[\mathbf{M}^{\prime}\right]\left[\mathbf{L}^{\prime}\right]\right)
$$

where $\mathbf{M}^{\prime}$ and $\mathbf{L}^{\prime}$ are the concentrations of the metal and ligand that are not bound to each other. These are related to the total metal $\mathbf{c}_{\mathbf{M}}$ and $\mathbf{c}_{\mathbf{L}}$ via

$$
\begin{aligned}
& {\left[\mathbf{M}^{\prime}\right]=\mathbf{c}_{\mathbf{M}}-[\mathbf{M L}]} \\
& {\left[\mathbf{L}^{\prime}\right]=\mathbf{c}_{\mathbf{L}}-[\mathbf{M L}]}
\end{aligned}
$$

The free metal $\left[\mathbf{M}^{\mathbf{n}+}\right]$ plus the metal bound to other inorganic ligands equals to $\left[\mathbf{M}^{\circ}\right]$ : 


$$
\left[\mathbf{M}^{\prime}\right]=\left[\mathbf{M}^{\mathbf{n}+}\right]+\sum \mathbf{M} \mathbf{X}_{\mathbf{i}}
$$

and the fraction of free metal in the solution without the organic ligand is given by

$$
\left[\mathbf{M}^{\mathbf{n}+}\right]=\left[\mathbf{M}^{\prime}\right] \mathbf{a}_{\mathbf{M}}
$$

where

$$
\alpha_{M}=1 /\left(1+\sum K_{M X_{i}}[X]_{i}\right)
$$

This has been expressed as the side reaction coefficient for $\mathbf{M}^{\prime}, \boldsymbol{\alpha}_{\mathbf{M}^{\prime}}$, which is the reciprocal of $\boldsymbol{\alpha}_{\mathbf{M}}$ or

$$
\boldsymbol{\alpha}_{\mathbf{M}^{\prime}}=\left[\mathbf{M}^{\prime}\right] /\left[\mathbf{M}^{\mathbf{n}+}\right]
$$

The conditional constant for $\mathbf{M}^{\prime} \mathbf{L}$ is related to $\mathbf{M}^{\mathbf{n}+} \mathbf{L}$ by

$$
\mathbf{K}_{\mathbf{M L}}=[\mathbf{M L}] /\left(\left[\mathbf{M}^{\mathbf{n}+}\right]\left[\mathbf{L}^{\prime}\right]\right)=\mathbf{K}_{\mathbf{M}_{\mathbf{L}}^{\prime}}\left(\boldsymbol{a}_{\mathbf{M}^{\prime}}\right)
$$

In terms of complexometric titration, after $M$ is added to the unknown sample in increments, equilibrium between metal ion and organic ligand(s) needs to be established before the measurement. The inorganic form of the metal is analyzed via SCP at the Hg electrode. The concentration of ML increases with the addition of metal ion until the complexation capacity of ligand(s) is saturated. Linearization of the titration data is typically performed by use of the Langmuir or Ruzic transformation [186-189]:

$$
\frac{\left[\mathbf{M}^{\prime}\right]}{[\mathbf{M L}]}=\frac{\left[\mathbf{M}^{\prime}\right]}{\mathbf{c}_{\mathbf{L}}}+\frac{{ }^{\alpha} \mathbf{M}^{\prime}}{\mathbf{K}_{\mathbf{M L}} \mathbf{c}_{\mathbf{L}}}
$$


A plot of $\left[\mathbf{M}^{\prime}\right] /[\mathbf{M L}]$ vs. $\left[\mathbf{M}^{\prime}\right]$ yields a straight line from which $\mathrm{K}_{\mathrm{ML}}$ (the conditional stability constant uncorrected for the side reaction coefficient of the ligand) can be evaluated from the intercept.

In stripping chronopotentiometry, $\left[\mathbf{M}^{\prime}\right]$ is the labile or inorganic $\mathbf{M}$, which is calculated as follows:

$$
\left[\mathbf{M}^{\prime}\right]=\frac{\tau}{\mathbf{s}}
$$

where $\tau$ is the relevant transition time, $\mathrm{s}$ is the sensitivity (the slope after the saturation of ML) of the technique. The side reaction coefficient, $\boldsymbol{a}_{\mathbf{M}^{\prime}}$, in these mine effluent samples could be obtained by:

$$
\begin{aligned}
& \alpha_{\mathrm{M}^{\prime}}=1+\alpha_{\text {in }}=1+\beta_{\mathrm{OH}}\left[\mathrm{OH}^{-}\right]+\beta_{\mathrm{OH}}\left[\mathrm{OH}^{-}\right]^{2}+\beta_{\mathrm{CO}_{3}}\left[\mathrm{CO}_{3}^{2-}\right] \\
& +\beta_{\mathrm{HCO}_{3}}\left[\mathrm{CO}_{3}^{2-}\right]\left[\mathrm{H}^{+}\right]+\beta_{\mathrm{Cl}}\left[\mathrm{Cl}^{-}\right]+\beta_{\mathrm{SO}_{4}^{2-}}\left[\mathrm{SO}_{4}^{2-}\right]
\end{aligned}
$$

Based on Eq. 5.3 and 5.8, the free metal concentration could be obtained if the total metal concentration is known, assuming all the metal is binding with DOC.

\subsection{Experimental}

\subsubsection{Sampling Sites and Sampling Protocol}

The effluent samples were collected from Copper Cliff Mine in Sudbury, Ontario, Canada. One was undiluted (to be called $100 \%$ ) effluent, the other was the same effluent 
but diluted with tap water so that it contained $45 \%$ of the original effluent (to be called $45 \%$ effluent).

The samples were filtered through $0.45 \mu \mathrm{m}$ AquaPrep 600 Capsules (Pall Corporation) in order to filter out the particulate matter within $24 \mathrm{~h}$ after the samples had been delivered to our lab. These filters were made of hydrophilic polyethersulfone. Each $0.45 \mu \mathrm{m}$ filter could filter approximately $4 \mathrm{~L}$ of water sample before they were clogged and discarded.

A small portion of the filtered samples was acidified with nitric acid (Seastar, Canada) to pH 1.5 (to prevent metal loss by adsorption to the container walls). The acidified sample was used to determine the total metal concentrations of cadmium and zinc by PerkinElmer Elan 6000 ICP-MS. The remaining filtered samples were stored in the dark at $4^{\circ} \mathrm{C}$ until analyzed by the complexometric titration, followed by stripping chronopotentiometry. The $\mathrm{pH}$ was measured by an Accumet $20 \mathrm{pH} /$ conductivity meter (Fisher Scientific). The DOC concentration of the filtered water samples was measured using a Total Organic Carbon Analyzer (OI Analytical Model 1010). The tap water used by Copper Cliff Mines to dilute the effluent samples contained $2 \mathrm{mg} / \mathrm{L} \mathrm{DOC}$.

\subsubsection{Reagents}

Standard solutions (1000 $\mu \mathrm{g} / \mathrm{ml})$ of $\mathrm{Cd}(\mathrm{II})$ and $\mathrm{Zn}$ (II) were purchased from SCP Science, Montreal, Canada. Ultrapure water of resistivity of $18.2 \mathrm{M} \Omega . \mathrm{cm}$ was obtained from a Milli-Q-Plus water purification system (Millipore Corporation, USA), fitted with an organic purification column to remove organic matter. A 2 M stock solution of MOPS (3- 
( $\mathrm{N}$-morpholino)propanesulfonic acid), a $2 \mathrm{M}$ stock solution of $\mathrm{NaOH}$ and a $2 \mathrm{M}$ stock solution of $\mathrm{KNO}_{3}$ were prepared by dissolving an appropriate quantity of MOPS (Sigma, $>99.5 \%$ ), sodium hydroxide (Caledon) or potassium nitrate (Aldrich) in ultrapure water. The $\mathrm{KNO}_{3}$ solution were then purified separately free of metal by electrolysis at $-1.5 \mathrm{~V}$ vs. SCE for at least $48 \mathrm{~h}$ prior to its use. To prevent the impurity metal from returning to the solution, the purified solution was removed while the electrolysis was going on. For $45 \%$ effluent samples, ionic strength of $0.1 \mathrm{M}, \mathrm{pH}$ of 7.2 was used in all experiments. For $100 \%$ effluent samples, $0.1 \mathrm{M}$ ionic strength and $\mathrm{pH} 7.3$ were used.

\subsubsection{Method}

A series of samples were spiked with different amounts of the standard metal solution. 2 $\mathrm{M} \mathrm{KNO}_{3}$ was added to the samples to maintain $0.1 \mathrm{M}$ ionic strength. The samples were buffered at the original $\mathrm{pH}$ with $\mathrm{MOPS} / \mathrm{NaOH}$, and then were left for equilibrium overnight (12 h).

\subsubsection{Apparatus}

The apparatus described in section 3.2.3 was used.

\subsubsection{Electrochemical Parameters}

Each sample solution was purged with $\mathrm{N}_{2}$ gas for $10 \mathrm{~min}$ before potential stripping analysis (PSA) method was employed. An oxidizing current, $I_{\mathrm{s}}$ of $1 \times 10^{-9} \mathrm{~A}$ was applied in solution after the deposition and equilibrium periods. The raw signal is the variation of potential with time that is automatically converted to the $\mathrm{d} t / \mathrm{d} E v s$. E format, being the 
area under the peak as the transition time. For each sample the potential was held at deposition potential of $-1.30 \mathrm{~V}$ for $120 \mathrm{~s}$, after the quiescent period of $20 \mathrm{~s}$ the oxidizing current was applied until a value well past the deposition plateau $(-0.25 \mathrm{~V}$ for $\mathrm{Cd}$ and $\mathrm{Zn}$ ). The stirring rate was $2000 \mathrm{rpm}$.

\subsubsection{Software}

The Windermere Humic Aqueous Model (WHAM) is a computer program to model chemical equilibria in oxic waters. In my experiments, WHAM VI was used to predict the free metal concentrations in these mine effluent waters assuming all the DOC is made up of fulvic acid.

\subsection{Results and Discussion}

\subsubsection{Characteristics and Composition of the Samples}

Table 6 presents the characteristics and compositions of the undiluted effluent sample (100\%) and diluted effluent sample (45\%). DOC is Dissolved Organic Carbon and DIC is Dissolved Inorganic Carbon. The concentrations for the metals are the total metal concentration. The concentration of $\mathbf{P O}_{4}^{3-}$ could not be detected since it is below the detection limit of ion chromatography (IC). 
Table 6 Characteristics and compositions of Copper Cliff Mine undiluted effluent sample (100\%) and diluted effluent sample (45\%)

\begin{tabular}{|c|c|c|}
\hline Properties & $100 \%$ effluent sample & $45 \%$ effluent sample \\
\hline$\overline{\mathbf{p H}}$ & $7.30 \pm 0.05$ & $7.20 \pm 0.05$ \\
\hline Conductivity (mS) & $300.0 \pm 3.0$ & $165.0 \pm 3.0$ \\
\hline Color & Colorless & Colorless \\
\hline$[\mathrm{DOC}]\left(\mathrm{mgL}^{-1}\right)$ & 6.12 & 3.25 \\
\hline$[\mathrm{DIC}]\left(\mathrm{mgL}^{-1}\right)$ & 1.73 & 11.23 \\
\hline$[\mathrm{Co}]\left(\mathrm{molL}^{-1}\right)$ & $2.14 \times 10^{-7}$ & $1.04 \times 10^{-7}$ \\
\hline$[\mathrm{Ni}]\left(\mathrm{molL}^{-1}\right)$ & $2.41 \times 10^{-6}$ & $1.05 \times 10^{-6}$ \\
\hline$[\mathrm{Cu}]\left(\mathrm{molL}^{-1}\right)$ & $3.81 \times 10^{-6}$ & $1.74 \times 10^{-6}$ \\
\hline$[\mathrm{Zn}]\left(\mathrm{molL}^{-1}\right)$ & $3.58 \times 10^{-7}$ & $2.58 \times 10^{-7}$ \\
\hline$[\mathrm{Cd}]\left(\mathrm{molL}^{-1}\right)$ & $3.65 \times 10^{-8}$ & $2.58 \times 10^{-8}$ \\
\hline$[\mathbf{N a}]\left(\mathrm{molL}^{-1}\right)$ & $4.35 \times 10^{-3}$ & $2.17 \times 10^{-3}$ \\
\hline$[\mathrm{Fe}]\left(\mathrm{molL}^{-1}\right)$ & $5.9 \times 10^{-7}$ & $2.6 \times 10^{-7}$ \\
\hline$[A]]\left(\mathrm{molL}^{-1}\right)$ & $5.97 \times 10^{-6}$ & $2.99 \times 10^{-6}$ \\
\hline$[\mathrm{Ca}]\left(\mathrm{molL}^{-1}\right)$ & $1.37 \times 10^{-2}$ & $6.87 \times 10^{-3}$ \\
\hline$[\mathrm{K}]\left(\mathrm{molL}^{-1}\right)$ & $8.95 \times 10^{-4}$ & $4.48 \times 10^{-4}$ \\
\hline$[\mathrm{Mg}]\left(\mathrm{molL}^{-1}\right)$ & $1.23 \times 10^{-3}$ & $6.16 \times 10^{-4}$ \\
\hline$\left[\mathrm{SO}_{4}^{2-}\right]\left(\mathrm{molL}^{-1}\right)$ & $2.08 \times 10^{-2}$ & $1.04 \times 10^{-2}$ \\
\hline$\left[\mathrm{Cl}^{-}\right]\left(\mathrm{molL}^{-1}\right)$ & $2.5 \times 10^{-3}$ & $1.3 \times 10^{-3}$ \\
\hline$\left[\mathrm{NO}_{3}^{-}\right]\left(\mathrm{molL}^{-1}\right)$ & $1.94 \times 10^{-4}$ & $4.90 \times 10^{-5}$ \\
\hline
\end{tabular}




\subsubsection{Titration Curve}

The stripping chronopotentiometric complexation curve $\tau=\mathrm{f}\left(\mathrm{c}_{\mathrm{addedM}}\right)$ for $\mathrm{Cd}(\mathrm{II})$ and $\mathrm{Zn}$ (II) in the $45 \%$ and $100 \%$ mine effluent samples are shown in Figure 19 (A), Figure 20 (A), Figure C1 (A) (APPENDIX) and Figure C2 (A) (APPENDIX). All the curves obtained have similar shapes with two linear portions. The first linear portion corresponds to the condition of $[\mathrm{M}] \ll<[\mathrm{L}]_{\mathrm{T}}$, under which almost all the metal are complexed with the DOC ligands, and the increase of transition time was smaller. With the more addition of the free metal ion, the binding sites of the DOC ligands become saturated at the electrode surface and the DOC ligands reach the limit of their complexation capacity. It was assumed that the complexes formed are electrochemically inert. Thereafter, another linear portion could be observed for an excess of metal ion [190], the slope of which is the sensitivity of the SCP technique.

In the course of a metal titration, the ratio between the concentrations of metal and ligand changes and this means that the electrochemical lability changes as well.

\subsubsection{Free Metal Concentrations}

All the free metal concentrations figured out based on Eq. 5.3 and 5.8 are lower than those predicted by WHAM VI in Table 7. Since there is no more information about these water samples, the concentration of DOC has been taken to represent the concentration of fulvic acid in WHAM VI. It is possible that some unknown ligands had been added to the effluent waters for the purpose of pollution reduction before they were discharged to the river. 


\subsubsection{Conditional Stability Constants}

Figure 19 (B), Figure 20 (B), Figure C1 (B) (APPENDIX) and Figure C2 (B) (APPENDIX) show the Langmuir transformation plots of $\left[\mathbf{M}^{\prime}\right] /[\mathbf{M L}]$ vs. $\left[\mathbf{M}^{\prime}\right]$ of $\mathrm{Zn}(\mathrm{II})$ and $\mathrm{Cd}(\mathrm{II})$ in two different samples: $45 \%$ and $100 \%$ Copper Cliff Mine effluent waters. The results are linear over the range of data, which means the titration data is modeled with one class of metal binding ligands.

The values of $\log \mathrm{K}_{\mathrm{ML}}$ were calculated from the intercept of the linear regressions of the Langmuir transformation plots. These $\log \mathrm{K}_{\mathrm{ML}}$ values for $\mathrm{Zn}$ (II)-DOC and Cd(II)-DOC complexes in the $45 \%$ and $100 \%$ Copper Cliff Mine effluent samples are presented in Table 7; the values are similar to the values reported by Ellwood, M. J. [200]. The conditional stability constant of $\mathrm{Zn}(\mathrm{II})-\mathrm{DOC}$ was found to be higher than that of $\mathrm{Cd}$ (II)DOC, which agrees with the Irving-Williams series. When the concentration of humic substances is not high and $\mathrm{pH}$ is high enough, i.e. DOC $<10 \mathrm{mg} / \mathrm{L}, \mathrm{pH} \sim 7$ in these effluent water samples, humic substances are prone to offer more charged and smaller size molecules, which prefer to interact more electrostatically with metal ions. The smaller metal ion, i.e. $\mathrm{Zn}(\mathrm{II})$, polarizes the ligand electrons more strongly into a stronger bond in terms of the hard-soft acid-base effect. Higher values for stability constants of $\mathrm{Zn}$ (II)-DOC might be hence expected. Other researchers also found that compared with $\mathrm{Cd}$, a higher affinity of $\mathrm{Zn}$ for complexation with the components of DOC was observed $[191,192]$. In the case of a soft cation, i.e. $\mathrm{Cd}(\mathrm{II})$, soft ligands, such as $\mathrm{N}$ and $\mathrm{S}$ in the functional groups of DOM may play an important role in its complexation in natural waters $[193,194]$. Another reason for lower conditional stability constant of Cd(II)-DOC 
may be the competition from chloride ion since not only are the stability constants of its chlorocomplexes very high $\left(\operatorname{logK}\left(\mathrm{CdCl}^{-}\right)=1.59 \pm 4, \operatorname{logK}\left(\mathrm{ZnCl}^{-}\right)=-0.2 \pm 1,25^{\circ} \mathrm{C}\right)$ but also the concentration of the $n$th complex is dependent on the $n$th power of the chloride concentration $[192]\left(45 \%\right.$ mine effluent: $\left[\mathrm{Cl}^{-}\right]=1.3 \times 10^{-3} \mathrm{M} ; 100 \%$ mine effluent: $\left[\mathrm{Cl}^{-}\right]=$ $\left.2.5 \times 10^{-3} \mathrm{M}\right)$.

Table 7 Free metal ion concentrations (determined by SCP and predicted by WHAM VI) and conditional stability constants of metal-DOC complexes in the $45 \%$ and $100 \%$ Copper Cliff Mine effluent waters determined by complexometric titration.

\begin{tabular}{ccccc}
\hline Samples & Metal & {$[\mathrm{M}]\left(\mathrm{molL}^{-1}\right)$} & {$[\mathrm{M}]$ WHAM vI $\left(\mathrm{molL}^{-1}\right)$} & $\operatorname{logK}$ \\
\hline $100 \%$ & $\mathrm{Cd}(\mathrm{II})$ & $3.14 \times 10^{-9}$ & $7.16 \times 10^{-9}$ & 7.56 \\
& $\mathrm{Zn}(\mathrm{II})$ & $1.11 \times 10^{-8}$ & $9.29 \times 10^{-8}$ & 8.81 \\
\hline $45 \%$ & $\mathrm{Cd}(\mathrm{II})$ & $2.01 \times 10^{-9}$ & $3.95 \times 10^{-9}$ & 7.52 \\
& $\mathrm{Zn}(\mathrm{II})$ & $1.08 \times 10^{-9}$ & $8.58 \times 10^{-8}$ & 9.70 \\
\hline
\end{tabular}



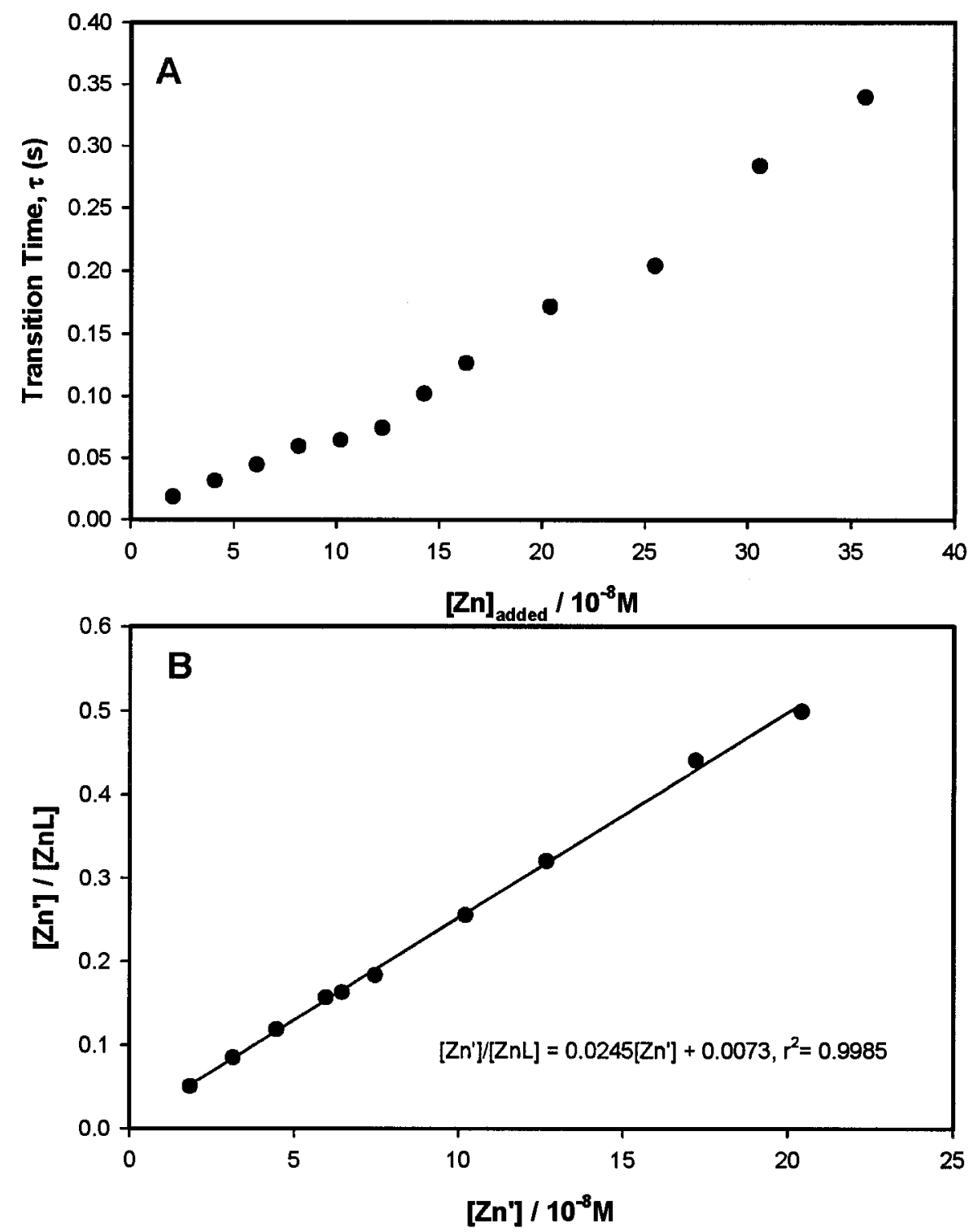

Figure 19 Complexometric titration of DOC in Copper Cliff Mine 100\% effluent water sample with $\mathrm{Zn}$ (II) by Stripping Chronopotentiometry: (A) titration curve of $\mathrm{Zn}-\mathrm{DOC}$; (B) Langmuir transformation of the titration data from (A). $\mathrm{pH}=$ $7.30 \pm 0.05, \mathrm{~T}=23 \pm 2^{\circ} \mathrm{C}$. 

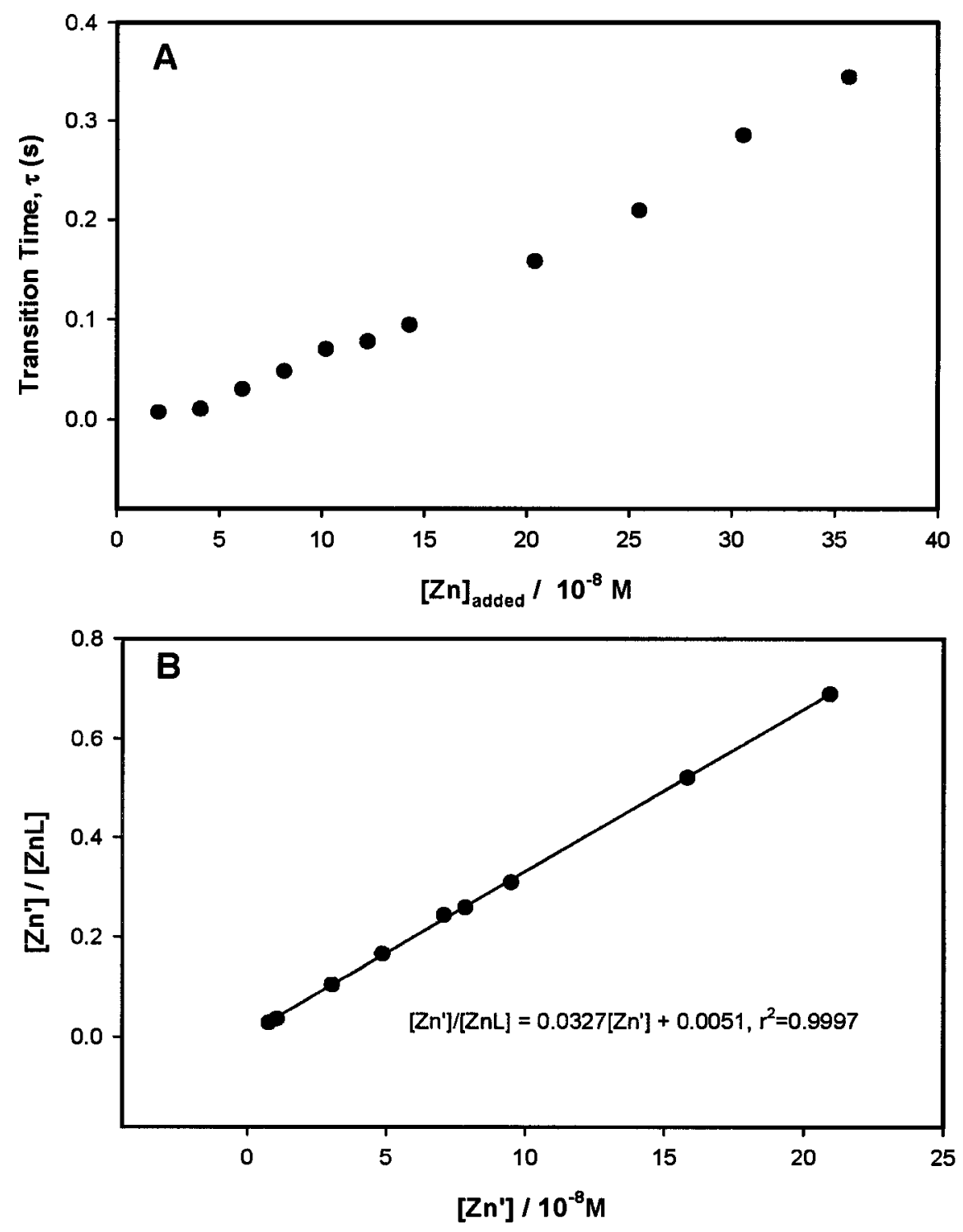

Figure 20 Complexometric titration of DOC in Copper Cliff Mine 45\% effluent water sample with $\mathrm{Zn}$ (II) by Stripping Chronopotentiometry: (A) titration curve of Zn-DOC; (B) Langmuir transformation of the titration data from (A). $\mathrm{pH}=$ $7.20 \pm 0.05, \mathrm{~T}=23 \pm 2^{\circ} \mathrm{C}$. 


\subsubsection{Dilution Factor}

Table 7 shows that dilution of Copper Cliff Mine effluent waters with tap water obviously raises the average conditional stability constant of $\mathrm{Zn}(\mathrm{II})$-DOC complexes, whereas it does not affect that of Cd(II)-DOC.

In the Copper Cliff Mine effluent water samples, which contain high concentrations of magnesium and calcium (100\%: $[\mathrm{Mg}]=1.23 \times 10^{-3} \mathrm{M},[\mathrm{Ca}]=1.37 \times 10^{-2} \mathrm{M} ; 45 \%:[\mathrm{Mg}]$ $\left.=6.16 \times 10^{-4} \mathrm{M},[\mathrm{Ca}]=6.87 \times 10^{-3} \mathrm{M}\right)$, as well as high concentration of copper $(100 \%$ : $\left.[\mathrm{Cu}]=3.81 \times 10^{-6} \mathrm{M} ; 45 \%:[\mathrm{Cu}]=1.74 \times 10^{-6} \mathrm{M}\right)$, the competitions for the humic ligands by calcium, magnesium and copper are sufficiently abundant to utilize the majority of the complexing capacity of the DOC ligand. The remaining trace metals occur predominantly as free metal ions, especially cadmium with less affinity for humic substances. Almost all cadmium may be present in inorganic chloro complexes [195]. Therefore, the average conditional stability constant of Cd(II)-DOC is not influenced by the dilution of the copper mine effluent water. Compared with cadmium, the affinity of zinc for DOC is more affected by the dilution under the experimental condition. The majority of zinc is complexed by organic ligands of natural origin [197-199]. Based on the fact that the total concentration of zinc in $100 \%$ effluent is $3.58 \times 10^{-7} \mathrm{M}$ and that of zinc in $45 \%$ effluent is $2.58 \times 10^{-7} \mathrm{M}$, it is reasonable to assume that the tap water used to dilute the effluent sample contains some zinc. The stability constant of $\mathrm{Zn}$ (II)-DOC could be increased as a result of the extra zinc joining to bind to the strong binding sites of humic substances. Zinc ion interacts with humic substances strongly as long as its local concentration is high, but the associations decline upon dispersal [196]. With the dilution of the Copper 
Cliff Mine effluent, more hidden binding sites of DOC are exposed to metal ions due to the disaggregation of humic substances; At the same time, $\mathrm{Zn}$ (II) ions gain mobility upon dispersal through the humate solution [196], and bind to strong sites, resulting in elevated value of $\mathrm{K}$. 
- Chapter 6-

Conclusions

Reproduced with permission of the copyright owner. Further reproduction prohibited without permission. 
Depletive Stripping Chronopotentiometry (SCP), a recently developed electroanalytical technique, has been investigated to understand the interactions of trace metals with organic complexants in aquatic systems. The work reported in this thesis has been divided into two parts: one is on Stripping Chronopotentiometry (SCP) technique itself; the other is on the complexation of metal with organic ligands in waters.

Depletive SCP in $\mathrm{d} t / \mathrm{d} E$ format, having low detection limit comparable to DP-SV may avoid the adsorption of organic complex on the electrode and is free of induced metal adsorption, both of which would confound the interpretation of results of stripping voltammetry.

The absolute sensitivity attainable of SCP is limited by the presence of trace dissolved oxygen in solution. The diffusion layer thickness is not affected by the deposition time when the stirring is efficient. To approach linear diffusion $\delta / r_{0} \ll 1$, faster stirring and larger drop size are recommended.

The stability constants of simple homogeneous metal complexes (e.g. $\mathrm{Cd}(\mathrm{II}), \mathrm{Pb}(\mathrm{II})$ with PDCA and NTA) can been determined by Scanned Stripping Chronopotentiometry (SSCP) based on the interpretation in a manner completely analogous to the DeFordHume treatment of polarograms. The results agree well with those from pseudopolarography (scanned stripping voltammetry) and the values from the literature. The reversibility of the metal electrode reaction can be tested by SSCP log analysis as well. The results are consistent with those obtained by pseudopolarography. 
SSCP has been further applied to study the complexation of metal with heterogeneous ligand, a well-characterized Standard Suwannee River Fulvic Acid (SRFA) under acidic conditions. The apparent stability constant and heterogeneity of the metal complexes with SRFA can be characterized by Differential Equilibrium Function (DEF). The diffusion coefficient of metal-FA complexes can also be calculated in terms of the limiting transition time. The results obtained by SSCP are compared with those obtained by Pseudopolarography. SSCP is immune from the secondary effects (e.g. induced metal adsorption, FA adsorption or insufficient ligand excess) in the presence of heterogeneous complexants, compared with Pseudopolarography. The order of both the heterogeneity and the stability constant of metal binding with SRFA has been found to be $\mathrm{Pb}(\mathrm{II})>$ $\mathrm{Cd}(\mathrm{II})>\mathrm{Zn}(\mathrm{II})$ at $\mathrm{pH} 4.8$ in waters.

In respect of the practical utility of depletive SCP, the effects of dilution of Sudbury Copper Cliff Mine effluent waters with tap water on the conditional stability constants of metal-DOC complexes have been investigated by complexometric titration followed by depletive SCP. Free metal concentrations are obtained and compared with those predicted by WHAM VI. At $\mathrm{pH}$ 7.2-7.3, when electrostatic binding is preferred, the conditional stability constant of $\mathrm{Zn}$ (II)-DOC is higher than of $\mathrm{Cd}(\mathrm{II})-\mathrm{DOC}$, consistent with the Irving-Williams series. The conditional stability constant of $\mathrm{Cd}(\mathrm{II})-\mathrm{DOC}$ is not affected by the dilution probably because the predominant form of cadmium in the sample is inorganic chloro species. As a result of extra $\mathrm{Zn}$ (II) from the tap water and the disaggregation of humic substances, the conditional stability constant of $\mathrm{Zn}$ (II)-DOC increases with the dilution. 


\section{REFERENCES}

1 R. C. Cornelis, J. A. Caruso, H. M. Crews, K. G. Heumann, Handbook of Elemental Speciation: Techniques and Methodology, John Wiley \& Sons, Chichester, 2003.

2 D. M. Templeton, F. Ariese, R. Cornelis, L. G. Danielsson, H. Muntau, H. P. Van Leeuwen and R. Lobinski, Pure Appl. Chem., 72, (2000), 1453.

3 J. P. Pinheiro, M. Minor, H. P. van Leeuwen, J. Electroanal. Chem. 587 (2006) 284.

4 A. M. Ure and C. M. Davidson, Chemical Speciation in the Environment (2nd edition), Blackwell science, Oxford, 2001.

5 T. M. Florence, G. E. Batley, CRC Crit. Rev. Anal. Chem. 9 (1980) 219.

6 S. J. de Mora, R. M. Harrison, Hazard Assess. Chem. Curr. Dev., 3 (1984) 1.

7 T. M. Florence, Talanta, 29 (1982) 345.

8 T. M. Florence, B. G. Lumsden, J. J. Fardy, Anal. Chim. Acta, 151 (1983) 281.

9 M. Whitfield, D. R. Turner, in E. A. Jenne, Chemical Modeling in Aqueous System, American Chemical Society, Washington, DC, 1979.

10 J. R. Donat, K. A. Lao and K. W. Bruland, Anal. Chim. Acta, 284 (1984) 547.

11 B. L. Lewis, G. W. Luther, H. Lane and T. M. Church, Electroanalysis, 7 (1995) 166.

12 J. Buffle and F. L. Greter, J. Electroanal. Chem. 101 (1979) 231.

13 A. M. A. Mota, J. Buffle, S. P. Kounaves, M. L. S. Goncalves, Anal. Chim. Acta $172(1985) 13$. 
14 C. M. S. Botelho, R. A. R. Boaventura, M. L. S. Goncalves, A. M. Mota, Electroanalysis 13 (2001) 1497.

15 M. A. G. T. van den Hoop, R. D. Porasso, J. C. Benegas, Colloid Surf. A 203 (2002) 105.

16 H. P. van Leeuwen, J. Buffle, J. Electroanal. Chem. 296 (1990) 359.

17 S. Bubic, M. Branica, Thal. Jugosl. 9 (1973) 47.

18 D. R. Turner, M. Whitfield, J. Electroanal. Chem. 103 (1979) 43.

19 D. R. Turner, M. Whitfield, J. Electroanal. Chem. 103 (1979) 61.

20 H. P. van Leeuwen, R. M. Town, Environ. Sci. Technol. 37 (2003) 3945-3952.

21 F. C. Anson, J. B. Flanagan, K. Takahashi, A. Yamada, J. Electroanal. Chem. 67 (1976) 253.

22 R. M. Town, H. P. van Leeuwen, J. Electroanal. Chem. 523 (2002) 1.

23 H. P. van Leeuwen, R. M. Town, J. Electroanal. Chem. 523 (2002) 16.

24 R. M. Town, H. P. van Leeuwen, J. Electroanal. Chem. 535 (2002) 11.

25 J. Buffle, J. Electroanal. Chem. 125 (1981) 273.

26 J. Buffle and R. R. De Vitre, Chemical and Biological Regulation of Aquatic Systems, CRC, Boca Raton, USA, 1994.

27 H. P. van Leeuwen, J. Stefan, J. Electroanal. Chem. 579 (2005) 337.

28 D. Mcknight, G. Aiken, In Aquatic Humic Substances. Ecology and Biogeochemistry (D. Hessen, and L. Tranvik, Eds.), Springer-Verlag, New York (1998).

29 F. J. Stevenson, In Humus Chemistry: Genesis, Composition, Reactions, $2^{\text {nd }}$ ed. John Wiley \& Sons: New York, (1994). 
30 S. A. Jansen, J. M. Varnum, S. Kolla, M. D. Paciolla, L. T. Sein, S. Nwabara, E. A. Ghabbour, A. Fataftah, G. Davies, In The Role of Humic Substances in Ecosystems and in Environmental Protection (J. Drozd, S. S. Gonet, N. Sensesi and J. Weber, Eds.), p. 741. Polish Society of Humic Substances, Wroclaw, Poland (1997).

31 J.Buffle, In Complexation Reactions in Aquatic Systems. An Analytical Approach; Ellis Horwood, Chichester, UK (1988).

32 P. MacCarthy, Aquatic humic substances and their influence in the fate and treatment of pollutants. In American chemical Society (I. H. Suffet and P. MacCarthy Eds.), pp. 17-30, Washington, DC. (1989).

33 F. R. Livens, Environ. Pollut. 70 (1991) 183.

34 J. R. Lead, K. J. Wilkinson, K. Starchev, S. Canonica and J. Buffle, Environ. Sci. Technol. 34 (2000) 1365.

35 H. R. Schulten, P. Leinweber and M. Schnitzer, IUPAC Analytical and Physical Chemistry Series Vol. 4; Wiley: Chichester, (1998) Chapter 8.

36 E. Balnois, K. J. Wilkinson, J. R. Lead and J. Buffle, Environ. Sci. Technol. 33 (1999) 3911.

37 A. J. Simpson, W. L. Kingery, M. Spraul, E. Humpfer, P. Dvortsak and R. Kerssebaum, Environ. Sci. Technol. 35 (2001) 4421.

38 E. M. Thurman, In Organic Geochemistry of Natural Waters, Kluwer Academic, Nijhhoff, Boston (1985).

39 J. Buffle, A. Tessier, and W. Haerdi, In Complexation of Trace Metals in Natural waters (1984). 
40 J. Buffle, K. Wilkinson, S. Stoll, M. Filella and J. Zhang, Environ. Sci. Technol. 32, (1998), 2887.

41 B. Adrian W, Current Separations, 18 (2000) 125.

42 L. Almestrand, D. Jagner, L. Renman, Anal. Chim. Acta 193 (1987) 71.

43 P. Ostapczuk, Clin. Chem. 38 (1992) 1995.

44 D. Jagner, M. Josefson, S. Westerlund, Anal. Chim. Acta 128 (1981) 155.

45 H. Huiliang, D. Jagner, L. Renman, Talanta 34 (1987) 539.

46 M. L. Gozzo, L. Colacicco, C. Callà, G. Barbaresi, R. Parroni, B. Giardina, S. Lippa, Clin. Chim. Acta 285 (1999) 53.

47 D. Jagner, S. Westerlund, Anal. Chim. Acta 117 (1980) 159.

48 M. Fröning, C. Mohl, P. Ostapczuk, Fresenius' J. Anal. Chem. 345 (1993) 233.

49 S. Mannino, M. Bianco, J. Micronutr. Anal. 1 (1985) 47.

50 Y. Li, F. Wahdat, R. Neeb, Fresenius' J. Anal. Chem. 351 (1995) 678.

51 L. G. Danielsson, D. Jagner, M. Josefson, S. Westerlund, Anal. Chim. Acta 127 (1981) 147.

52 D. Jagner, M. Josefson, S. Westerlund, Anal. Chim. Acta 129 (1981) 153.

53 D. Jagner, E. Sahlin, L. Renman, Talanta 41 (1994) 515.

54 R. Cleven, L. Fokkert, Anal. Chim. Acta 289 (1994) 215.

55 H. P. van Leeuwen, R. M. Town, J. Electroanal. Chem. 523 (2002) 16.

56 M. F. Tutunji, Fresenius' J. Anal. Chem. 356 (1996) 90.

57 D. Crowther, V. Rogerson, M. Cooke, Anal. Commun. 33 (1996) 93.

58 C. Yarnitzky, J. Wang, B. Tian, Talanta 51 (2000) 333. 
59 A. M. Green, A. C. Clark and G. R. Scollary, Fresenius' J. Anal. Chem. 358, (1997), 711.

60 A. G. Fogg and J. Wang, Pure Appl. Chem., 71, (1999), 891.

61 P. Ostapczuk, M. Stoeppler and H. W. Dürbeck, Fresenius' Z. Anal. Chem. 332, (1988), 662.

62 H. P. van Leeuwen, R. M. Town, J. Electroanal. Chem. 536 (2002) 129.

63 A. M. A. Mota, J. Buffle, S. P. Kounaves, M. L. S. Goncalves, Anal. Chim. Acta $172(1985) 13$.

64 R. M. Town, H. P. Van Leeuwen, J. Electroanal. Chem. 509 (2001) 58.

65 S. Bubić, M. Branica, Thalassis. Jugoslav. 9 (1973) 47.

66 H. W. Nurnberg, P. Valenta, L. Mart, B. Raspor, L. Sipos, Z. Anal. Chem. 282 (1976) 357.

67 M. Branica, D. M. Novak, S. Bubić, Croat. Chem. Acta 49 (1977) 539.

68 A. Zirino, S. P. Kounaves, Anal. Chem. 49 (1977) 56.

69 M. S. Shuman, J. L. Cromer, Anal. Chem. 51 (1979) 1546.

70 M. Lovrić, M. Branica, Croat. Chem. Acta 53 (1980) 485.

71 S. P. Kounaves, Anal. Chem. 64 (1992) 2998.

72 G. Branica, M. Lovrić, Electrochim. Acta 42 (1996) 1247.

73 M. Lovrić, Electroanalysis 10 (1998) 1022.

74 S. D. Brown, B. R. Kowalski, Anal. Chem. 51 (1979) 2133.

75 S. P. Kounaves, A. Zirino, Anal. Chim. Acta 109 (1979) 327.

76 A. Zirino, S. P. Kounaves, Anal. Chim. Acta 113 (1980) 79. 
77 L. Sipos, P. Valenta, H. W. Nurnberg, M. Branica, in: M. Branica, Z. Konrad (Eds.), Lead in the Marine Environment, Pergamon Press, Oxford, 1980.

78 Š. Komorsky-Lovrić, M. Lovrić, M. Branica, J. Electroanal. Chem. 214 (1986) 37.

79 Š. Komorsky-Lovrić, M. Branica, J. Electroanal. Chem. 226 (1987) 253.

80 P. Croot, J. W. Moffet, G. W. Luther III, Mar. Chem. 67 (1999) 219.

81 M. Vega, R. Pardo, M. M. Herguedas, E. Barrado, Y. Castrillejo, Anal. Chim. Acta 310 (1995) 131.

82 R. M. Town, M. Fillela, J. Electroanal. Chem. 488 (2000) 1.

83 M. Branica, I. Pižeta, I. Marić, J. Electroanal. Chem. 214 (1986) 95.

84 D. Omanović, M. Branica, Croat. Chem. Acta 71 (2) (1998) 421.

85 C. L. Chakrabarti, J. Cheng, W. F. Lee, M. H. Back, W. H. Schroeder, Environ. Sci. Technol. 30 (4) (1996) 1245.

86 Z. Lukaszewski, W. Zembrzuski, A. Piela, Anal. Chim. Acta 318 (1996) 159.

87 J. Buffle, J. J. Vuilleumier, M. L. Tercier, N. Parthasarathy, Sci. Total Environ. 60 (1987) 75 .

88 G. W. Luther III, T. F. Rozan, A. Witter, B. Lewis, Geochem. Trans. 2 (2001) 65.

89 T. F. Rozan, G. W. Luther III, D. Ridge, S. Robinson, Environ. Sci. Technol. 37 (2003) 3845 .

90 R. M. Town, H. P. van Leeuwen, J. Electroanal. Chem. 541 (2003) 51.

91 H. P. van Leeuwen, R. M. Town, J. Electroanal. Chem. 561 (2004) 67.

92 R. M. Town, H. P. van Leeuwen, J. Electroanal. Chem. 573 (2004) 147.

93 D. Omanović, M. Branica, J. Electroanal. Chem. 543 (2003) 83. 
94 D. Omanović, M. Branica, J. Electroanal. Chem. 565 (2004) 37.

95 D. D. DeFord and D. N. Hume, J. Am. Chem. Soc., 73 (1951) 5321.

96 R. F. M. J. Cleven, H. G. De Jong, H. P. Van Leeuwen, J. Electroanal. Chem. 202 (1986) 57.

97 J. P. Pinheiro, H. P. Van Leeuwen, J. Electroanal. Chem. 570 (2004) 79.

98 C. M. G. van den Berg, Anal. Chim. Acta, 250, (1991), 265.

99 H. Emons, Th. Schmd and G. Werner, Anal. Chim. Acta, 228, (1990), 55.

100 C. Leon, H. Emons, P. Ostapczuk and K. Hoppstock, Anal. Chim. Acta, 356, (1997), 99.

101 E. P. Achterberg, C. M. G. van den Berg, M. Boussemart, W. Davison, Geochim. Cosmochim. Acta 61 (1997) 5233.

102 S. H. Khan, C. M. G. van den Berg, Mar. Chem. 27 (1989) 31.

103 M. L. A. M. Campos, C. M. G. van den Berg, Anal. Chim. Acta 284 (1994) 481.

104 M. Nimmo, G. R. Fones, R. Chester, Croat. Chem. Acta 71(1998) 323.

105 K. B. Averyt, J. P. Kim, K. A. Hunter, Limnol. Oceanogr. 49 (2004) 20.

106 E. L. Rue, K. W. Bruland, Mar. Chem. 50 (1995) 117.

107 C. M. G. van den Berg, P. J. M. Buckley, Z. Q. Huang, M. Nimmo, Estuarine, Coastal Shelf Sci. 22 (1986) 479.

108 C. M. G. van den Berg, Z. Q. Huang, J. Electroanal. Chem. 177 (1984) 269.

109 M. R. Twiss, J. W. Moffett, Environ. Sci. Technol. 36 (2002) 1061.

110 W. W. Bedsworth, D. L. Sedlak, Environ. Sci. Technol. 33 (1999) 926.

111 A. M. Bond, D. L. Luscombe, J. Electroanal. Chem. 214 (1986) 21.

112 M. J. Ellwood, C. M. G. van den Berg, Mar. Chem. 75 (2001) 33. 
113 C. M. G. van den Berg, Mar. Chem. 50 (1995) 139.

114 P. L. Croot, M. Johansson, Electroanalysis 12 (2000) 565.

115 C. M. G. van den Berg, Analyst, 114 (1989) 1527.

116 D. L. Olson, M. S. Shuman, Geochim. Cosmochim. Acta 49 (1985) 1371.

117 R. Mandal, M. S. A. Salam, J. Murimboh, N. M. Hassan, C. L. Chakrabarti, M. H. Back, D. C. Gregoire, Environ. Sci. Technol. 34 (2000) 2201.

118 C. L. Chakrabarti, M. H. Back, D. C. Gregoire, W. H. Schroeder, Anal. Chim. Acta 293 (1994) 95.

119 F. M. M. Morel and J. G. Hering, Principles and Applications of Aquatic Chemistry, John Wiley and Sons, New York, USA, 1993.

120 A. M. A. Mota, J. Buffle, S. P. Kounaves, M. L. S. Goncalves, Anal. Chim. Acta $172(1985) 13$.

121 T. M. Florence, Analyst 111 (1986) 489.

122 A. K. Pandey, S. D. Pandey, V. Misra, Ecotoxicology and Environmental Safety, $47(2000) 195$.

123 M. Schnitzer and E. H. Hansen, Soil Sci. 109 (1970) 333.

124 J. G. Hering, F. M. M. Morel, Geochim. Cosmochim. Acta, 53 (1989) 611.

$125 \mathrm{~J}$. G. Hering, S. Kraemer, Environmental chemistry of trace metals. In Perspectives in Environmental Chemistry (D. L. Macalady, Ed.), pp.57-74. Oxford Univ. Press, New York.

126 W. T. De Vries, J. Electroanal. Chem. 9 (1965) 448.

127 W. T. De Vries, E. van Dalen, J. Electroanal. Chem. 14 (1967) 315. 
128 J. Schiewe, K. B. Oldham, J. C. Myland, A. M. Bond, V. A. Vicente-Beckett, S. Fletcher, Anal. Chem. 69 (1997) 2673.

129 D. Omanović, I. Pižeta, Ž. Peharec, M. Branica, Mar. Chem. 53 (1996) 121.

130 J. Wang, B. Tian, Anal. Chem. 65 (1993) 1529.

131 S. Daniele, C. Bragato, M. A. Baldo, J. Wang, J. Lu, Analyst 125 (2000) 731.

132 G. Schulze, E. Han, W. Frenzel, Fresenius' Z. Anal. Chem. 332 (1989) 844.

133 H. J. S. Sand, Philos. Mag. 1 (1901) 45.

134 S. K. Lovric. M. Lovric, M. Branica, J. Electroanal. Chem. 214 (1986) 37.

135 S. K. Lovric and M. Branica, J. Electroanal. Chem. 226 (1987) 253.

136 M. S. Shuman, J. L. Cromer, Anal. Chem. 51 (1979) 1546.

137 J. Koryta, Coll. Czech. Chem. Commun. 24 (1959) 3057.

138 M. S. Shuman, I. Shain, Anal. Chem. 41 (1969) 1818.

139 K. R. Bullock, D. E. Smith, Anal. Chem. 46 (1974) 1069.

140 G. Branica, M. Lovrić, Electrochimica Acta, 42 (1997) 1247.

141 A. E. Martell, R. M. Smith, Critical stability constants, Vols. 1 - 6; Plenum: New York, 1974 - 1989.

142 H. P. Van Leeuwen, H. G. De Jong, K. Holub, J. Electroanal. Chem. 260 (1989) 213.

143 I. Pižeta, G. Billon, D. Omanović, V. Cuculić, C. Garnier, J. C. Fischer, Anal. Chim. Acta, 551 (2005) 65.

144 B. Raspor, P. Valenta, Mar. Chem. 25 (1988) 211.

145 A. M. Mota, J. P. Pinheiro, M. L. S. Goncalves, Wat. Re. 28 (1994) 1285. 
146 J. P. Pinheiro, A. M. Mota, M. L. S. Goncalves, H. P. van Leeuwen, Environ. Sci. Technol. 28 (1994) 2112.

147 M. Ochs, B. Ćosović, W. Stumm, Geochim. Cosmochim. Acta 58 (1994) 639.

148 M. Plavšić, B. Ćosović, Mar. Chem. 36 (1991) 39.

149 J. P. Pinheiro, A. M. Mota, M. L. S. Goncalves, M. van der Weijde, H. P. van Leeuwen, J. Electroanal. Chem. 410 (1996) 61.

150 M. Filella, J. Buffle, H. P. van Leeuwen, Anal. Chim. Acta, 232 (1990) 209.

151 J. D. Ritchie and E. M. Perdue, Geochim. Cosmochim. Acta, 67 (2003) 85.

152 H. P. van Leeuwen, R. M. Town, J. Electroanal. Chem. 556 (2003) 93.

153 H. P. van Leeuwen, R. M. Town, Environ. Sci. Technol. 37 (2003) 3945.

154 J. Buffle and A. Cominoli, J. Electroanal. Chem. 121 (1981) 273.

155 J. Buffle, A. M. Mota and M. L. S. Simoes Goncalves, J. Electroanal. Chem. 223 (1987) 235.

156 J. Buffle, R. S. Altmann and M. Filells, Anal. Chim. Acta, 232 (1990) 225.

157 J. Buffle and R. S. Altmann, in W. Stumm (Ed.), Aquatic Surface Chemistry Chemical Processes at the Particle Water Interface, Wiley, New York, (1987) 351.

158 R. S. Altmann and J. Buffle, Geochim. Cosmochim Acta, 52 (1988) 1505.

159 P. A. Maurice, M. J. Pullin, S. E. Cabaniss, Q. H. Zhou, K. NamjesnikDejanovic, G. R. Aiken, Water Res. 36 (9) (2002) 2357.

160 V. G. Levich, Physicochemical Hydrodynamics, Prentice-Hall, Englewood cliffs, NJ, 1962.

161 M. Schnitzer, Soil Sci. Soc. Am. Proc. 33 (1969) 75. 
162 D. S. Gamble, Can. J. Chem. 48 (1970) 2662.

163 D. S. Gamble and C. H. Langford, Environ. Sci. Technol. 22 (1988) 1325.

164 D. G. Kinniburgh, C. J. Milne, M. F. Benedetti, J. P. Pinheiro, J. Filius, L. K. Koopal, W. H. van Riemsdijk, Environ. Sci. Technol. 30 (1996) 1687.

165 M. F. Benedetti, W. H. van Riemsdijk, L. K. Koopal, D. G. Kinniburgh, D. C Gooddy, C. J. Milne, Geochim. Cosmochim. Acta 60 (1996) 2503.

166 I. Christl, C. J. Milne, D. G. Kinniburgh, R. Kretzschmar, Environ. Sci. Technol. 35 (2001) 2512.

167 J. P. Pinheiro, A. M. Mota, M. L. S. Goncalves, Anal. Chim. Acta 284 (1994) 525.

168 G. Abate, J. C. Masini, Org. Geochem. 33 (2002) 1171.

169 M. Filella, R. M. Town, Environ. Chem. (2005) 121.

170 R. M. Town, M. Filella, Sci. Total Environ. 300 (2002) 143.

171 C. H. Langford, D. W. Gutzman, Anal. Chim. Acta, 256 (1992) 183.

172 I. I. Fasfous, T. Yapici, C. L. Chakrabarti, N. M. Hassan, M. H. Back, J. Murimboh, D. R. S. Lean and D. C. Grégoire. Environ. Sci. Technol. 38 (2004) 4979.

173 K.B. Oldham, J. C. Myland, Fundamentals of Electrochemical Science, Academic Press, San Diego, (1994).

174 K. J. Powell, Mini-SCDatabase, UK (2000).

175 M. Filella, H. P. van Leeuwen, J. Buffle and K. Holub, J. Electroanal. Chem. 485 (2000) 144

176 M. Filella, R. M. Town, Fresenius J. Anal. Chem. 370 (2001) 413. 
177 J. Buffle, M. Filella, Anal. Chim. Acta, 313 (1995) 144.

178 R. H. Byrne, L. R. Kump, K. J. Cantrell, Mar. Chem. 25 (1988) 163.

179 R. Al-Farawati, C. M. G. van den Berg, Mar. Chem. 63 (1999) 331.

180 R. F. Breault, J. A. Colman, G. R. Aiken, D. Mcknight, Environ. Sci. Technol. 30 (1996) 3477.

181 H. Xue, L. Sigg, Aquat. Geochem. 5 (1999) 313.

182 M. L. Wells, P. B. Kozelka, K. W. Bruland, Mar. Chem. 62 (1998) 203.

183 J. W. Moffett, L. E. Brand, Limnol. Oceanogr. 41 (1996) 388.

184 A. J. Ringbom, Complexation in Analytical Chemistry, Interscience, New York, N. Y. 1963.

185 R. Town, H. P. Van Leeuwen, J. Electroanal. Chem. 523 (2002) 1.

186 I. Ružić, Anal. Chim. Acta 140 (1982) 99.

187 C. M. G. van den Berg, Mar. Chem. 15 (1984) 1.

188 I. Ružić, Kinetics of complexation and determination of complexation parameters in natural waters, in Complexation of trace metals in natural waters, ed. C. J. M. Kramer and J. C. Duinker, Dr W Junk Publishers, The Hague, (1983), pp. 131147.

189 C. M. G. van den Berg and J. R. Donat, Anal. Chim. Acta, 257 (1992) 281.

190 Y. K. Chau and K. Lum Shue Chan, Water Res., 8 (1974) 383.

191 C. M. G. van den Berg, A. G. A. Merks, E. K. Duursma, Estuar. Coast. Mar. Sci. $24(1987) 785$.

192 B. Willy, G. Leo, M. Frank, E. Marc, Hydrobiologia, 366 (1998) 81.

193 D. F. Cameron, M. L. Sohn, Sci. Tot. Environ. 113 (1992) 121. 
194 Y. Cao, M. Conklin, E. Betterton, Environ. Health Perspect 103 (1995) 29.

195 R. F. C. Mantoura, D. Andrew, J. P. Riley, Estuarine and Coast. Mar. Sci. 6 (1978) 387.

196 J. Riggle, R. von Wandruszka, Talanta, 62 (2004) 103.

197 K. W. Burland, Limnology and Oceanography, 34 (1989) 269.

198 J. R. Donat, K. W. Bruland, Mar. Chem. 28 (1990) 301.

199 M. J. Ellwood, C. M. G. van den Berg, Mar. Chem. 68 (2000) 295.

200 M. J. Ellwood, Mar. Chem. 87 (2004) 37.

201 G. Roesijadi, W. E. Robinson, Metal regulation in aquatic animals: Mechanism of uptake, accumulation, and release. In D. C. Malins, G. K. Ostrander, eds, Aquatic Toxicology. Molecular, Biochemical and Cellular Perspectives, CRC, Boca Raton, FL, USA, 1994, pp. 387-420.

202 P. G. G. Campbell, O. Errécalde, C. Fortin, V. P. Hiriart-Baer and B. Vigneault, Comparative Biochemistry and Physiology, 2002, Part C 133, 189.

203 F. M. M. Morel, J. G. Hering, Principles and Applications of Aquatic Chemistry, John Wiley, New York, 1993. 


\section{APPENDIX}

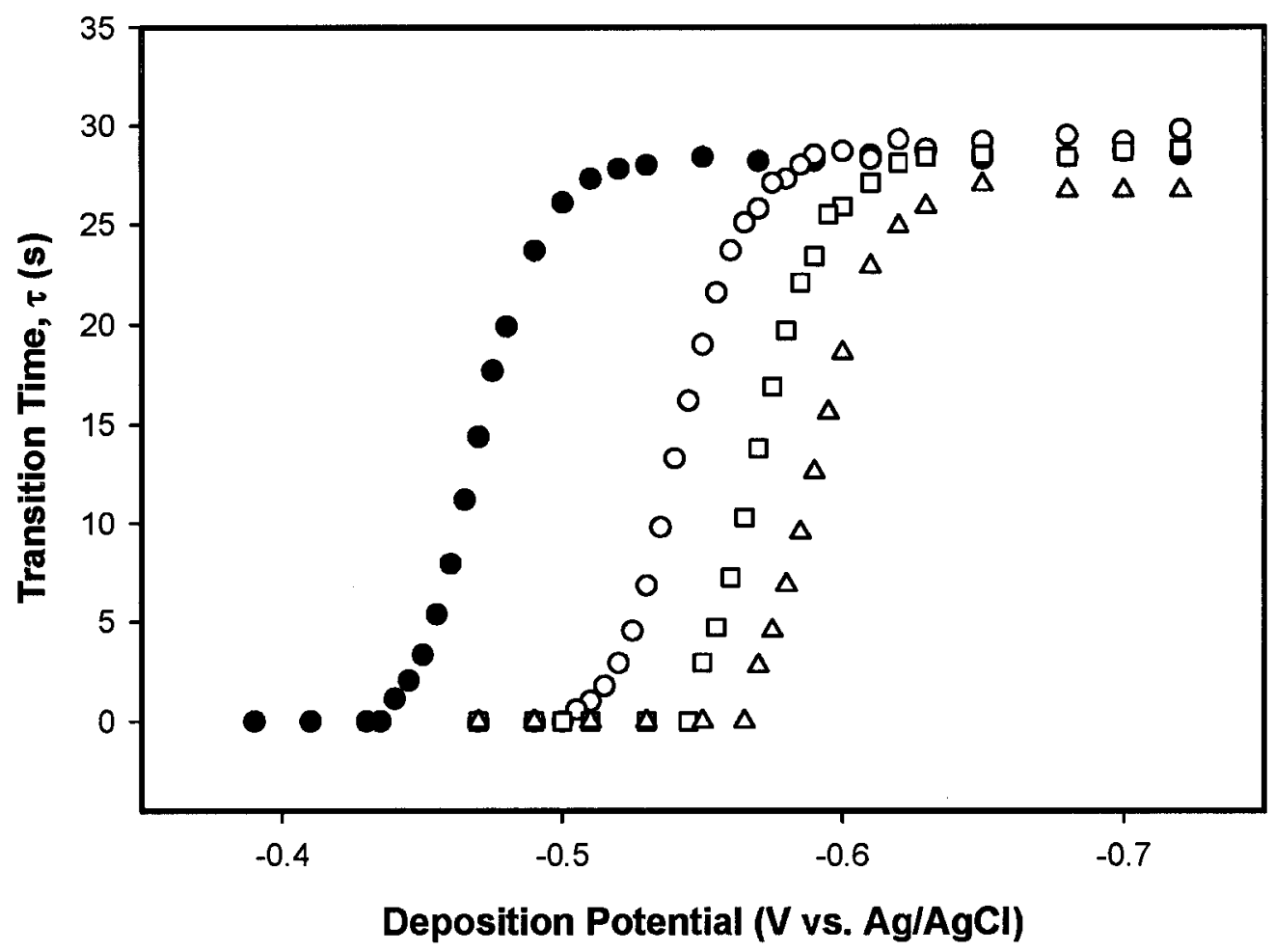

Figure A1 Experimentally determined depletive SSCP curves for $\mathrm{Pb}$ (II) in the presence of different concentrations of PDCA at SMDE. Curves correspond to (•) $2 \mathrm{x}$ $10^{-7} \mathrm{M} \mathrm{Pb}(\mathrm{II}) ;(\mathrm{O}) 2 \times 10^{-7} \mathrm{M} \mathrm{Pb}(\mathrm{II}), 2 \times 10^{-6} \mathrm{M}$ PDCA; (ㅁ) $2 \times 10^{-7} \mathrm{M}$ $\mathrm{Pb}(\mathrm{II}), 2 \times 10^{-5} \mathrm{M} \operatorname{PDCA} ;(\Delta) 2 \times 10^{-7} \mathrm{M} \mathrm{Pb}(\mathrm{II}), 1 \times 10^{-4} \mathrm{M}$ PDCA. Deposition time $120 \mathrm{~s}$, stripping current $1 \times 10^{-9} \mathrm{~A}$, ionic strength $0.1 \mathrm{M}, \mathrm{pH}$ $4.8 \pm 0.1, \mathrm{~T}=23 \pm 2{ }^{\circ} \mathrm{C}$. 


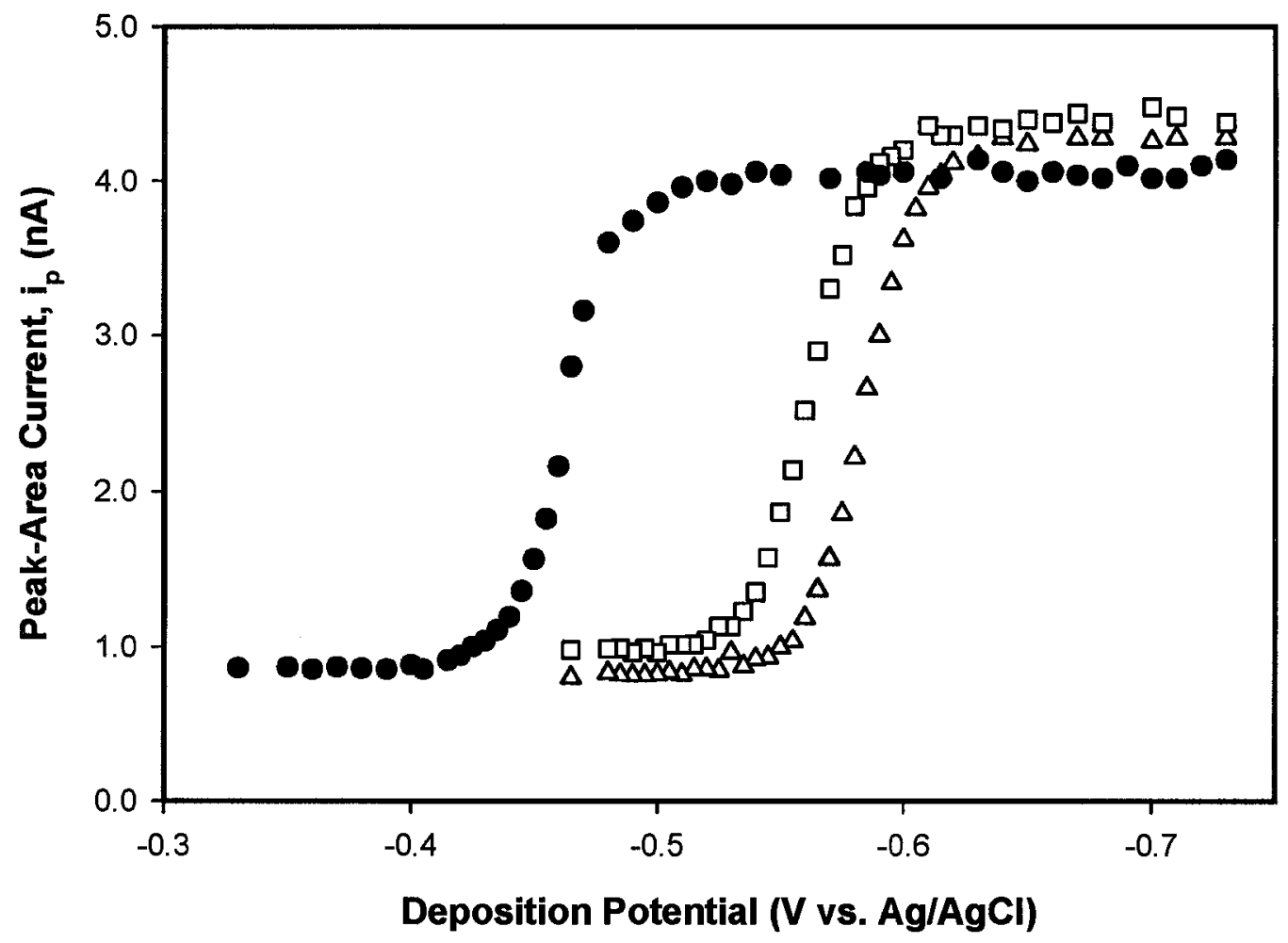

Figure A2 Experimentally determined pseudopolarograms for $\mathrm{Pb}(\mathrm{II})$ in the presence of different concentrations of PDCA at SMDE. Curves correspond to (•) $2 \mathrm{x}$ $10^{-7} \mathrm{M} \mathrm{Pb}(\mathrm{II}) ;(\square) 2 \times 10^{-7} \mathrm{M} \mathrm{Pb}(\mathrm{II}), 2 \times 10^{-5} \mathrm{M}$ PDCA; $(\Delta) 2 \times 10^{-7} \mathrm{M} \mathrm{Pb}(\mathrm{II})$, $1 \times 10^{-4} \mathrm{M}$ PDCA. Deposition time $120 \mathrm{~s}$, scan rate $0.0102 \mathrm{~V} / \mathrm{s}$, ionic strength $0.1, \mathrm{pH} 4.8 \pm 0.1, \mathrm{~T}=23 \pm 2{ }^{\circ} \mathrm{C}$. 


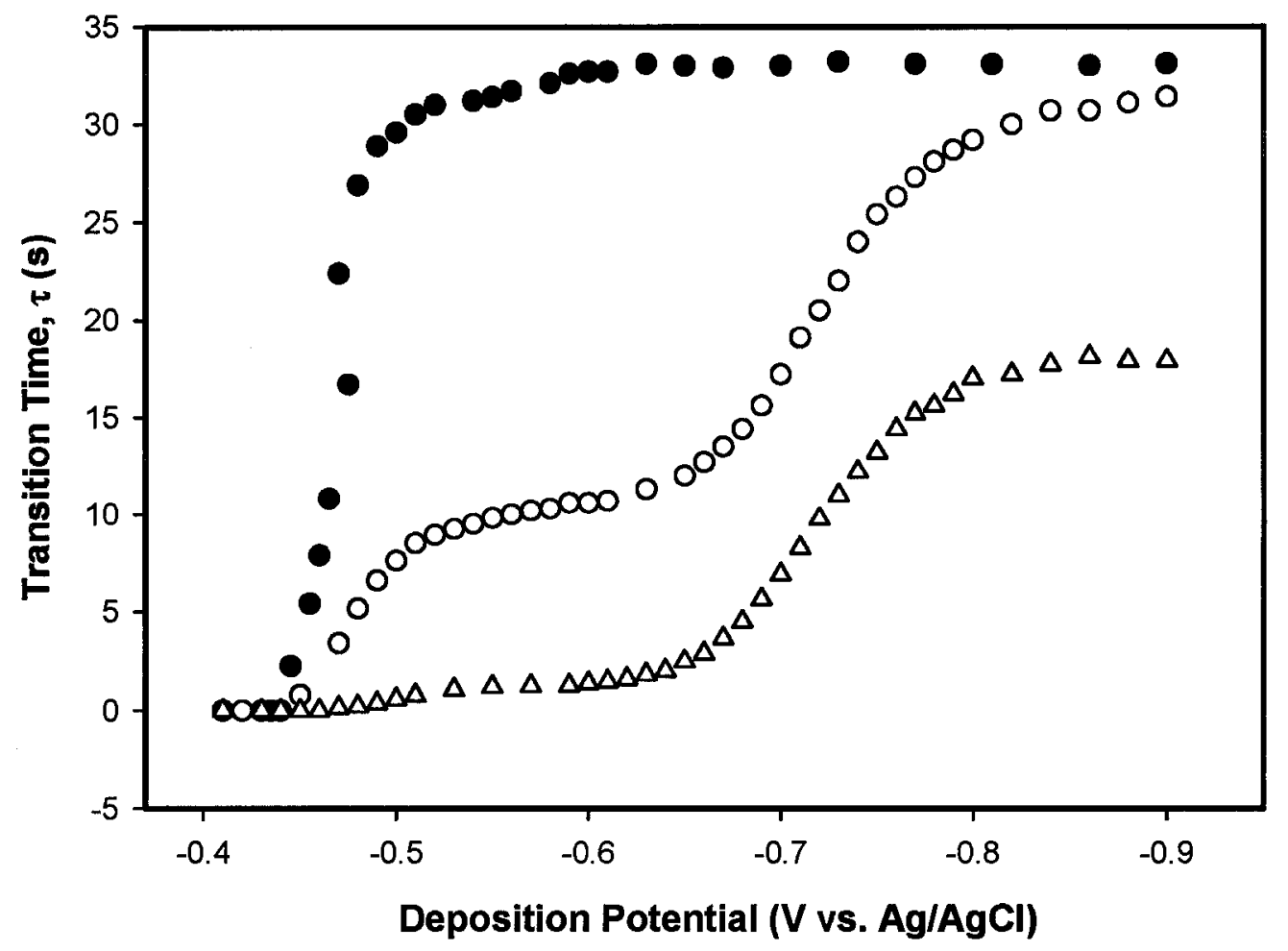

Figure A3 Experimentally determined depletive SSCP curves for $\mathrm{Pb}(\mathrm{II})$ in the presence of different concentrations of NTA at SMDE. Curves correspond to $(\bullet) 2 \mathrm{x}$ $10^{-7} \mathrm{M} \mathrm{Pb}(\mathrm{II}) ;(0) 2 \times 10^{-7} \mathrm{M} \mathrm{Pb}(\mathrm{II}), 2 \times 10^{-6} \mathrm{M} \mathrm{NTA} ;(\Delta) 2 \times 10^{-7} \mathrm{M} \mathrm{Pb}(\mathrm{II})$, $1 \times 10^{-4} \mathrm{M}$ NTA. Deposition time 120 s, stripping current $1 \times 10^{-9} \mathrm{~A}$, ionic strength $0.1 \mathrm{M}, \mathrm{pH} 4.8 \pm 0.1, \mathrm{~T}=23 \pm 2^{\circ} \mathrm{C}$. 


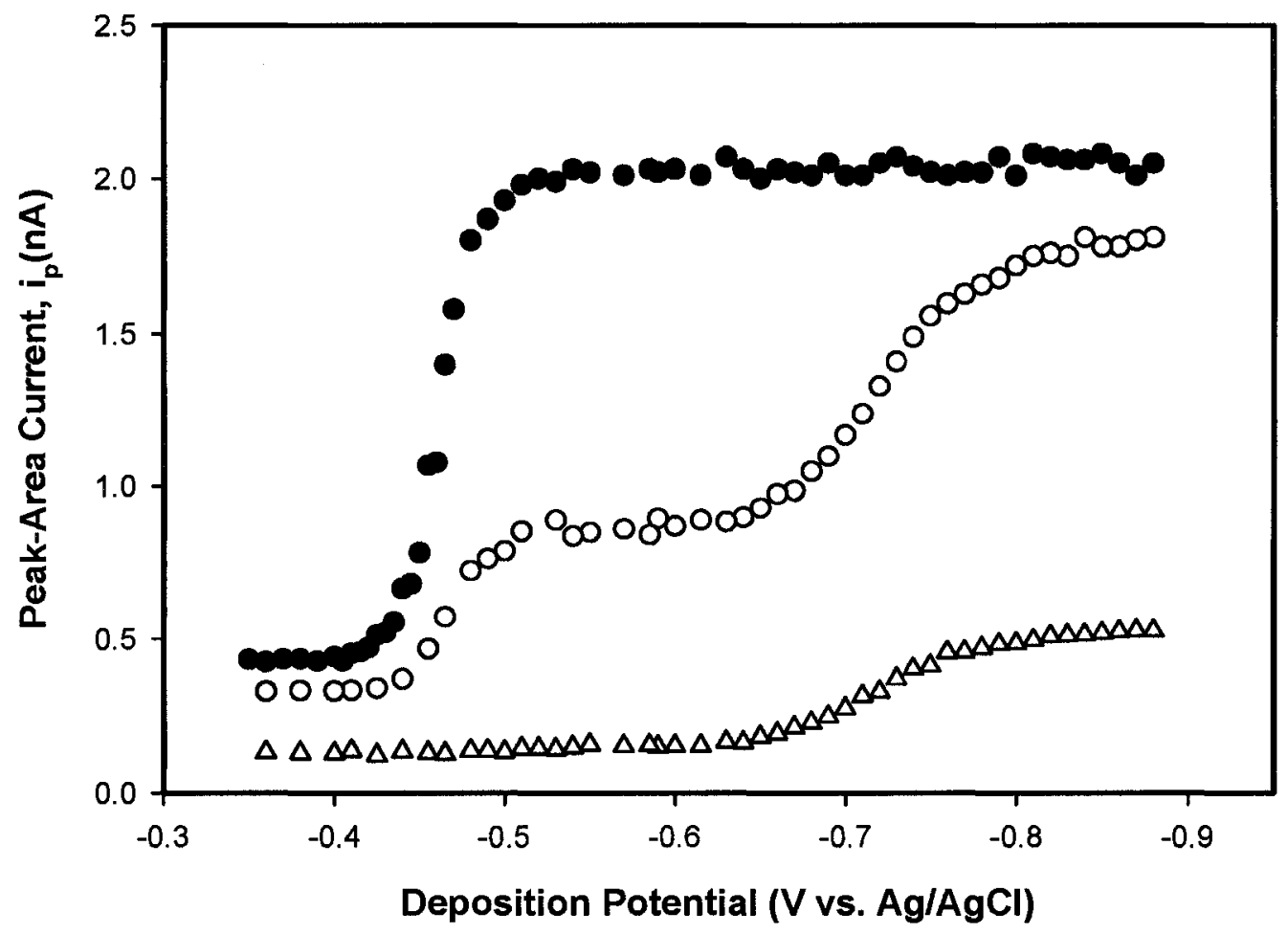

Figure A4 Experimentally determined pseudopolarograms of $\mathrm{Pb}$ (II) in the presence of different concentrations of NTA at SMDE. Curves correspond to $(\bullet) 2 \times 10^{-7}$ $\mathrm{M} \mathrm{Pb}(\mathrm{II}) ;(\mathrm{O}) 2 \times 10^{-7} \mathrm{M} \mathrm{Pb}(\mathrm{II}), 2 \times 10^{-6} \mathrm{M}$ NTA; $(\Delta) 2 \times 10^{-7} \mathrm{M} \mathrm{Pb}(\mathrm{II}), 1 \times$ $10^{-4} \mathrm{M}$ NTA. Deposition time $120 \mathrm{~s}$, scan rate $0.0102 \mathrm{~V} / \mathrm{s}$, ionic strength $0.1 \mathrm{M}, \mathrm{pH} 4.8 \pm 0.1, \mathrm{~T}=23 \pm 2^{\circ} \mathrm{C}$ 


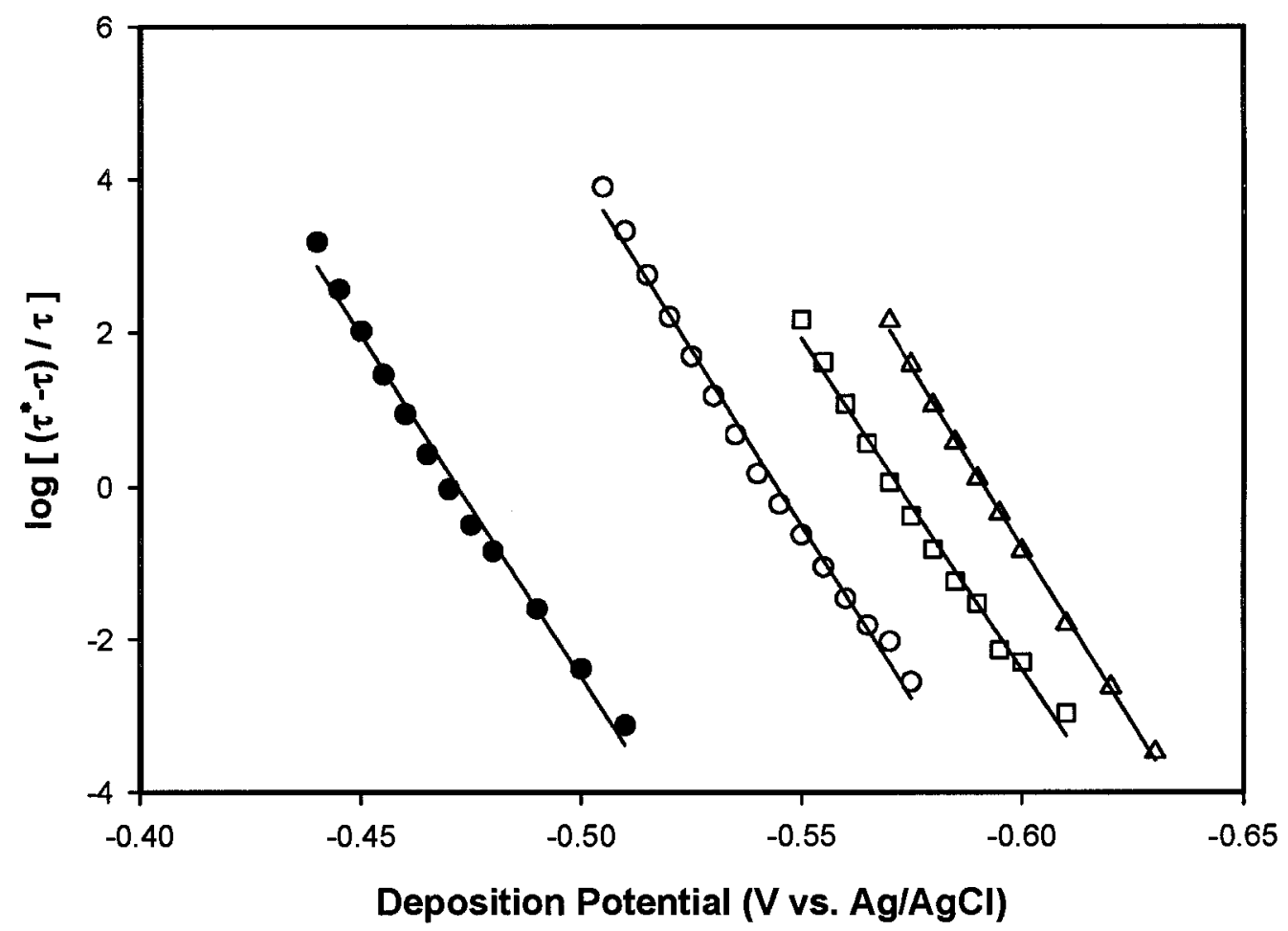

Figure A5 Log analysis of SSCP curves for $\mathrm{Pb}(\mathrm{II})$ in the presence of different concentrations of PDCA shown in Figure Al. Lines are shown for $(\bullet) 2 \times 10^{-7}$ $\mathrm{M} \mathrm{Pb}(\mathrm{II}) ;(\mathrm{O}) 2 \times 10^{-7} \mathrm{M} \mathrm{Pb}(\mathrm{II}), 2 \times 10^{-6} \mathrm{M}$ PDCA; () $2 \times 10^{-7} \mathrm{M} \mathrm{Pb}(\mathrm{II}), 2 \times$ $10^{-5} \mathrm{M} \operatorname{PDCA} ;(\Delta) 2 \times 10^{-7} \mathrm{M} \mathrm{Pb}(\mathrm{II}), 1 \times 10^{-4} \mathrm{M}$ PDCA. Solid lines indicate the regions of steepest slope at the foot of the waves with slope $38.9 \mathrm{~V}^{-1}$. 


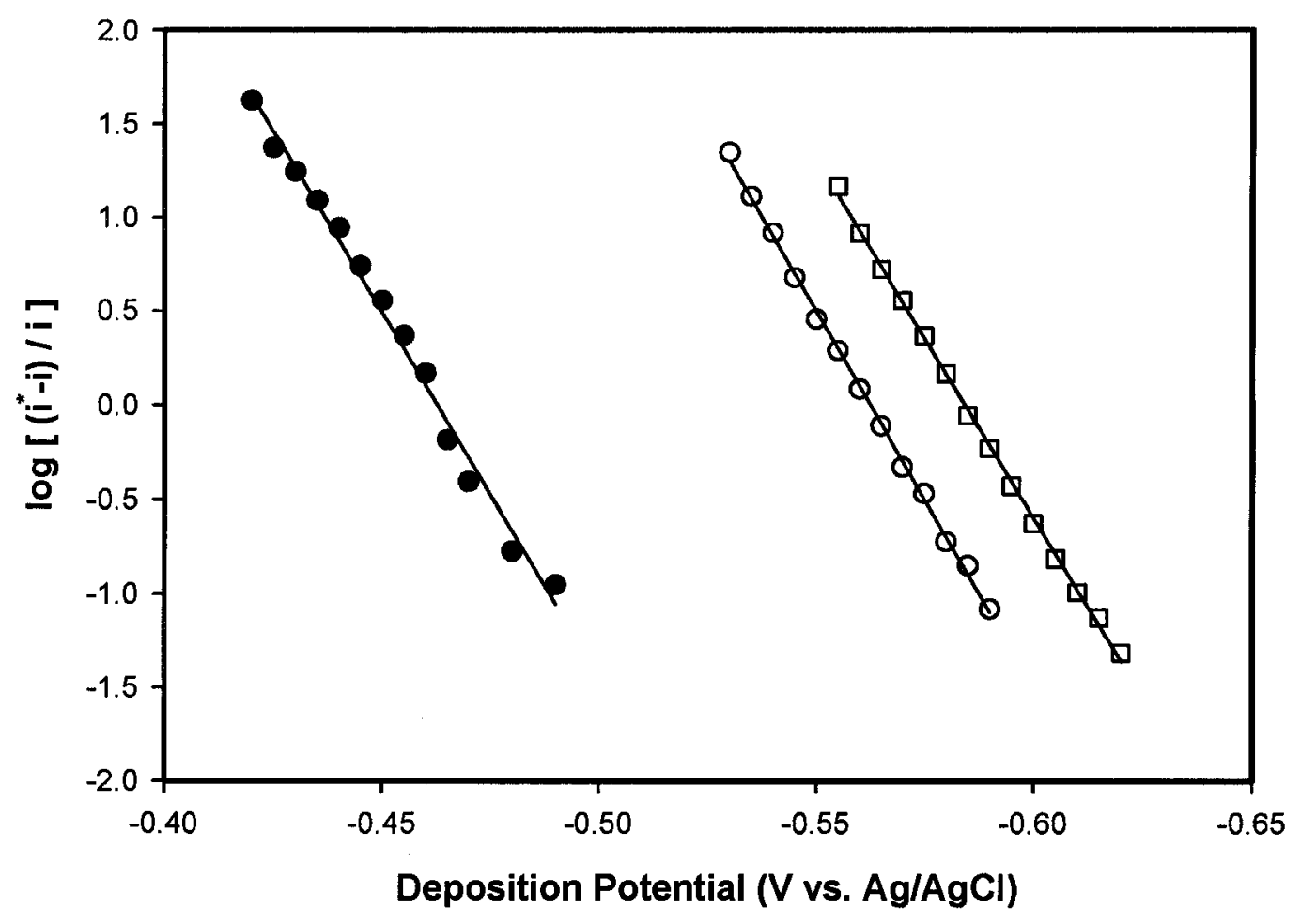

Figure A6 Log analysis of pseudopolarograms for $\mathrm{Pb}(\mathrm{II})$ in the presence of different concentrations of PDCA shown in Figure A2. Lines are shown for $(\bullet) 2 \times 10^{-7}$ $\mathrm{M} \mathrm{Pb}(\mathrm{II}) ;(\mathrm{O}) 2 \times 10^{-7} \mathrm{M} \mathrm{Pb}(\mathrm{II}), 2 \times 10^{-5} \mathrm{M}$ PDCA; (ㅁ) $2 \times 10^{-7} \mathrm{M} \mathrm{Pb}(\mathrm{II}), 1 \times$ $10^{-4} \mathrm{M}$ PDCA. Solid lines indicate the regions of steepest slope at the foot of the waves with slope $38.9 \mathrm{~V}^{-1}$. 


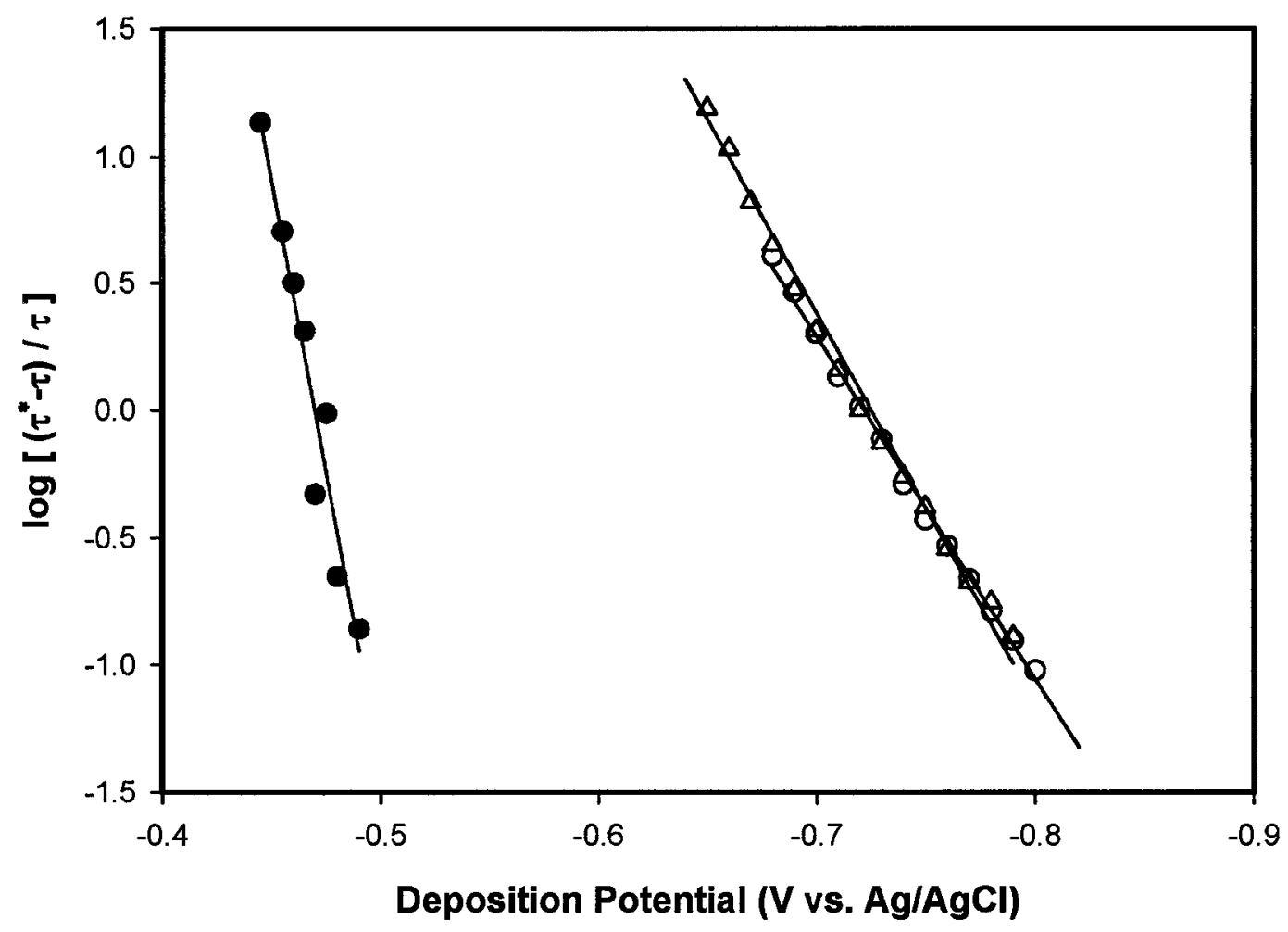

Figure $\mathbf{A} 7$ Log analysis of SSCP curves for $\mathrm{Pb}$ (II) in the presence of different concentrations of NTA shown in Figure A3. Lines are shown for $(\bullet) 2 \times 10^{-7}$ $\mathrm{M} \mathrm{Pb}(\mathrm{II}) ;(\circ) 2 \times 10^{-7} \mathrm{M} \mathrm{Pb}(\mathrm{II}), 2 \times 10^{-6} \mathrm{M}$ NTA; $(\Delta) 2 \times 10^{-7} \mathrm{M} \mathrm{Pb}(\mathrm{II}), 1 \times 10^{-}$ ${ }^{4}$ M NTA. Solid lines indicate the regions of steepest slop at the foot of the waves. 


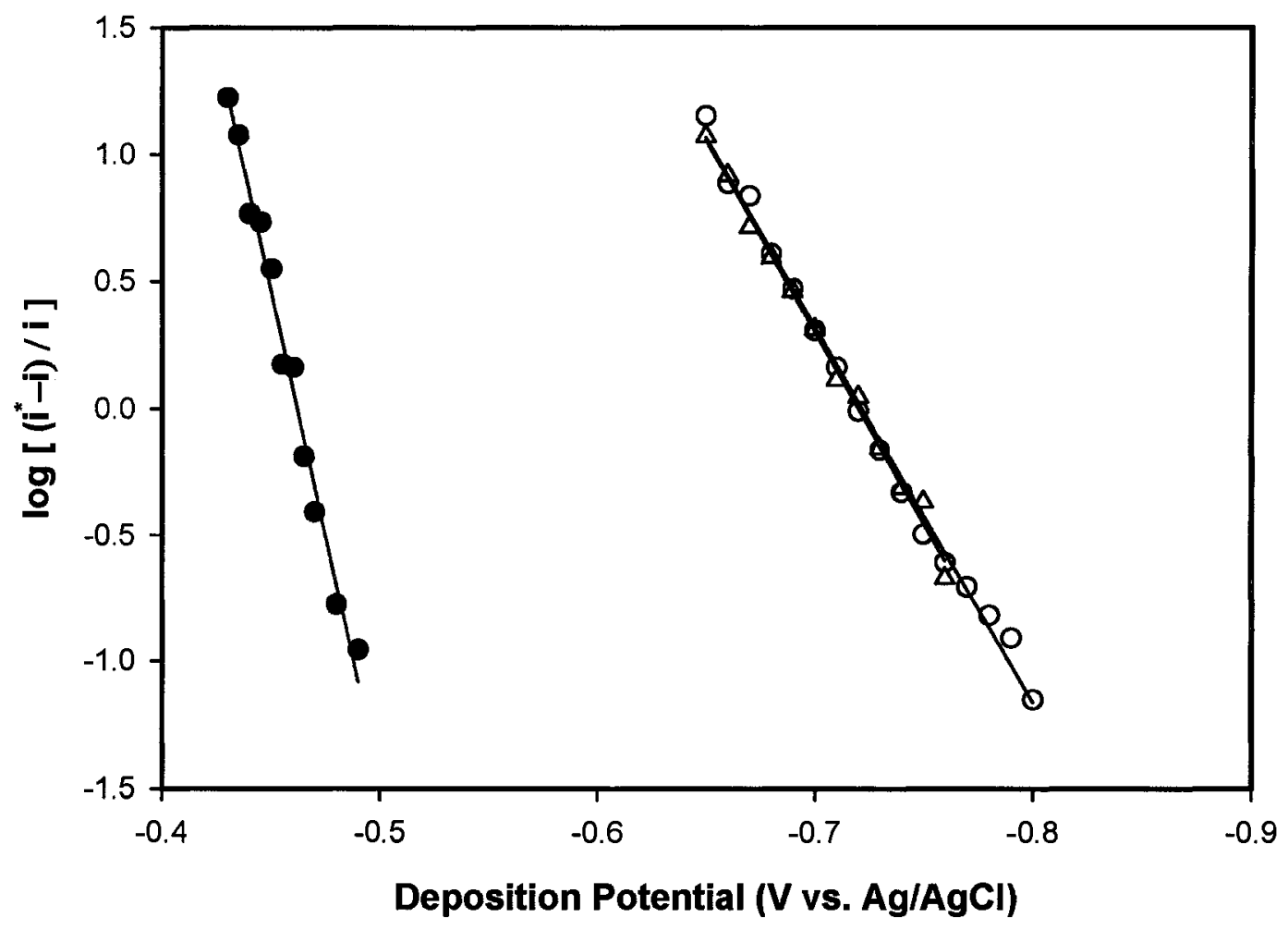

Figure A8 $\mathrm{Log}$ analysis of pseudopolarograms for $\mathrm{Pb}(\mathrm{II})$ in the presence of different concentrations of NTA shown in Figure A4. Lines are shown for $(\bullet) 2 \times 10^{-7}$ $\mathrm{M} \mathrm{Pb}(\mathrm{II}) ;(\mathrm{O}) 2 \times 10^{-7} \mathrm{M} \mathrm{Pb}(\mathrm{II}), 2 \times 10^{-6} \mathrm{MNTA} ;(\Delta) 2 \times 10^{-7} \mathrm{M} \mathrm{Pb}(\mathrm{II}), 1 \times 10^{-}$ ${ }^{4}$ M NTA. Solid lines indicate the regions of steepest slope at the foot of the waves. 


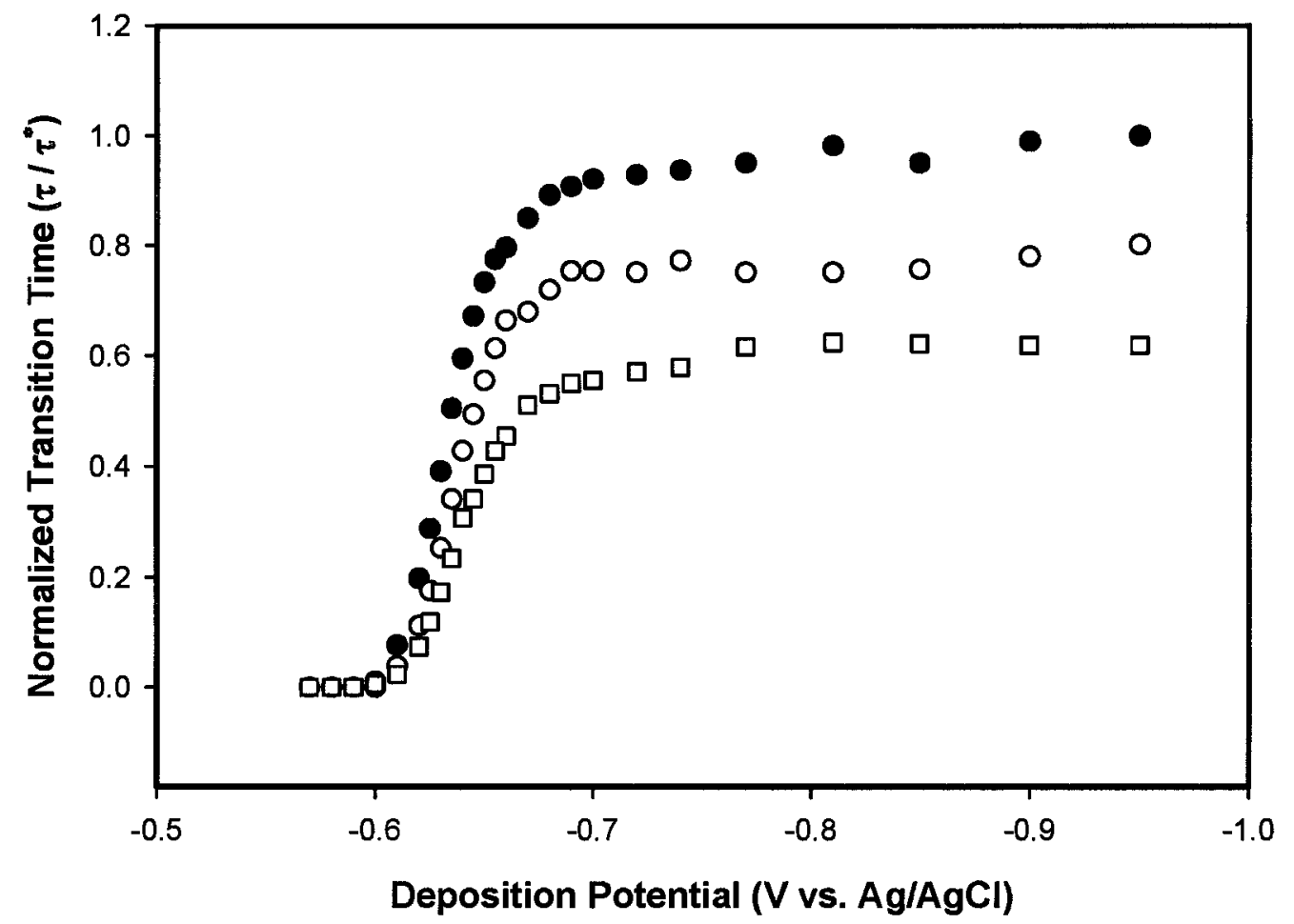

Figure B1 Experimentally determined depletive SSCP curves for Cd(II) in the presence of different concentrations of SRFA at SMDE. Curves correspond to $(\bullet) 2 \mathrm{x}$ $10^{-7} \mathrm{M} \mathrm{Cd}(\mathrm{II}) ;\left(\right.$ ) $2 \times 10^{-7} \mathrm{M} \mathrm{Cd}(\mathrm{II}), 8 \times 10^{-5} \mathrm{M}$ SRFA; () $2 \times 10^{-7} \mathrm{M}$ $\mathrm{Cd}(\mathrm{II}), 2 \times 10^{-4} \mathrm{M}$ SRFA. Deposition time $120 \mathrm{~s}$, stripping current $1 \times 10^{-9}$ A, ionic strength $0.1 \mathrm{M}, \mathrm{pH} 4.8 \pm 0.1, \mathrm{~T}=23 \pm 2^{\circ} \mathrm{C}$. 


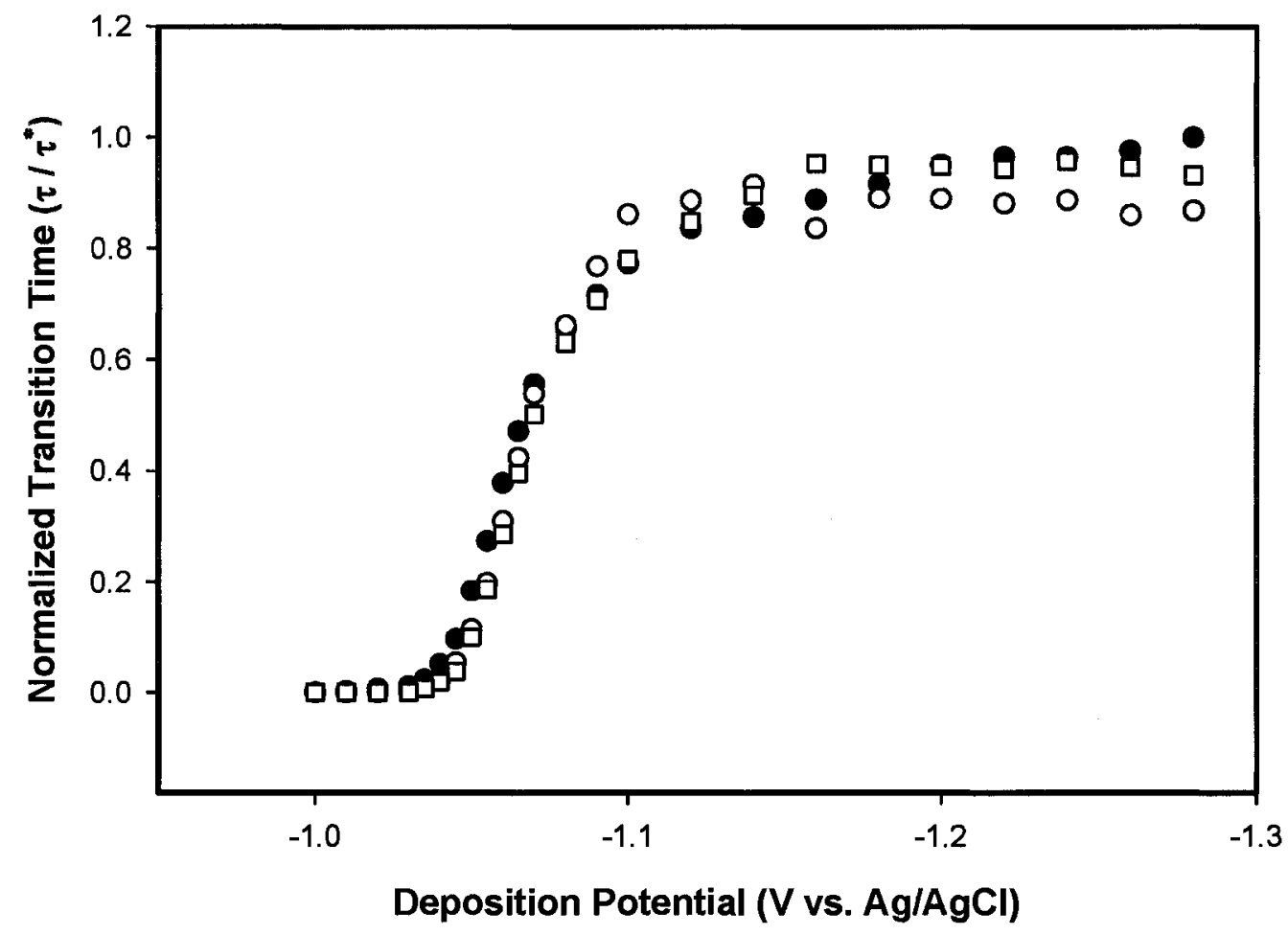

Figure B2 Experimentally determined depletive SSCP curves for $\mathrm{Zn}(\mathrm{II})$ in the presence of different concentrations of SRFA at SMDE. Curves correspond to $(\bullet) 2 \mathrm{x}$ $10^{-7} \mathrm{M} \mathrm{Zn(II);(O)} 2 \times 10^{-7} \mathrm{M} \mathrm{Zn}(\mathrm{II}), 8 \times 10^{-5} \mathrm{M} \mathrm{SRFA}$; (口) $2 \times 10^{-7} \mathrm{M} \mathrm{Zn}(\mathrm{II})$, $2 \times 10^{-4} \mathrm{M}$ SRFA. Deposition time $120 \mathrm{~s}$, stripping current $1 \times 10^{-9} \mathrm{~A}$, ionic strength $0.1 \mathrm{M}, \mathrm{pH} 4.8 \pm 0.1, \mathrm{~T}=23 \pm 2^{\circ} \mathrm{C}$. 


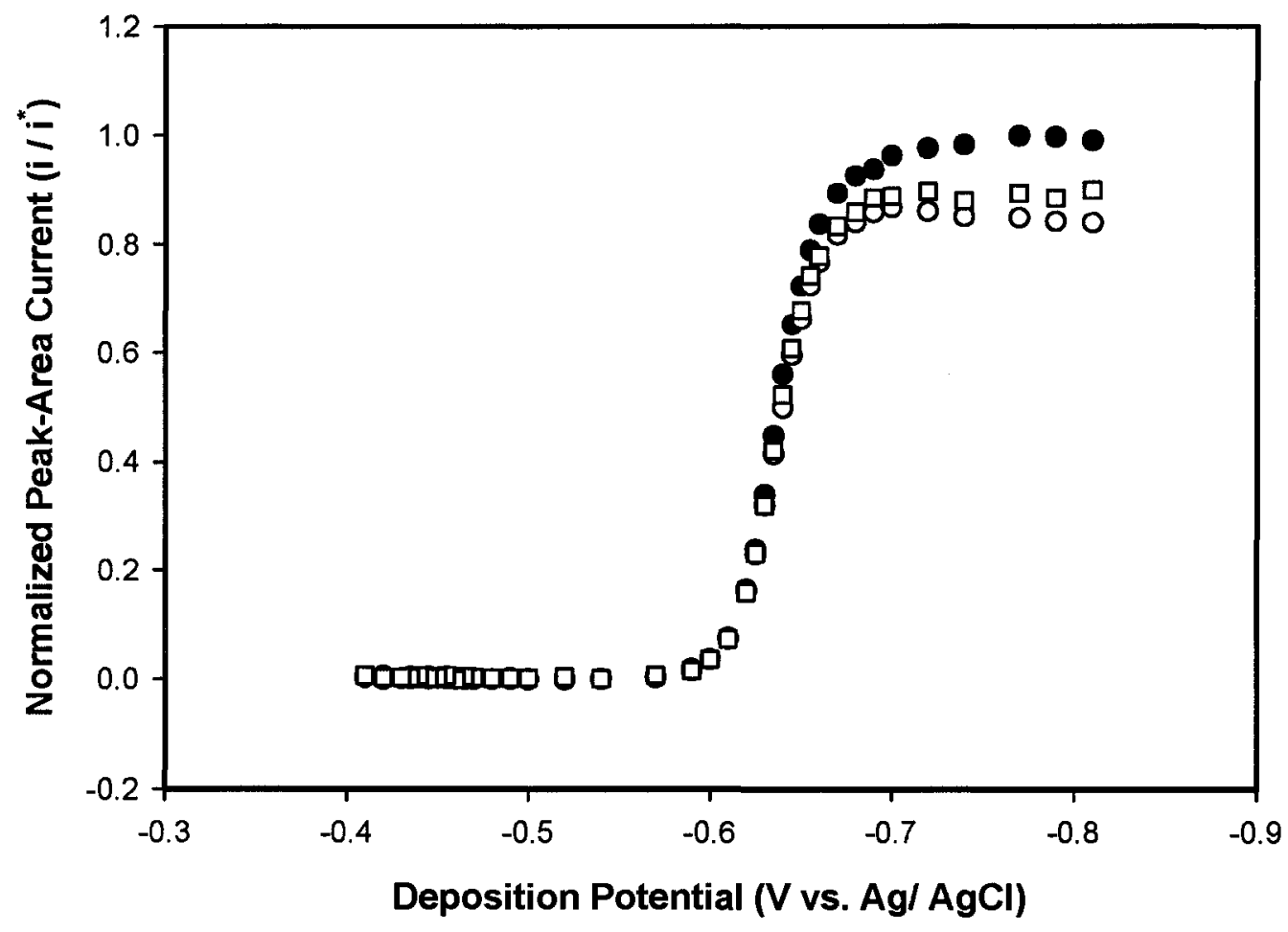

Figure B3 Experimentally determined pseudopolarograms for Cd(II) in the presence of different concentrations of SRFA at SMDE. Curves correspond to $(\bullet) 2 \times$ $10^{-7} \mathrm{M} \mathrm{Cd}(\mathrm{II}) ;(\circ) 2 \times 10^{-7} \mathrm{M} \mathrm{Cd}(\mathrm{II}), 8 \times 10^{-5} \mathrm{M}$ SRFA; () $2 \times 10^{-7} \mathrm{M}$ $\mathrm{Cd}(\mathrm{II}), 2 \times 10^{-4} \mathrm{M}$ SRFA. Deposition time $120 \mathrm{~s}$, scan rate $0.0102 \mathrm{~V} / \mathrm{s}$, ionic strength $0.1 \mathrm{M}, \mathrm{pH} 4.8 \pm 0.1, \mathrm{~T}=23 \pm 2^{\circ} \mathrm{C}$. 


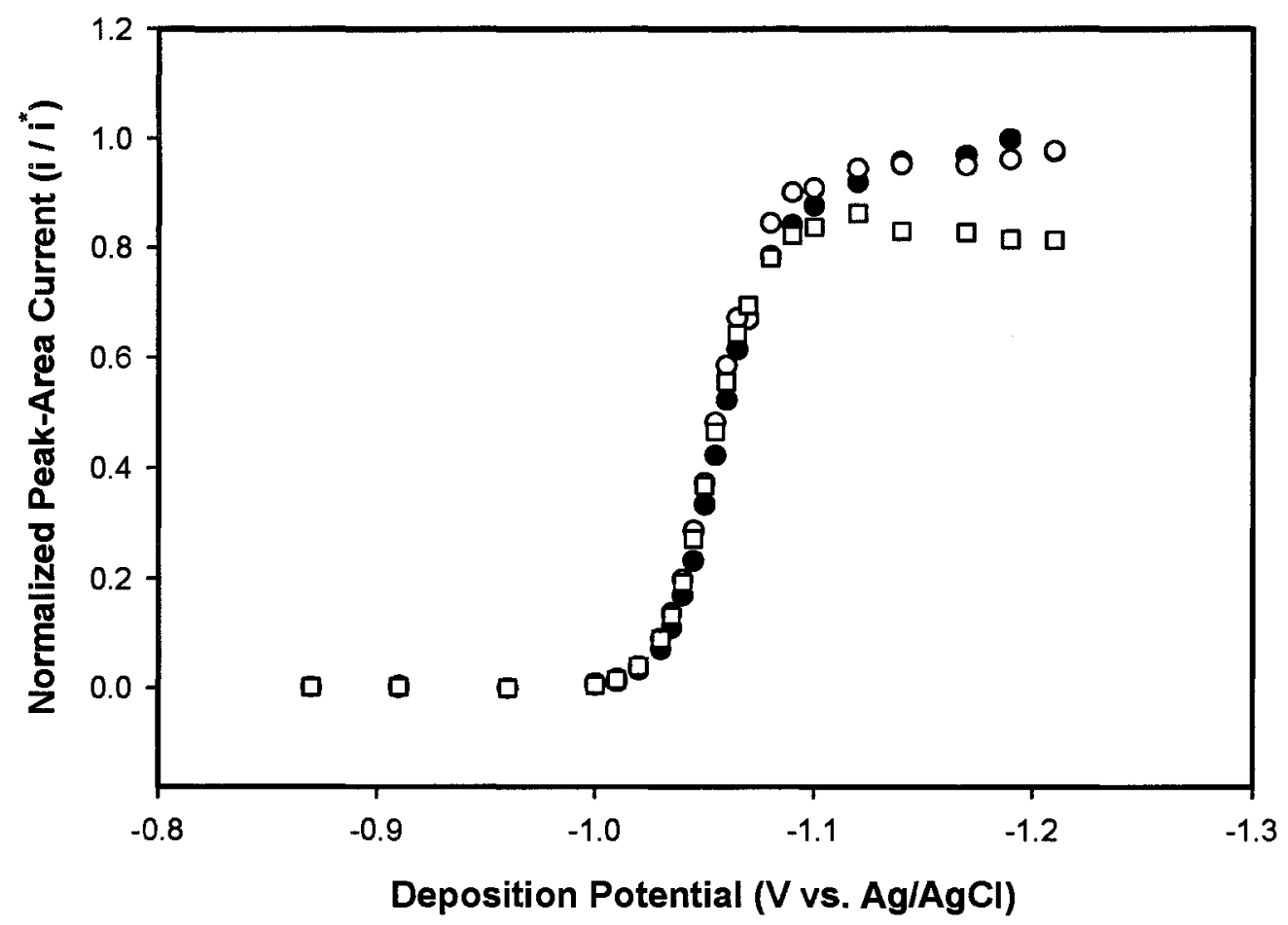

Figure B4 Experimentally determined pseudopolarograms for $\mathrm{Zn}$ (II) in the presence of different concentrations of SRFA at SMDE. Curves correspond to (•) $2 \times$ $10^{-7} \mathrm{M} \mathrm{Zn(II);(O)} 2 \times 10^{-7} \mathrm{M} \mathrm{Zn(II),} 8 \times 10^{-5} \mathrm{M}$ SRFA; () $2 \times 10^{-7} \mathrm{M} \mathrm{Zn(II),}$ $2 \times 10^{-4}$ M SRFA. Deposition time $120 \mathrm{~s}$, scan rate $0.0102 \mathrm{~V} / \mathrm{s}$, ionic strength $0.1 \mathrm{M}, \mathrm{pH} 4.8 \pm 0.1, \mathrm{~T}=23 \pm 2^{\circ} \mathrm{C}$. 

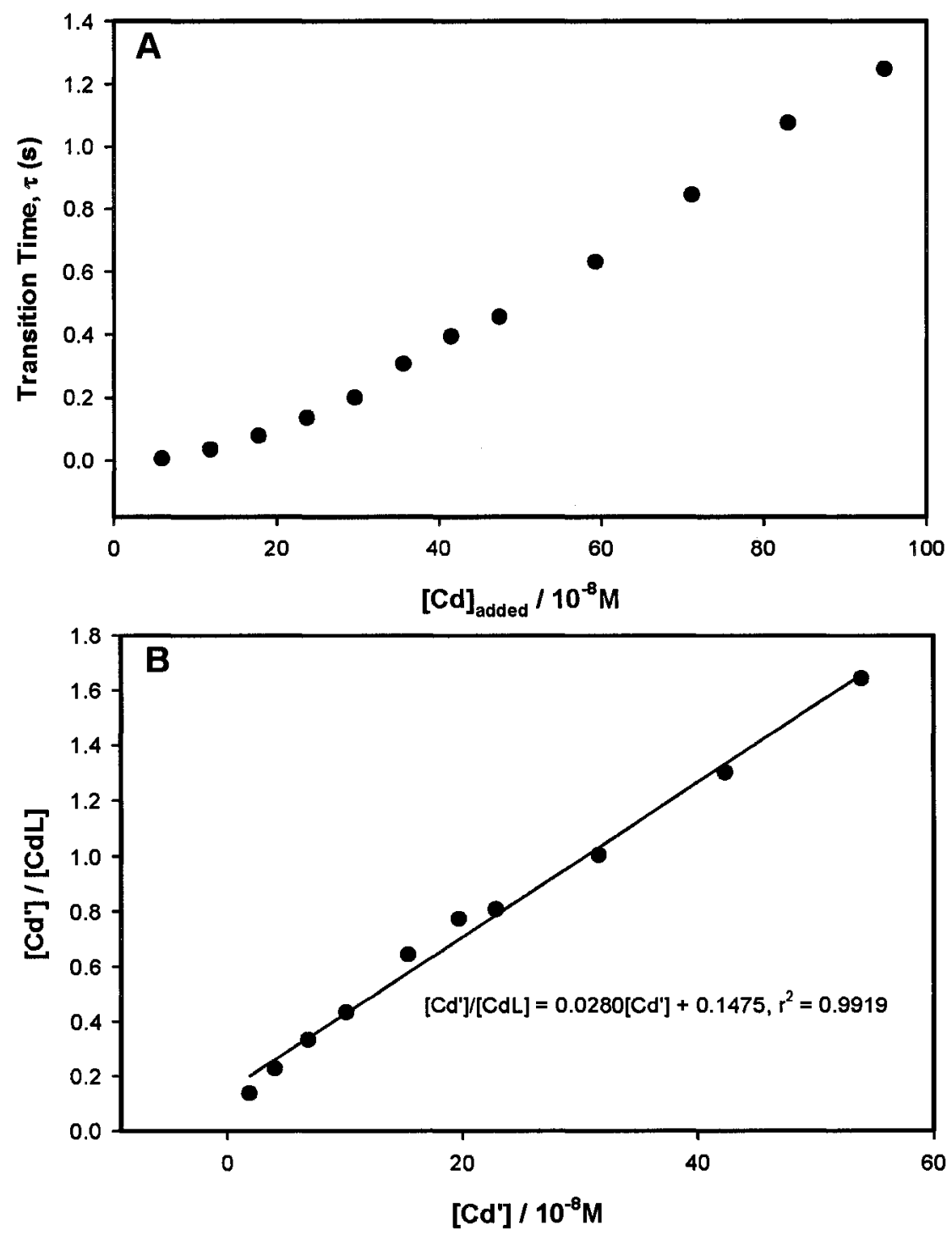

Figure C1 Complexometric titration of DOC in Copper Cliff Mine 100\% effluent water sample with $\mathrm{Cd}(\mathrm{II})$ by Stripping Chronopotentiometry: (A) titration curve of Cd-DOC; (B) Langmuir transformation of the titration data from (A). $\mathrm{pH}=$ $7.30 \pm 0.05, \mathrm{~T}=23 \pm 2^{\circ} \mathrm{C}$. 

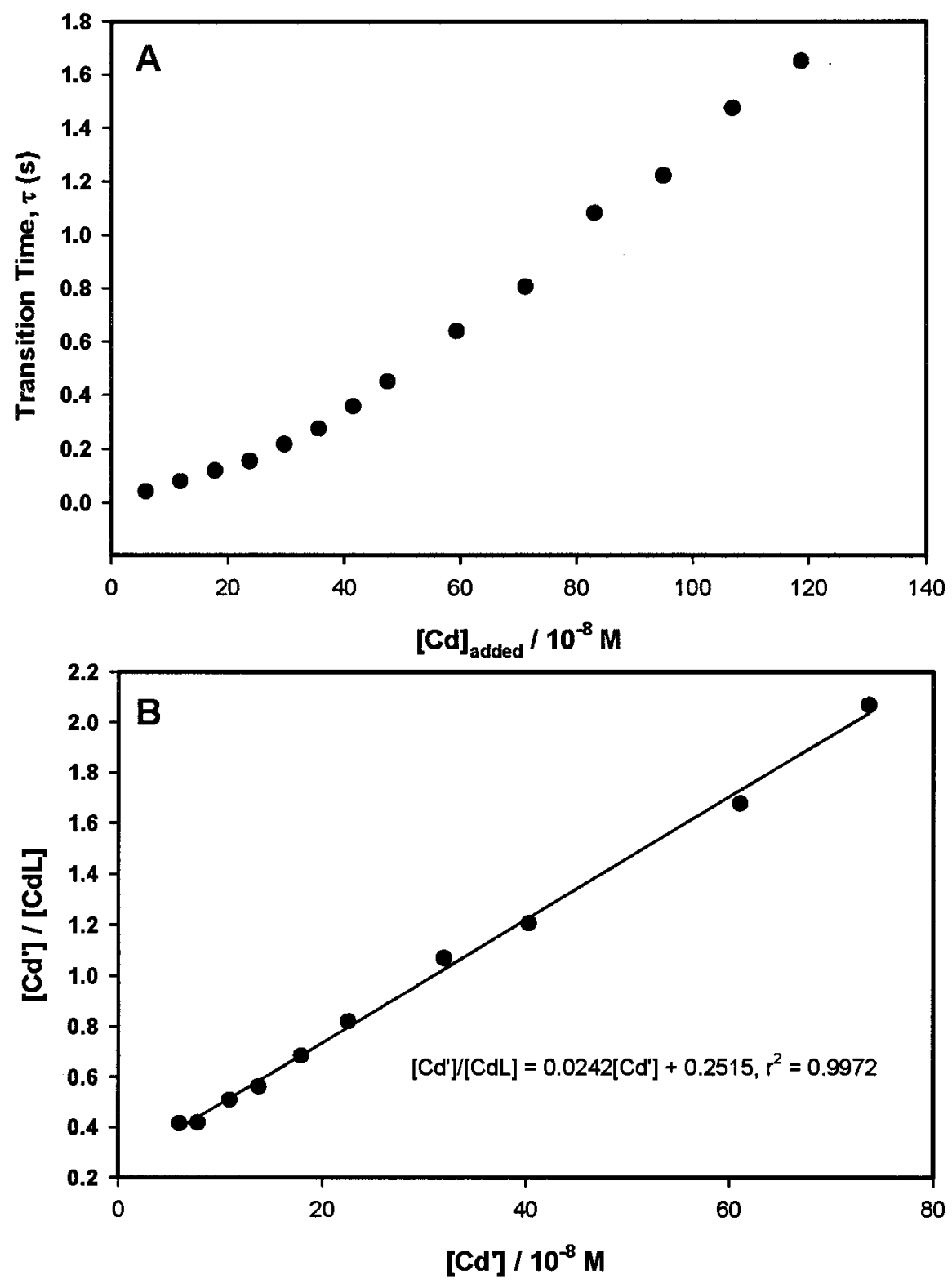

Figure C2 Complexometric titration of DOC in Copper Cliff Mine $45 \%$ effluent water sample with $\mathrm{Cd}(\mathrm{II})$ by Stripping Chronopotentiometry: (A) titration curve of Cd-DOC; (B) Langmuir transformation of the titration data from (A). $\mathrm{pH}=$ $7.20 \pm 0.05, \mathrm{~T}=23 \pm 2^{\circ} \mathrm{C}$. 